\title{
Dissertation: Building and Recovering Trust in the Buyer-Seller Relationship
}

Christopher A. Nelson

Follow this and additional works at: https://researchrepository.wvu.edu/etd

\section{Recommended Citation}

Nelson, Christopher A., "Dissertation: Building and Recovering Trust in the Buyer-Seller Relationship" (2017). Graduate Theses, Dissertations, and Problem Reports. 6306.

https://researchrepository.wvu.edu/etd/6306

This Dissertation is protected by copyright and/or related rights. It has been brought to you by the The Research Repository @ WVU with permission from the rights-holder(s). You are free to use this Dissertation in any way that is permitted by the copyright and related rights legislation that applies to your use. For other uses you must obtain permission from the rights-holder(s) directly, unless additional rights are indicated by a Creative Commons license in the record and/ or on the work itself. This Dissertation has been accepted for inclusion in WVU Graduate Theses, Dissertations, and Problem Reports collection by an authorized administrator of The Research Repository @ WVU.

For more information, please contact researchrepository@mail.wvu.edu. 
Dissertation: Building and Recovering Trust in the Buyer-Seller Relationship

\author{
Christopher A. Nelson
}
Dissertation submitted to the College of Business and Economics at West Virginia University in partial fulfillment of the requirements
for the degree of
Doctor of Philosophy
in
Marketing

\author{
James R. Brown, D.B.A., Chair \\ Annie Cui, Ph.D. \\ M. Paula Fitzgerald, Ph.D. \\ Mark B. Gavin, Ph.D. \\ Michael F. Walsh, Ph.D. \\ Department of Marketing
}

\author{
Morgantown, West Virginia \\ 2017
}

Keywords: trust recovery, facial trustworthiness, equity theory, approach-avoidance theory, salesperson trust, trust repair strategies

Copyright 2017 Christopher A. Nelson 


\section{ABSTRACT \\ Building and Recovering Trust in the Buyer-Seller Relationship}

\section{Christopher A. Nelson}

This three-essay dissertation examines how trust is developed and recovered in the buyer-seller relationship. Specifically, the first essay examines how initial facial trustworthiness evaluations subconsciously affect trust perceptions based on an approach-avoidance decision. Findings from fMRI meta-analysis of nine studies supported this theory and uncovered the network of brain regions involved in this process. In the second essay, a grounded theory approach was used to examine trust recovery in the buyer-seller relationship. The results of this analysis indicated a three-step trust repair process is an optimized approach for achieving trust recovery. Contrary to the dominant view in the literature, this trust repair process focused on "making things right" with buyer instead of using persuasion techniques to shift blame for the trust damaging incident to a source external to the salesperson. The third essay developed a conceptual model for understanding trust recovery that was examined through the lens of equity theory. A longitudinal business-to-business experiment and a business-to-business survey provide evidence that fairness is a key missing mediator to increased trust recovery that explains why both verbal and behavioral repair strategies are effective. 


\section{DEDICATION}

This dissertation is dedicated to my wife, Staci. I am fortunate to have such a wonderful partner and friend. My love for you is unconditional and is continually growing. 


\section{ACKNOWLEDGMENT}

I am grateful for the people that have encouraged and supported me throughout the Ph.D. process.

First, I would like to thank my advisor, Dr. Jim Brown, for his guidance on this dissertation. Without his mentorship and feedback, I would not have been able to successfully complete the Ph.D. program. His tireless efforts have helped my development as a researcher immensely.

I am also grateful to my committee members: Dr. Paula Fitzgerald, Dr. Annie Cui, Dr. Mike Walsh, and Dr. Mark Gavin. I could not have asked for a more supportive and helpful committee. I also appreciate the feedback that I received on my work from Dr. Rick McFarland, Dr. Ed Tomlinson, Dr. Julie Brefczynski-Lewis, and Dr. Jesse Wozniak.

My journey in this program would not have been as enjoyable without my fellow Ph.D. students. I enjoyed the time that we spent together over the past five and a half years.

I would like to thank my dad, who in addition to copy editing much of my work and providing a useful practitioner viewpoint, provided much needed wisdom and perspective through this dissertation process. I also appreciate the continuous support and encouragement of my mom and my brother.

I can't even begin to thank my wife, Staci, who was willing to uproot our family and to take on the lion's share of the work at home so that I could chase my dream. Your unconditional love and support is the reason that I was successful in this endeavor. I appreciate my children: Peyton, Abby, Haley, and Caleb, all of whom brought me joy in the difficult parts of this process.

Finally, I would like to thank God for being a reliable source of strength and guidance in my life. 


\section{TABLE OF CONTENTS}

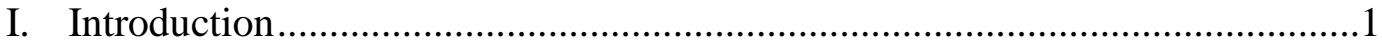

A. Overview of Research Context ........................................................ 1

B. Theoretical Contributions ................................................................2

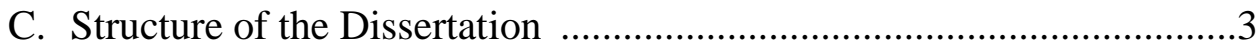

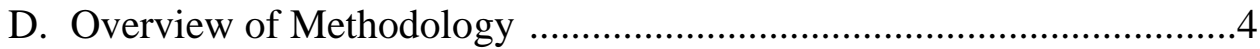

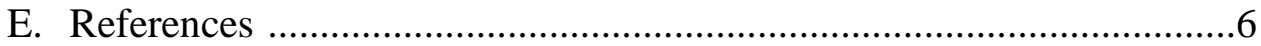

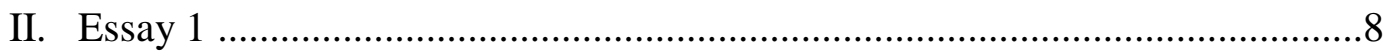

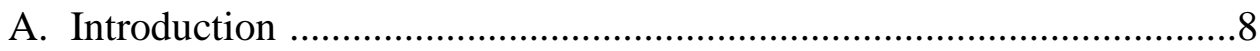

B. Theoretical Framework ..................................................................11

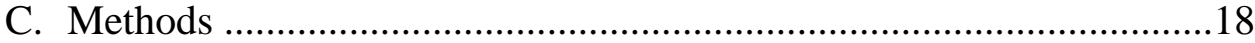

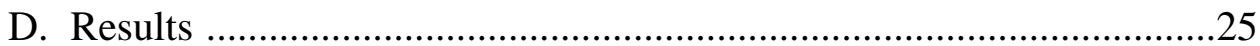

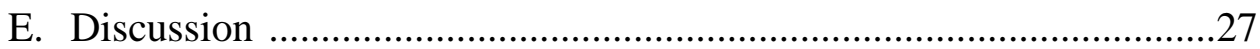

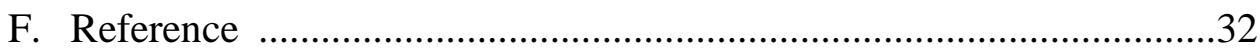

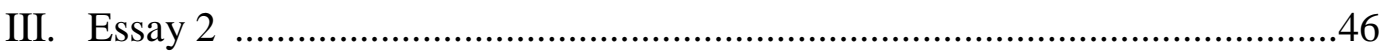

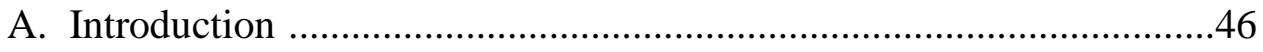

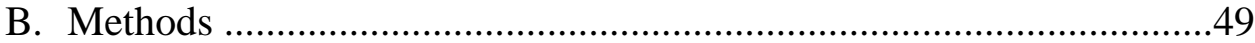

C. Breach of Trust Conceptualization and Definition ...............................53

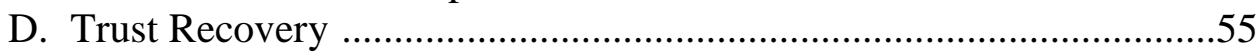

E. Factors Affecting Trust Recovery Effectiveness .................................61



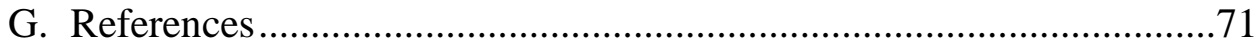

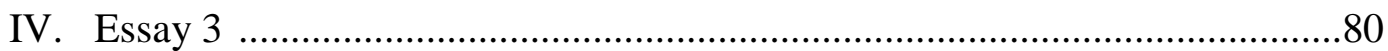

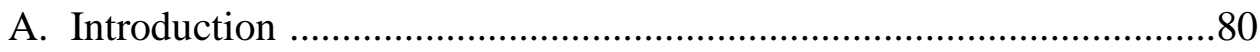

B. Prior Theory and Research …………………………………….......83

C. A Theoretical Framework for Trust Recovery .....................................87

D. Conceptual Model and Hypotheses ...................................................96

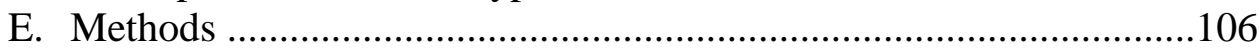

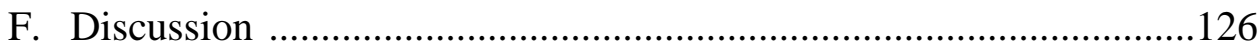

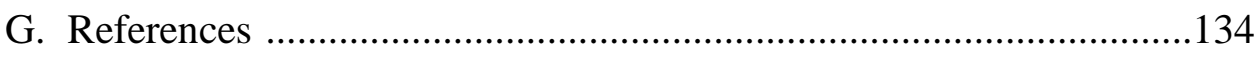

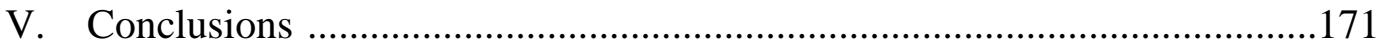

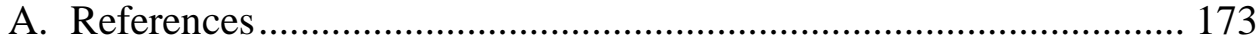




\section{LIST OF FIGURES}



Figure 1.2 ................................................................ 40

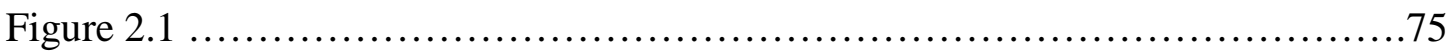



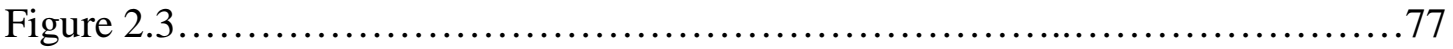

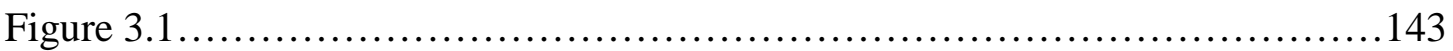

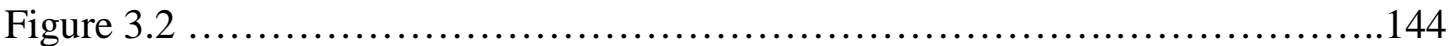

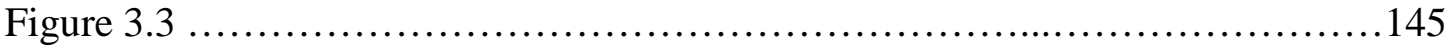

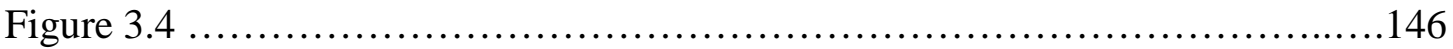

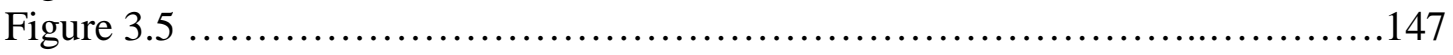




\section{LIST OF TABLES}

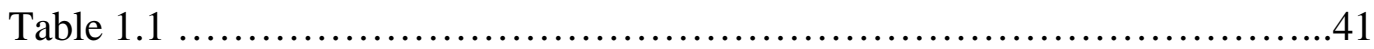

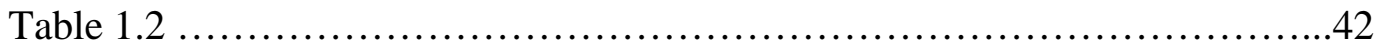

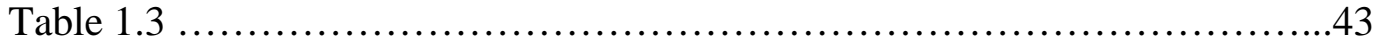

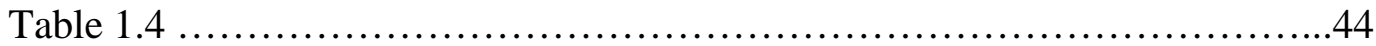

Table 1.5 .........................................................45

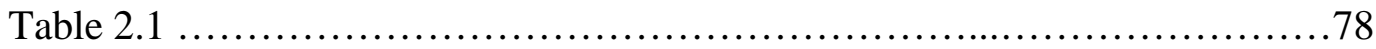

Table 2.2 ....................................................... 79

Table 3.1 ............................................................148

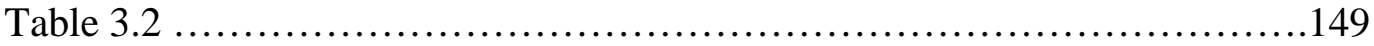

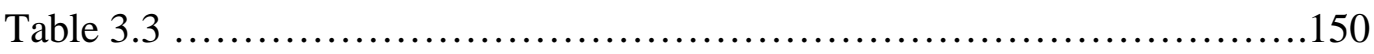

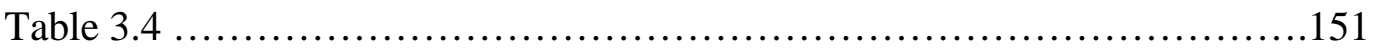

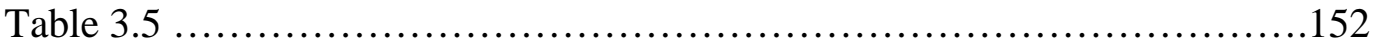

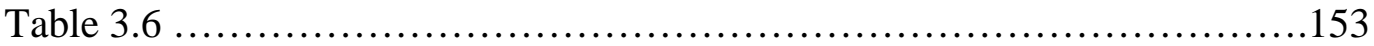

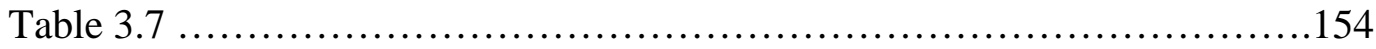

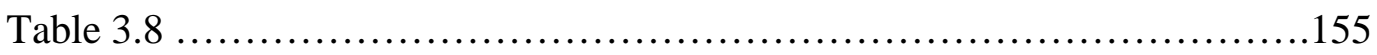

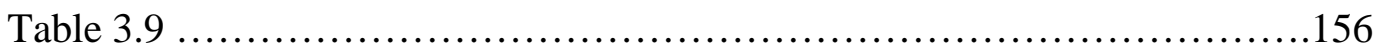

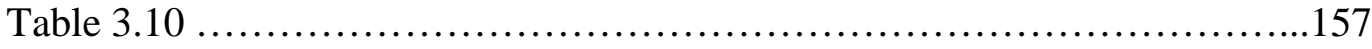

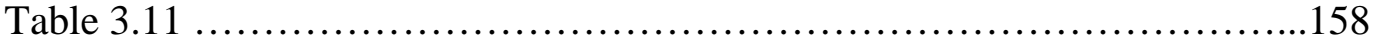




\section{Chapter 1: Introduction OVERVIEW OF RESEARCH CONTEXT}

Trust research has been of key importance to a variety of marketing contexts, such as the relational governance (Bradach and Eccles, 1989; Chiles and McMackin, 1996), relationship marketing (Palmatier et al., 2006; Morgan and Hunt 1994; Dwyer et al., 1987), and personal selling (Doney and Cannon, 1997; Lagace et al., 1991; Swan et al., 1988). While the theory developed in this paper may be broadly applicable to other contexts, the focus of this dissertation is on salespeople, specifically at the individual or single salesperson-buyer dyadic level. To complement this focus, viewpoints from alternative areas are drawn upon at times during the paper.

Before proceeding, it is important to define the trust construct which is the focus of the dissertation. There are two primary ways that trust is conceptualized in the marketing literature; the first is as a confidence in the credibility and benevolence of an exchange partner and the second is a willingness to accept risk or vulnerability (Lusch et al., 2011). While both viewpoints have merit, for this dissertation, I employ the first conceptualization in this research.

Additionally, there are a variety of theoretical traditions regarding the trust development process, it is necessary to identify the theoretical tradition that one is using before delving deeper into the theory (Lewicki et al., 2006). Traditionally, trust development has been viewed either through the lens of stages in which relationships progress through distinct junctures over the development of the relationship (e.g., Lewicki and Bunker 1995; Lewicki et al., 2006) or relationship age which suggests that trust grows in a linear manner over time (e.g., Hibbard et al., 2001). Palmatier's et al., (2013) innovative work on exchange relationships suggests that trust should be measured neither by the age of the relationship, nor by the stage it is in, but by its 
current rate and direction. This approach better predicts key performance outcomes such as sales growth (Palmatier et al., 2013).

Taking this perspective, I examined two key points in time that are expected to rapidly change the rate and direction of the relationship: 1) initial trust formation and 2) trust repair. In Essay 1, I examined how facial trustworthiness can establish the trust either positively or negatively during the initial meeting. In Essay 2 and 3, I examined how salesperson trust repair strategies can positively impact trust after it has been damaged. In the following sections, I will begin with a discussion of the contributions contained in the essays. This will be followed by describing the structure of the dissertation. Finally, I will conclude with an overview of the methodology for each of the three essays.

\section{THEORETICAL CONTRIBUTIONS}

This research contributes to our understanding of trust in several important ways. First, Evans et al. (2012) suggest that there is limited information on how a salesperson can establish trust with a buyer during an initial encounter. Essay 1 answers this call by describing how buyers make facial trustworthiness evaluations during the initial meeting that can influence subsequent trust decisions. I contend that these evaluations are based on approach-avoidance theory and thin slice theory, which suggest that small pieces of information can be used to make predictive decisions. This work builds on the research on this subject that is being developed in marketing scholarship (e.g., Ahearne et al. 2015). Essay 1 also makes a methodological contribution to marketing scholarship through introducing fMRI meta-analysis, and describing how other scholars can employ this approach.

Next, trust recovery is an underexplored topic in marketing research, and theory developing work such as research conducted in my qualitative paper (Essay 2) lays the 
framework for future trust recovery research. Finally, the trust recovery literature treats responsibility shifting strategies (e.g., excuses and denials) as superior to responsibility strategies (e.g., apologies) and behavioral repair strategies (i.e, actions). The research that I am conducting in Essay 3 provides theoretical guidance and empirical evidence on why this is not the case in marketing exchange relationships. Fundamental to this change in perspective is the introduction of fairness as a key mediating variable that impacts the relationship between salesperson trust repair strategies and trust recovery. While this discussion has provided an explanation of the overall contribution of the dissertation, the next section provides a description of the specific structure of my dissertation research.

\section{STRUCTURE OF THE DISSERTATION}

The dissertation follows a three-essay structure in which the dissertation is structured as three distinct papers that are connected by their importance in affecting trust. Essay 1 begins with a summary of the facial trustworthiness literature that makes the case that facial trustworthiness evaluations are the first step in the trust development process. This is followed by an explanation of how approach-avoidance theory drives these facial trustworthiness evaluations. Approachavoidance theory suggests that faces convey large amounts of information that is useful in a social interaction. Individuals can process and evaluate this trustworthiness information very quickly due to its adaptive importance. I contend that because of its adaptive importance, facial trustworthiness evaluations are key to a variety of marketing relationships, such as a professional purchasing agent evaluating a salesperson during their initial encounter. After the theoretical setup, a detailed account of the methodology is provided that introduces fMRI meta-analysis to the marketing literature, which is followed by an explanation of how this technique was used in my paper. 
Essay 2 begins by synthesizing knowledge about the breach of trust construct and better clarifying its domain. Next, this paper summarizes the extant view of trust repair and builds on it by suggesting a four-step trust repair process. Finally, a conceptual model and propositional inventory is developed that introduces new trust repair strategies and depicts the importance of combining verbal and behavioral (i.e. actions) repair strategies for improved trust recovery.

Essay 3 begins by advancing a theoretically driven conceptual model based on equity theory that describes how verbal and behavioral repair strategies affect trust recovery. This is followed by a discussion of the study's methods, which detail the longitudinal experiment and panel based study used to test the conceptual model. Next, the results provide evidence for my theory that fairness is a key missing mediator in the trusty recovery literature. Finally, a discussion of the theoretical and managerial implications of this research are then discussed.

\section{OVERVIEW OF METHODOLOGY}

In Essay 1, I conducted an fMRI meta-analysis on facial trustworthiness. This began with a comprehensive search of the Web of Science and Pubmed databases. Based on the predetermined selection criteria that was driven by the procedures utilized by previous scholars (e.g., Fan et al. 2010; Martinelli, Sperduti, and Piolino 2013; Northoff et al. 2006; Phan et al. 2002), nine facial trustworthiness studies were included in the analysis. The data from these nine studies were analyzed using an ALE meta-analytic procedure that was in accordance with the recommendations of the leading scholarship on this methodology (Eickhoff et al. 2009; Langer and Eickhoff 2013; Martinelli, Sperduti, and Piolino 2013). The ALE meta-analytic procedure aggregated the combined results of the individual studies and determined the brain activation areas (i.e., brain coordinates) that were involved in the processing of facial trustworthiness. 
For Essay 2, a grounded theory approach was used to develop the theoretical models described in the study on trust recovery (Strauss and Corbin 1998). This began with a review of the academic literature on trust repair, which provided a theoretical background for my interviews. The next step was to conduct 30 interviews with business-to-business salespeople, sales executives, and professional buyers. The results of the interviews developed themes that caused me to return to the academic literature to explore relevant research streams such as service recovery and justice theory. Additionally, some of the executive interviews suggested key business books that shaped their perceptions of trust recovery. The next step of the process was to analyze these books along with 30 years of the Wall Street Journal by performing a discourse analysis. Performing a discourse analysis allowed for an improved understanding of how trust repair was viewed by business practitioners. This provides a broad overview of how I triangulated these three data sources to develop the theory that is discussed in the essay.

Two studies were conducted for Essay 3: (1) a business-to-consumer experimental study with 481 insurance customers and (2) a business-to-business panel study with 204 professional purchasing agents. In both studies, a measurement model was run to examine convergent validity, discriminant validity, and measurement reliability of the latent variables in accordance with accepted practices (Fornell and Larker 1981; Hair et al. 2006; Hu and Bentler 1999; Nunally 1978). The primary analysis for both studies was a multiple regression analysis that followed the procedures described in Aiken and West (1991) and Hayes (2013) to test for main effects, interactions, mediation, and moderated-mediation described in the hypotheses. 


\section{REFERENCES}

Aiken, Leona S. and Stephen G. West (1991), Multiple regression: Testing and interpreting interactions. Thousand Oaks: Sage Publications Inc.

Bradach, Jeffrey L., and Robert G. Eccles (1989), "Price, Authority, and Trust: From Ideal Types to Plural Forms," Annual Review of Sociology, 15 (1), 97-118.

Chiles, Todd H., and John F. McMackin (1996), "Integrating Variable Risk Preferences, Trust, and Transaction Cost Economics," Academy of Management Review, 21 (1), 73-99.

Evans, Kenneth R., Richard G. McFarland, Bart Dietz, and Fernando Jaramillo (2012), "Advancing Sales Performance Research: A Focus on Five Underresearched Topic Areas," Journal of Personal Selling \& Sales Management, 32 (1), 89-105.

Doney, Patricia M., and Joseph P. Cannon (1997), "An Examination of the Nature of Trust in Buyer-Seller Relationships," Journal of Marketing, 61 (2), 35-51.

Dwyer, F. Robert, Paul H. Schurr, and Sejo Oh (1987), "Developing Buyer-Seller Relationships," The Journal of Marketing, 11-27.

Eickhoff, Simon B., Angela R. Laird, Christian Grefkes, Ling E. Wang, Karl Zilles, and Peter T. Fox (2009), "Coordinate-Based Activation Likelihood Estimation Meta-Analysis of Neuroimaging Data: A Random-Effects Approach Based on Empirical Estimates of Spatial Uncertainty," Human Brain Mapping, 30 (9), 2907-2926.

Fan, Yan, Niall W. Duncan, Moritz de Greck, and Georg Northoff (2011), "Is There a Core Neural Network in Empathy? An fMRI Based Quantitative MetaAnalysis," Neuroscience \& Biobehavioral Reviews, 35 (3), 903-911.

Fornell, Claes and David F. Larcker (1981), "Structural Equation Models with Unobservable Variables and Measurement Error: Algebra and Statistics," Journal of Marketing Research, 382-388.

Hayes, Andrew F (2013), "Introduction to Mediation, Moderation, and Conditional Process Analysis: A Regression-Based Approach,” Guilford Press.

Hibbard, Jonathan D., Nirmalya Kumar, and Louis W. Stern (2001), "Examining the Impact of Destructive Acts in Marketing Channel Relationships," Journal of Marketing Research, 38 (1), 45-61.

Hu, Li-tze and Peter M. Bentler (1999), "Cutoff Criteria for Fit Indexes in Covariance Structure Analysis: Conventional Criteria Versus New Alternatives," Structural Equation Modeling: A Multidisciplinary Journal, 6(1), 1-55. 
Lagace, Rosemary R., Robert Dahlstrom, and Jule B. Gassenheimer (1991), "The Relevance of Ethical Salesperson Behavior on Relationship Quality: The Pharmaceutical Industry," Journal of Personal Selling \& Sales Management, 11 (4), 39-47.

Lewicki, Roy J., and Bunker, Barbara B. (1995), Trust in relationships: A model of development and decline, Jossey-Bass.

-------, Edward C. Tomlinson, and Nicole Gillespie (2006), "Models of Interpersonal Trust Development: Theoretical Approaches, Empirical Evidence, and Future Directions," Journal of Management, 32 (6), 991-1022.

Lusch, Robert F., James R. Brown, and Matthew O’Brien (2011), "Protecting Relational Assets: a Pre and Post Field Study of a Horizontal Business Combination," Journal of the Academy of Marketing Science, 39 (2), 175-197.

Martinelli, Pénélope, Marco Sperduti, and Pascale Piolino (2013), "Neural Substrates of the Selfmemory System: New Insights from a Meta-Analysis," Human Brain Mapping 34 (7), 1515-1529.

Mattavelli, Giulia, Timothy J. Andrews, Aziz UR Asghar, John R. Towler, and Andrew W. Young (2012), "Response of Face-Selective Brain Regions to Trustworthiness and Gender of Faces," Neuropsychologia, 50 (9), 2205-2211.

Morgan, Robert M., and Shelby D. Hunt (1994), "The Commitment-Trust Theory of Relationship Marketing," The Journal of Marketing, 58(3), 20-38.

Northoff, Georg, Alexander Heinzel, Moritz De Greck, Felix Bermpohl, Henrik Dobrowolny, and Jaak Panksepp (2006), "Self-Referential Processing in Our Brain—a Meta-Analysis of Imaging Studies on the Self," Neuroimage, 31 (1), 440-457.

Nunnally, Jum (1978), "Psychometric Methods." 464-465.

Palmatier, Robert W., Mark B. Houston, Rajiv P. Dant, and Dhruv Grewal (2013), "Relationship Velocity: Toward a Theory of Relationship Dynamics," Journal of Marketing 77 (1), 1330.

Phan, K. Luan, Tor Wager, Stephan F. Taylor, and Israel Liberzon. "Functional neuroanatomy of emotion: a meta-analysis of emotion activation studies in PET and fMRI." Neuroimage 16, no. 2 (2002): 331-348.

Swan, John E, I. Fred Trawick Jr, David R. Rink, and Jenny J. Roberts (1988), "Measuring Dimensions of Purchaser Trust of Industrial Salespeople," Journal of Personal Selling \& Sales Management, 8 (1), 1-10.

Strauss, Anselm, and Juliet Corbin (1998), "Basics of Qualitative Research: Procedures and Techniques for Developing Grounded Theory." 


\section{Chapter 2: Essay 1 - Initial Facial Trustworthiness Evaluations: an fMRI Meta-analysis}

One of the most important factors in developing a successful exchange relationship is the ability to establish trust. Trust is a key ingredient in cooperative and committed relationships that are expected to persist over time (Kingshott and Pecotich, 2007; Palmatier et al., 2006). For that reason, establishing trust is important in a variety of marketing contexts including: personal selling (e.g., Doney and Cannon, 1997; Guenzi and Georges, 2010; Lagace et al., 1991), relational governance (e.g., Bradach and Eccles, 1989; Chiles and McMackin, 1996), and relationship marketing (e.g., Morgan and Hunt, 1994; Dwyer et al., 1987).

Despite the fact that trust has been examined extensively in the marketing literature, surprisingly, very little is known about how trust is established at the beginning of relationships (Evans et al., 2012). The dearth of research in this area is surprising because the failure to establish trust can negatively impact willingness to begin or stay in a relationship and ultimately economic performance (De Wulf et al., 2001; Hibbard et al., 2001). For example, if a salesperson is unable to demonstrate trustworthiness during the initial sales call, the buyer will likely move on to other providers and the opportunity is lost. Similarly, if a distributer is not able demonstrate trustworthiness during the initial meeting with the manufacturer, the manufacturer is less willing to engage in cooperative actions and will shift resources and business away from that distributer toward a different partner.

Initial trust formation is particularly important in professional selling contexts because of the interpersonal nature and often long-term duration of buyer-seller relationships. While trust formation has not been widely examined in the sales literature, it has been examined in the economics literature using behavioral experiments (e.g., Berg 1995). More recently, researchers have begun incorporating neuroscientific methods into these experiments to begin to determine 
the neural processes that accompany these initial trust decisions (e.g., Fett et al., 2013, KingCasas et al., 2005, Van den Bos et al., 2010).

Neurological research makes the case that individuals make trustworthiness evaluations based on looking at an individual's face both when that individual is being expressive (e.g., happy, sad, angry) or when that individual is displaying a neutral expression (Todorov, 2008). These implicit evaluations of faces have been shown not only to affect initial trust, but subsequent trust decisions as well (Kim et al., 2012). An implicit evaluation of faces can be defined as subconsciously forming impressions about an individual based on an examination of that individual's face (Engell et al., 2007). These evaluations draw on an instinct inherent in all humans to approach those who appear trustworthy and to avoid those who do not (i.e., approachavoidance theory). For that reason, approach-avoidance theory can be advanced as a mechanism behind the development of initial trust. I contend that approach-avoidance theory is important to marketing because the trust decisions made during exchange may be heavily influenced by implicit evaluations of faces. Since it is not possible to study these types of automatic evaluations using traditional methods (e.g., surveys, experiments, etc.), I follow the neurological approach to examine the implicit evaluation of faces when making a trust determination.

More specifically, I employ a functional magnetic resonance imaging (fMRI) metaanalysis of nine facial trustworthiness studies to help resolve the debate on whether the establishment of initial trust is a merely a rational and intentional process or if it is also impacted by intuition and automatic processing. The facial trustworthiness literature can be described as research in which an implicit evaluation of faces occurs that is linked to a trust decision. In these studies, fMRI technology estimates neural activity indirectly by identifying areas of the brain with excess oxygen flow (Yoon et al., 2006). An fMRI meta-analysis provides the statistical 
power necessary to answer our primary research questions: (1) how does the trust process begin when meeting another individual for the first time?; and (2) what are the network of brain regions which are active in implicit evaluation of faces regardless of task, stimuli manipulation, and fMRI analysis method? Uncovering these types of networks of brain regions is vital for understanding any type of social behavior and is especially relevant when examining a complex social decision such as trusting another individual (Stanley and Adolphs, 2013). Developing this network of brain regions using an fMRI meta-analysis also aids in future research by identifying regions of interest (ROI) that are used to develop neurologically based hypotheses.

This study contributes to the literature on trust in several ways. First, this study extends the current understanding of how trust is developed in marketing exchange relationships, such as the buyer-seller relationship, by explicating the role of implicit evaluations of faces in trust development. In doing so, I depart from the traditional reasoning, which suggests that trust formation is primarily a calculative process; I argue trust formation is largely an unconscious process driven by intuition that can also influence subsequent intentional trust decisions. Second, I extend approach-avoidance theory by providing evidence that while an approach-avoidance decision related to a facial trustworthiness evaluation is based on a valence decision, that valence decision ignites a cost-reward calculation that uses higher order cognitive processing to further evaluate whether that individual should be trusted. This provides a theoretical explanation for why subconscious valence decisions can impact subsequent intentional processing. Finally, I make a methodological contribution to marketing scholarship through introducing fMRI metaanalysis and describing how other scholars can employ this approach.

In the next section, I begin with a brief description of the trust formation process. Next, I develop a theoretical framework and develop hypotheses on the implicit evaluation of faces in 
making a trust determination. This is followed by an analysis of the facial trustworthiness literature using an fMRI meta-analysis. Finally, I conclude with a summary, managerial implications, limitations, and directions for future research.

\section{THEORETICAL FRAMEWORK}

Trust can be defined as confidence in an exchange partner's credibility and benevolence (Doney and Cannon 1997, p. 36; Ganesan 1994; Kumar, Scheer, and Steenkamp 1995). Trust is typically developed over time as experience is accumulated, but it may develop quickly in some instances (Berg, 1995, McKnight et al., 1998). When trust is (or is not) first established, there is no prior experience from upon which to base that trust decision. In this case, trust decisions may be made based on the anticipated value of a future relationship. This is accomplished by calculating the costs versus the rewards of the potential relationship and making a decision about whether or not it is worth the risk to trust the other individual (Lewicki and Bunker, 1995). This cost-reward calculation may begin with reputational information if it is available, and is updated as the buyer receives more information (Doney and Cannon, 1997).

Trust formation has typically been viewed as an active, intentional process in the marketing and organizational behavior literatures (e.g., Doney and Cannon, 1997; Lewicki and Bunker, 1995). Some research has cast doubt on the proposition that initial trust decisions are made based solely on rational predictions. The neuroscientific literature advances the perspective that individuals begin to form trust impressions based on a brief look at the face of the individual. This implicit evaluation of faces can in turn influence subsequent intentional trust decisions. This view is supported by thin slice theory, which has demonstrated that accurate predictions can be quickly made about other individuals based simply on intuition (Ambady and Rosenthal, 1993; Hamamura and Li, 2012; Kraus and Keltner, 2009; North et al., 2010). This 
occurs because individuals can take thin slices (brief exposures) of information and make accurate predictions. These thin slice predictions can be made based on non-verbal cues (e.g., implicit evaluation of faces, body language) to aid in the decision making process (Ambady, 2010).

Specifically, an implicit evaluation of faces can determine whether another individual is trusted (Engell et al., 2007). Approach-avoidance theory is the basic theory behind this determination, which states that when meeting someone new, a subconscious evaluation is made on whether that person should be approached or avoided based on how that individual looks. In the following section, I describe how approach-avoidance theory drives whether new individuals will be trusted based on an implicit evaluation of faces along with an explanation of how I advance approach-avoidance theory. This will be followed by neurologically based hypotheses that describe how implicit evaluation of faces impact trust determinations. For a visual depiction of how an implicit evaluation of faces fits within the trust formation framework that is promoted in the marketing literature, see Figure 1. The definitions of these key antecedents to trust along with representative papers that have studied trust from this vantage point can be found in Table 1.

$<<<<<<<<<$ Insert Figure 1 and Table 1 about here $>>>>>>>>>>$

\section{Approach-Avoidance Theory}

The idea that humans have an innate motivation to approach positive stimuli (e.g., friendly individuals) and avoid negative stimuli (e.g., hostile individuals) has a long theoretical history dating back over 2,000 years to Greek philosophers such as Democritus, Aristippus, and Epicurus, and was echoed by many prominent psychologists around the turn of the twentieth century (e.g., James, 1890; Freud, 1915; Jung, 1921). More formally, “approach motivation may 
be defined as the energization of behavior by, or the direction of behavior toward, positive stimuli (objects, events, people), whereas avoidance motivation may be defined as the energization of behavior by, or the direction of behavior away from, negative stimuli (objects, events, people)” (Elliot, 2006, p. 112). Many marketing scholars have begun to integrate this theory into their own work: for example, in determining how consumers evaluate advertisements (Jain et al., 2009), making valuations critical to marketing strategy (Mowen and Mowen, 1991), and evaluating a firm's physical surroundings (Bitner ,1992).

Early facial trustworthiness research in the neuroscience literature highlighted the importance of approach-avoidance theory in motivating decisions (e.g., Adolphs et al., 1998; Winston et al., 2002), and Todorov and Engell (2008) were the first to provide evidence that implicit evaluation of faces were in essence a valence decision. Trustworthy faces are considered positive and should be approached while untrustworthy faces are negative and should be avoided. This prediction can be made in a fraction of a second and is processed automatically within the brain (Engell et al., 2007).

While a traditional view of approach-avoidance theory looks at the process as a simple valence evaluation where potentially positive individuals are approached and potentially negative individuals are avoided, this research seeks to advance approach-avoidance theory by explaining the neurological complexity that occurs when making this evaluation. I argue that the approachavoidance determination, which occurs when implicitly evaluating faces is more than an automatic valence determination, but is also the start of more intentional processing. So, when meeting another individual for the first time, subconsciously there will be an intuitive inclination to approach or avoid that individual. Concurrently, the brain will start to look for other information to evaluate the cost vs. reward of engaging with this new individual. Since automatic 
processing is faster acting than intentional processing (Kahneman, 2011), it is expected that there will be more brain regions associated with automatic processing activated during this rapid evaluation. This is supported by facial trustworthiness research that suggests that automatic and intentional trustworthiness processing is connected with automatic processing impacting more intentional decisions (Doalla et al., 2012; Kim et al., 2012). To validate this theory, neurological evidence would be needed that demonstrates activation in a brain region associated with eliciting this type of cost-benefit analysis occurring simultaneously with automatic neurological processing. This advances approach-avoidance theory by taking an evaluative process, which is theorized to be largely automatic, and explains how it relates to more intentional processing.

\section{Hypotheses}

In our conceptual framework, I contend that when making implicit evaluations of faces, there is a subconscious approach-avoidance decision that determines whether or not that individual is trusted. To neurologically test this theory, I develop hypotheses that link the use of specific brain regions that are recorded during implicit evaluations of faces (both when making conscious and subconscious trust decisions) with approach-avoidance theory. These hypothesized brain regions are supported by the neuro-scientific literature, which has established the linkage between activation of specific brain regions with valence determinations, affective processing, and stimuli evaluation all of which are key to making an approach-avoidance evaluation. This linkage can be identified by utilizing an fMRI, which determines the areas of the brain that are active when subjects are making evaluations. ${ }^{1}$

Brain activation is typically mapped onto two distinct types of decision processes (Satpute and Lieberman, 2006). The first process is affective in nature and is typically processed

\footnotetext{
${ }^{1}$ I will discuss this process in greater detail in the methodology section.
} 
automatically. The second decision process is rational in nature and typically requires higher order cognitive processing (i.e., intention processing). To this point the neurological literature on implicit evaluations of faces when making a trust decision has focused primarily on automatic processing. Our research uses existing research to suggest and examine a network of automatic neural processes that are active when making an implicit evaluation of faces. I also build neurological theory by suggesting that high order cognitive processing begins as well during this approach-avoidance evaluation. While I predict that higher order cognitive processing will be involved, the evaluation will be primarily automatic in nature. Since these implicit evaluation of faces occur early in the initial trust development process and impact subsequent trust decisions, a large degree of automatic processing during the implicit evaluation of faces would provide evidence that intuition does impact initial trust evaluations.

$\mathrm{H}_{1}$ : When first encountering an individual, an implicit evaluation of that individual's face will be made based primarily on automatic neural processing.

\section{Automatic processing}

Facial trustworthiness research demonstrated that individuals with bi-lateral (i.e., the right and left hemispheres of the brain are active) amygdala damage were unable to accurately detect trustworthiness by evaluating faces. This leads them to make poor decisions on approaching or avoiding other individuals, demonstrating that the amygdala is key in evaluating whether an individual should be trusted when making an implicit evaluation of faces. (Adolphs et al., 1998). The amygdala's role in making approach-avoidance decisions when making an implicit evaluation of faces was found to be robust in a variety of situations. The brain activation that occurs during the implicit evaluations of faces is a strong predictor or whether an individual will be trusted regardless of whether or not an explicit evaluation of trust was made when viewing the face or if trust was measured subsequently. In both instances, brain activation in the 
amygdala is equally effective in predicting whether an individual is perceived as trustworthy or untrustworthy (Winston et al., 2002). This predictive ability associated with brain activation holds both when examining idiosyncratic (that subject's) trust determinations and when using trust ratings determined from group norms (Engell et al., 2007). This provides evidence that trust decisions based on an implicit evaluation of faces occur subconsciously and those decisions are largely homogeneous among individuals.

Negative trust determinations when making an implicit evaluation of faces was first theorized to have a positive linear relationship with amygdala activation (i.e., the more untrustworthy a face is perceived to be the greater the activation in the amygdala) (Engell, et al., 2007; Winston et al., 2002). Subsequent research demonstrated that amygdala activation is actually curvilinear with faces evaluated as extremely trustworthy and extremely untrustworthy producing a similar amygdala reaction (Said et al., 2009; Todorov et al., 2008). In other words, amygdala activation does not only indicate negative trustworthiness; instead the amygdala indicates that a positive or negative trustworthiness evaluation is being made. This is in line with other studies, which suggest that the amygdala indicates a strongly positive or negative valence evaluation (Hamann et al., 1999; Pessoa et al., 2002; Summerville et al., 2006). The amygdala does not act in isolation when making implicit evaluations of faces, but instead acts as part of a network of brain regions. See Table 2 for a description of the key brain areas involved in the automatic processing that occurs when making an implicit evaluation of faces. Specifically, the insula has also been found to be key to emotional and automatic processing related to trust, and the fusiform gyrus is used to quickly evaluate stimuli (Baas et al., 2008; Dimoka, 2010). Based on this research, I contend that when making an implicit evaluation of faces, there will be automatic neural activation in the amygdala, insula, and fusiform gyrus. This neural activation 
will allow for individuals to quickly make a positive or negative evaluation that manifest itself as intuition. This occurs whether the individual realizes that they are evaluating trust or not.

$\mathrm{H}_{2}$ : When making an implicit evaluation of a face there will be neural activation in the amygdala, insula, and fusiform gyrus.

$<<<<<<<<<<$ Insert Table 2 about here $>>>>>>>>>>$

Higher order cognition

Implicit evaluation of faces is important to exchange relationships not only because they impact initial trust, but also because they are shown to impact subsequent decision-making. For example, when a face is evaluated as untrustworthy individuals are more likely to reject a fair offer, and when a face is evaluated as trustworthy individuals are more likely to accept an unfair offer in simulated negotiations (Kim et al., 2012). This gives individuals with faces that are evaluated as trustworthy an advantage when entering in a negotiation. In a buyer-seller dyad, a buyer may accept a suboptimal deal because the salesperson that he/she is dealing with looks trustworthy. The reason behind why this lies within approach-avoidance theory.

I contend that while approach-avoidance evaluations are primarily made using automatic processing, a higher order cognitive process is also employed when making these evaluations. This cognitive process would signal the beginning of the more intentional evaluation of whether it would be rewarding to interact with another individual. The automatic processing that occurs when first evaluating an individual's face produces an intuition or "gut reaction" that biases this high order cognition. This is consistent with confirmation bias theory, which suggest that individuals give more weight to information that supports their expectations and less weight to information that disconfirms their expectations (Campbell and Warren, 2015; Klayman and Ha, 1987; Mazodier and Merunka, 2012; Nickerson, 1998). For example, in the initial buyer-seller meeting, the buyer will make an intuitive decision about the salesperson's trustworthiness based 
on an initial impression of the salesperson's face. The buyer may then unconsciously look for evidence to support that facial trustworthiness evaluation when making a cost-reward decision about the value of making a deal with that salesperson. The buyer will do this using the information that he/she has accumulated about the salesperson over the remainder of the interaction. Since the medial prefrontal cortex is associated with high order cognition related to cost-reward processing, it would be sense for that brain region to be active when making an approach-avoidance evaluation (Lieberman, 2007; Satpute and Lieberman, 2006). For these reasons, I hypothesize that the medial prefrontal cortex will be employed when making an implicit evaluation of faces.

$\mathrm{H}_{3}$ : When making an implicit evaluation a face there will be neural activation in the medial prefrontal cortex.

\section{METHODS}

This paper employs a meta-analysis of facial trustworthiness research that includes fMRI data. This meta-analytic procedure aggregates the results from multiple papers to provide a more accurate understanding of the brain regions involved in making implicit evaluation of faces. In this study, I explore how a system of brain regions associated with implicit evaluation of faces impacts trust decisions. To accomplish this, I combine the available neurological data on implicit evaluation of faces in order add to what is known about the trust development process. This fulfills the purpose of a neurologically based meta-analysis, which is to build a consensus of the neural mechanisms behind a specific behavior (Turkeltaub et al., 2002).

While neurologically based meta-analysis has some similarities with traditional metaanalyses, which are typically conducted in marketing; there are also some very important differences (see Table 2). Since this is the first fMRI meta-analysis to be performed in marketing, I have the expressed objective of thoroughly explaining the process, so that it might 
be employed in future marketing scholarship. I explain the neurological meta-analytic process by focusing on selecting data, understanding fMRI data, and describing fMRI meta-analytic procedures.

$$
<<<<<<<<<<\text { Insert Table } 3 \text { about here }>>>>>>>>>>
$$

\section{Collection of Studies}

I performed a systematic review of neuroimaging studies that focused on trust. This review uncovered that trust has been studied through multiple vehicles such as facial trustworthiness, trust games, and verbal descriptions. Based on the substantive differences in these approaches, I find it more appropriate to focus on a single approach and thus examine studies on facial trustworthiness. Papers published through January 2014 (inclusive) were evaluated for this review as described in the computer based search below. This is followed by the guidelines used for selecting the studies and the within study decisions which were made.

For a comprehensive meta-analytic search it is useful to search multiple databases. Some of the popular choices in exemplary meta-analyses are: PubMed/Medline (Fan et al., 2010; Martinelli et al., 2013; Ortigue et al., 2010; Spreng et al., 2008; Svoboda et al., 2006; Van Overwalle, 2009), Web of Science/Science Citation Index (Fan et al., 2010; Spreng et al., 2008; Svoboda et al., 2006), and PsycInfo (Spreng et al., 2008; Svoboda et al., 2006; Van OverWalle, 2009). Previous scholarship has suggested that after performing a keyword search of multiple databases, a reference list search of the retrieved papers can uncover additional papers to be used in the analysis (Fan et al., 2010; Martinelli et al., 2013; Ortigue et al., 2010; Spreng et al., 2008; Svoboda et al., 2006). Since the selection process is very stringent in meta-analytic research, relevant articles that are excluded should be included in the discussion to aid in understanding and increase the comprehension of the subject (Vigneau et al., 2006). 
I searched the Web of Science and Pubmed databases for fMRI studies examining the neural correlates of trust. Keyword searches: "trust," "trustworthiness," "facial trustworthiness," "PET," and "fMRI," were used to uncover relevant articles. The reference lists from these articles were also investigated. There were no restrictions placed on the date of publication. See Table 3 for a final list of studies that were included in the meta-analysis along with a brief summary of each.

$<<<<<<<<<<$ Insert Table 4 about here $>>>>>>>>>>$

Selection criteria. The next step was to determine the studies to be included included in the meta-analysis. A priori decision rules should be set before any analysis is performed (Fox et al., 1998). Exemplars of previous neurologically based meta-analyses were used to suggest rules of thumb for future research. Based on this, five general selection criteria were used to select studies for use in the meta-analysis: (1) studies must use PET or fMRI methods (Northoff et al., 2006; Martinelli et al., 2013; Ortigue et al., 2010; Phan et al., 2002); (2) articles must include either MNI or Talairach and Tournoux coordinates, which are the standard method of indicating brain activation location (Fan et al. 2010; Martinelli et al., 2013; Northoff et al., 2006; Phan et al., 2002); (3) scans must include whole brain information and not just region of interest (ROI) data (Fan et al., 2010; Martinelli et al., 2013; Northoff et al., 2006; Phan et al., 2002); (4) subjects should be healthy adults free from any known disorders, substance abuse, or pharmacological treatment (Fan et al. 2010; Martinelli et al., 2013; Northoff et al., 2006; Ortigue et al., 2010; Phan et al., 2002); and (5) activation data only was used with deactivation data excluded (Fan et al., 2010; Northoff et al., 2006; Phan et al., 2002). Activation data is an increase in blood flow to a particular area of the brain (surrogate for brain activity), while deactivation is lower than normal blood flow to the brain. 
In addition to these general guidelines that are applicable to most neurologically based meta-analyses, some study specific decision rules were decided upon a priori. For this study, I only used studies that include facial evaluations, which either implicitly or explicitly measure facial trustworthiness. This is done for compatibility of collected data.

Within study inclusion decisions. After a study is chosen for inclusion in a meta-analysis, the researcher must deal with questions such as at what significance levels should an activation be included and should each study have equal weight in the analysis? Lieberman and Cunningham (2009) suggest that neurological research has enacted such stringent activation criterion that type II errors are becoming more abundant. This leaves researchers wondering what significance level is appropriate in a meta-analysis that compiles multiple studies. There is not a hard and fast industry standard for significance cutoffs in neuroimaging so researchers utilize different significance levels when analyzing activation levels. A case can be made that an activation should be included if it is specified as significant based on the original authors' criteria (Northoff et al., 2006; Phan et al., 2002). Since, I am suggesting only including peer reviewed articles in the meta-analysis, it seems reasonable to accept this decision rule. It is also important to determine if each included study should have equal weight in the meta-analysis. Etkin and Wager (2007) suggest that larger studies deserve to have a greater impact and weight by the square root of the sample size. Eickhoff et al., (2009) also agree that studies with larger samples are more reliable and less prone to sampling error. Weighting based on sample size can be included in the ALE algorithms to give larger studies more influence on the results. These ALE algorithms aggregate and analyze the results using a Monte Carlo simulation, and provide statistically significant brain activation coordinates based on the results of all of the studies in the 
analysis. A common reporting practice is to include both weighted and unweighted brain activation coordinates as are included in this study.

\section{Explanation of fMRI Research}

Neuroimaging research frequently uses functional magnetic resonance imaging (fMRI) technology to measure brain activation in its subjects. This process uses the same MRI machines which are employed when determining the severity of a torn knee ligament (Brefczynski-Lewis, 2011). The difference being that a head coil is used to help record the oxygenated blood that is found in active parts of the brain. When an area of the brain is recruited for a neurological process it will have this additional oxygenated blood. For this reason, blood flow can be used as a surrogate measure for neural activation.

In fMRI studies, neural activation is the dependent variable which is measured in response to the manipulated independent variables. These independent variables are treated in the same way as would be found in a traditional experiment. For example, Dimoka (2010) manipulated trust (high vs. low) and distrust (high vs. low) as her independent variables and the brain activation results (e.g. caudate nucleus and amygdala) from the fMRI served as her dependent variables. Researchers are typically able to analyze group differences in analysis, which is very similar to a factorial ANOVA.

Results are then depicted using aggregated brain images and tables that reference brain locations. While human brains are similar in structure, there are discrepancies based on individual differences of size and shape. Since neurological research combines the brain activation of multiple subjects, it is necessary to standardize brain location.

Uttal (2013) states that there are three such methods for standardizing location: Brodmann areas, narrative locations, and three-dimensional coordinate systems (i.e. Talairach or 
MRI). Brodmann areas have been around for over 100 years and are used to locate neurophysiological functions (Strotzer, 2009). The drawback of relying exclusively on this method is that many times neuro-activation will span across the defined boundaries. Another option is the use of narrative locations (e.g. orbito frontal cortex, amygdala, etc.), but this qualitative approach can make it difficult to make apples to apples comparisons between studies (Uttal, 2013). This is because these narrative locations can cover a wide range of brain coordinates, so using this lacks the precision that accompanies using coordinate systems. The third option is to utilize a three dimensional coordinate atlas. There are two major atlases, the first was created by Talairach and Tournoux (1988) using a single human brain and the second was a modified version by Evans et al., (1992) called MNI which is comprised of 250 subjects. Most meta-analyses require either Talairach or MNI coordinates for inclusion into the study. While there are differences in the two atlases, they can be easily converted http://www.mrccbu.cam.ac.uk/Imaging/Common/mnispace.shtml (Svoboda et al., 2006, Vigneau et al., 2006); some meta-analytic software has conversion capabilities streamlining the process. In this study, Talairach data was converted to MNI coordinates for analysis because it is necessary for all coordinates to be on the same system before aggregating. Narrative locations were only used in tables to aid in description.

\section{ALE Meta-Analysis}

The most complete approach for summarizing neuroimaging results is to use coordinate based algorithms (Bzdok et al., 2011). This methodology evolved from previously approaches with less statistical rigor. In fact, early reviews were conducted using qualitative procedures or simple statistical approaches. A description of these methodologies is discussed by BangertDrowns and Rudner (1991). Chein et al., (2002) pushed the field forward by introducing the 
Aggregated Gaussian Estimated Sources method, which creates an aggregated three-dimensional probability map representing voxel convergence. The major criticism of this technique is that the process for determining the map's thresholds is viewed as subjective. This was rectified in subsequent research in ALE and kernel density approaches.

Turkeltaub et al., (2002) attempted to rectify this problem by creating an approach where clusters of peak brain activations from multiple studies are examined to better understand a cognitive task. This approach, activation likelihood estimates (ALE), can be understood as a probability distribution around a peak instead of a single point (Turkeltaub et al., 2002). ALE attempts to assess how likely an activation is to appear in a given voxel (brain area measured in small cubes 3-5 mm). This process aggregates the studies and provides probabilities of specific brain activations for a specific psychological process.

There are three reasons ALE technique is superior to previous meta-analytic methods: "(1) the automation of the analysis, (2) the quantification of the level of concordance in addition to the location, and (3) the use of significance thresholds, providing statistically defensible conclusions” (Turkeltaub et al., 2002, p. 765). Building on this work, Eickhoff et al., (2009) were able to improve the ALE algorithm in three important ways. The first is that it estimated between template and between subject variability. Second, it accounts for white matter activations that may bias the results. Third, it introduces random-effects analysis that is more generalizable. This revised algorithm is frequently used in recent neurological meta-analytic research and is available for free download at (GingerAle 2.0, http://brainmap.org) (Langer and Eickhoff, 2013; Martinelli et al., 2013). Simply stated, the ALE algorithm searches for better than random activation across studies, treats activation coordinates as probability distributions weighted by sample size, and models the results on an activation map (Langer and Eickhoff, 2013). 
For this study, an ALE meta-analysis was run to examine the network of brain regions that are active during implicit evaluations of faces. The analysis was conducted using a conservative ALE approach to improve accuracy. Four steps were employed: (1) determining the ALE scores, (2) creating a null distribution, (3) thresholding, and (4) producing cluster statistics (Eickhoff et al., 2009; Eickhoff et al., 2012; Turkeltaub et al., 2012). When determining the appropriate p-value, the false discovery rate was set at .01 as recommended by Laird et al., (2005).

Employing this four step ALE meta-analytic procedure will produce a list of statistically significant clusters of brain voxels. From a neuroscientific perspective, a voxel can be defined as “a three-dimensional volume element" located within the brain (Dimoka, 2012). So, in the ALE results table (see Table 5), cluster size indicates the volume of activation in a particular brain area. This table also labels the significant brain areas that were determined in this analysis using the previously described methods for identifying brain location: narrative locations, Brodmann areas, and three-dimensional coordinate systems. While the narrative locations and Broadmann areas are useful for description, the three-dimensional coordinates are the more precise method for describing brain location. These coordinates represent the center of the cluster of brain voxels. Both the unweighted and weighted three-dimensional coordinates are provided in the table with unweighted coordinates indicating that each study received equal weight in the ALE calculation and with weighted coordinates indicating that studies were weighted based on sample size. In addition, visual depictions of the meta-analytic results are provided.

\section{RESULTS}

This paper sought to determine the role of the implicit evaluation of faces on trust decisions through conducting a fMRI meta-analysis using nine individual studies. Below I 
describe the neurological network that was uncovered from this fMRI meta-analysis. This is important because developing a brain activation network provides a more comprehensive explanation for what is occurring during implicit evaluation of faces than can be found in the individual studies. This network also provided an opportunity to test our theory about the role of approach-avoidance theory in trust decisions.

The results of the ALE meta-analysis are depicted in Table 5 and Figure 2. These brain regions make up the neurological network for this study and are ordered according to the magnitude of brain activation. The magnitude of brain activation is the number of voxels (i.e., 3 mm cubes of the brain) that are active and clustered together in a particular brain region. Both weighted (based on the sample size) and unweighted results are included in the table. As expected, the amygdala plays a prominent role in the implicit evaluation of faces. Amygdala activation occurs bilaterally (i.e. in both the left and right regions) and comprises the two largest activation clusters in our model. The next largest brain activation cluster occurred in the medial prefrontal cortex. This brain area has been associated with cost-reward analysis and determinations of intentionality (Lieberman, 2007; Satpute and Lieberman, 2006). There was also bilateral activation in the fusiform gyrus, which is not surprising because of its known role in stimuli processing, especially related to processing faces (Baas et al., 2008). The insula was also active in this model. This brain region has been found to be associated with emotional processing and gut feelings (Winston et al., 2002). There is also evidence that the occipital cortex is active; this region is suggested to be amplified by the amygdala to help determine facial valence. Other small clusters of brain activation that are more task related (e.g., viewing the screen) are not mentioned in this analysis. Taken together, this shows that there is a greater 
number of brain regions that are engaged in automatic processing than are engaged in higher order cognition supporting hypothesis 1.

$<<<<<<<<<<$ Insert Table 5 and Figure 2 about here $>>>>>>>>>>$

The brain activation in the amygdala, insula, and occipital cortex are key to providing evidence that valence decisions are being made based on the perceived positive or negative evaluations of the faces providing support for hypothesis 2. This supports the contention that approach-avoidance theory drives implicit evaluation of faces (e.g., Todorov, 2008). What is of

particular note is the large degree of activation in the medial prefrontal cortex. This is associated with initiating cost-reward analysis. This supports hypothesis 3, which predicts that while implicit evaluation of faces are automatic approach-avoidance decisions, they also concurrently initiate more effortful processing. This effortful processing is likely associated with the intentional trust calculations made early in the relationship.

\section{DISCUSSION}

\section{Summary}

This paper provides evidence that unconscious evaluations about whether to trust an individual based on his/her face can be made based on a split second evaluation that is reliable. This is driven by the instinct to approach individuals that appear safe and avoid those which may be threatening. The paper also advances theory by suggesting that these initial implicit evaluations of faces stimulate more effortful cost-benefit processing. This cost-benefit processing is what has been previously theorized to drive trust decisions. This is key to marketing research because it shows that exchange relationships are affected by unconscious evaluations that can occur before either party has the chance to speak. This supports the growing 
thin slice theory literature, which suggests that accurate predictions can be made using only brief exposures to information.

In this study, a meta-analysis was used to advance theory on trust formation that could not be examined using traditional methods (e.g., survey, experimentation) because of the unconscious nature of the processing that was occurring. This study also determined the network of brain activation that occurs during implicit evaluation of faces. This can be used in future neurological research around trust to set predefined regions of interest for hypothesis testing. In addition, a methodological contribution was made through fMRI meta-analysis being introduced to marketing research. This technique can be used in future research to explain issues critical to marketing (e.g., consumer decision making, emotional reactions to messages) and advance marketing theory (e.g., theory of mind).

\section{Managerial Implications}

Individuals make unconscious trust decisions based on implicit evaluations of faces giving individuals with more naturally trustworthy faces an advantage in channel partnerships and buyer-seller relationships. Unfortunately, it is neither practical nor fair for firms to hire individuals for client-facing roles based on the perceived trustworthiness of an individual's face. There are still ways that this information can be strategically applied. For example, when researchers used computer software to exaggerate the features of neutral faces to make them look trustworthy, they also began to look happier; in the same way exaggerating features to emphasize distrust made the faces look angrier (Todorov, 2008). In other studies of facial trustworthiness, happiness and anger had to be controlled in the pictures that were evaluated because happiness was shown to enhance trustworthiness evaluations while anger was shown to squelch it (Winston et al., 2002). This agrees with exploratory marketing research that suggests that smiling can 
improve trustworthiness perceptions in an exchange relationship (Wood et al., 2008). So

salespeople who frequently smile are more likely to be perceived as trustworthy and will likely have greater client success than salespeople who do not. Salespeople should not send false signals (i.e., signals that do not accurate demonstrate the salesperson's true intentions), such as smiling at a customer that they wish to exploit. Salespeople should instead be genuine in their desire to help buyers, and their friendly smile at the beginning of a meeting (i.e., the approach phase of the sales call) should be a true signal of that desire to help. Research has shown that individuals are fairly proficient at detecting "genuine smiles," so a forced or insincere smile may be less effective than a natural smile that comes stems from a desire to help (Oda et al., 2009).

On the other side of the relationship, it is important to note that individuals with more trustworthy faces can learn to become successful liars (Todorov, 2008). It is important for the trusting party (e.g., buyer) to be aware of this and be more vigilant in evaluating the messages of trustworthy looking individuals. In the same way, it may not be wise to turn down a deal because an individual does not look trustworthy, instead an evaluation should be made as to whether both parties interests are aligned before making a trust decision (Scheer, 2012). Taken together, it demonstrates that while thin slice judgments can be accurate in a social context such as trust evaluations, it is possible for other individuals to manipulate these evaluations.

\section{Limitations}

Meta-analyses possess many strengths, but are subject to limitation inherent to the methodology. First, meta-analyses are subject to potential publication biases that limit null results (Rosenthal, 1979). Second, due to the recent development of fMRI research in this area, there were a limited amount of studies included in this analysis. All but one of the studies has been published within the last ten years. Despite this limitation, all results were significant at the 
.01 level and survived corrections accounting for multiple comparisons. Third, neuroimaging studies may be influenced by intersubject variability based on low sample size (Simon et al., 2010). Aggregating the results of multiple studies is helpful in mitigating this concern, but the concern is still present in any fMRI meta-analysis. In spite of these limitations, it should be noted “coordinate-based meta-analysis algorithms such as ALE are currently the most comprehensive approach for summarizing neuroimaging findings in a particular field” (Bzdok et al., 2011, p. 219).

\section{Future Research}

After decades of research on trust in the marketing literature, the antecedents of trust that are intentionally processed at a cognitive level are well established. Our research indicates that marketers may need to shift their focus to also examining the antecedents of trust, which are processed automatically such as the implicit evaluation of faces. Specifically this meta-analysis opens the door for four key avenues of future scholarship. First, while implicit evaluations of faces impact trust decisions, it is unclear whether other antecedent variables of trust can counteract the effect of an evaluation that a face is untrustworthy. For example, preconceptions based on firm trust or salesperson reputation may or may not influence a purchasing agent to ignore the subconscious trust cues from an implicit evaluation of faces. Second, while this study has demonstrated that implicit evaluations of faces have an effect, it is uncertain whether this effect persists over time. Future research should explore whether the negative effects of an avoid determination continue in an exchange relationship into subsequent interactions. Third, research has demonstrated the importance of company avatars (e.g., Holzwarth et al., 2006) and salesperson social media accounts (e.g., Agnihotri et al., 2012; Andzulis et al., 2012) on exchange. In both of these research areas, buyers will likely make implicit evaluations of faces 
that may influence sales, which suggests a need for additional research. Finally, while the implicit evaluation of faces is an important component to the automatic processing that occurs during initial trust decisions, other subconscious processing should be explored such as the role of body language and speech patterns in trust formation. 


\section{REFERENCES}

Adolphs, Ralph, Daniel Tranel, and Antonio R. Damasio (1998), "The Human Amygdala in Social Judgment," Nature, 393 (6684), 470.

Agnihotri, Raj, Prabakar Kothandaraman, Rajiv Kashyap, and Ramendra Singh (2012), "Bringing “Social” Into Sales: The Impact of Salespeople’s Social Media Use on Service Behaviors and Value Creation," Journal of Personal Selling \& Sales Management, 32 (3), 333-348.

Ambady, Nalini (2010), "The Perils of Pondering: Intuition and Thin Slice Judgments," Psychological Inquiry, 21 (4), 271-278.

-------, and Robert Rosenthal (1993), "Half a Minute: Predicting Teacher Evaluations from Thin Slices of Nonverbal Behavior and Physical Attractiveness," Journal of Personality and Social Psychology, 64 (3), 431.

Anderson, James C., and James A. Narus (1990), "A Model of Distributor Firm and Manufacturer Firm Working Partnerships," The Journal of Marketing, 54 (1), 42-58.

Anderson, Erin, and Barton Weitz (1989), "Determinants of Continuity in Conventional Industrial Channel Dyads," Marketing Science, 8 (4), 310-323.

Andzulis, James, "Mick, Nikolaos G. Panagopoulos, and Adam Rapp (2012), "A Review of Social Media and Implications for the Sales Process," Journal of Personal Selling \& Sales Management, 32 (3), 305-316.

Baas, Daan, André Aleman, Matthijs Vink, Nick F. Ramsey, Edward HF de Haan, and René S. Kahn (2008), "Evidence of Altered Cortical and Amygdala Activation During Social Decision-Making in Schizophrenia," Neuroimage, 40 (2), 719-727.

Bangert-Drowns, Robert L., and Lawrence M. Rudner (1991), "Meta-Analysis in Educational Research. ERIC Digest.” (Accessed January 14, 2015), [available at: http://ericae.net/edo/ED339748.htm].

Berg, Joyce, John Dickhaut, and Kevin McCabe (1995), "Trust, Reciprocity, and Social History," Games and Economic Behavior, 10 (1), 122-142.

Bitner, Mary Jo (1992), "Servicescapes: The Impact of Physical Surroundings on Customers and Employees," The Journal of Marketing, 57-71.

Bradach, Jeffrey L., and Robert G. Eccles (1989), "Price, Authority, and Trust: From Ideal Types to Plural Forms," Annual Review of Sociology, 15 (1), 97-118.

Brefczynski-Lewis, Julie A (2011), "Neuroimaging: Directions and Potentials for Communication Research," Communication Research Reports, 28 (2), 196-204. 
Bzdok, D., R. Langner, S. Caspers, F. Kurth, U. Habel, K. Zilles, A. Laird, and Simon B. Eickhoff (2011), "ALE Meta-Analysis on Facial Judgments of Trustworthiness and Attractiveness," Brain Structure and Function, 215 (4), 209-223.

Chein, J. M., K. Fissell, S. Jacobs, and Julie A. Fiez (2002), "Functional Heterogeneity within Broca's Area During Verbal Working Memory," Physiology \& Behavior, 77 (4), 635-639.

Chiles, Todd H., and John F. McMackin (1996), "Integrating Variable Risk Preferences, Trust, and Transaction Cost Economics," Academy of Management Review, 21 (1), 73-99.

Crosby, Lawrence A., Kenneth R. Evans, and Deborah Cowles (1990), "Relationship Quality in Services Selling: An Interpersonal Influence Perspective," The Journal of Marketing, 54 (3), 68-81.

Dane, Erik, and Michael G. Pratt (2007), "Exploring Intuition and Its Role in Managerial Decision Making," Academy of Management Review, 32 (2), 33-54.

Dagger, Tracey S., and Timothy K. O'Brien (2010), "Does Experience Matter? Differences in Relationship Benefits, Satisfaction, Trust, Commitment and Loyalty for Novice and Experienced Service Users," European Journal of Marketing, 44 (9), 1528-1552.

Dimoka, Angelika (2012), "How to Conduct a Functional Magnetic Resonance (FMRI) Study in Social Science Research.

Doallo, Sonia, Jane E. Raymond, Kimron L. Shapiro, Monika Kiss, Martin Eimer, and Anna C. Nobre (2012), "Response Inhibition Results in the Emotional Devaluation of Faces: Neural Correlates as Revealed by fMRI," Social Cognitive and Affective Neuroscience, 7 (6), 649-659.

Doney, Patricia M., and Joseph P. Cannon (1997), "An Examination of the Nature of Trust in Buyer-Seller Relationships," Journal of Marketing, 61 (2), 35-51.

Dwyer, F. Robert, Paul H. Schurr, and Sejo Oh (1987), "Developing Buyer-Seller Relationships," The Journal of Marketing, 11-27.

Eickhoff, Simon B., Angela R. Laird, Christian Grefkes, Ling E. Wang, Karl Zilles, and Peter T. Fox (2009), "Coordinate-Based Activation Likelihood Estimation Meta-Analysis of Neuroimaging Data: A Random-Effects Approach Based on Empirical Estimates of Spatial Uncertainty," Human Brain Mapping, 30 (9), 2907-2926.

Elliot, Andrew J (2006), "The Hierarchical Model of Approach-Avoidance Motivation," Motivation and Emotion, 30 (2), 111-116.

Engell, Andrew D., James V. Haxby, and Alexander Todorov (2007), "Implicit Trustworthiness Decisions: Automatic Coding of Face Properties in the Human Amygdala," Journal of Cognitive Neuroscience, 19 (9), 1508-1519. 
Etkin, Amit, and Tor D. Wager (2007), "Functional Neuroimaging of Anxiety: A Meta-Analysis of Emotional Processing in PTSD, Social Anxiety Disorder, and Specific Phobia," American Journal of Psychiatry, 164 (10), 1476-1488.

Evans, Alan C., D. Louis Collins, and Brenda Milner (1992), "An MRI-Based Stereotactic Atlas From 250 Young Normal Subjects," In Soc. Neurosci. Abstr, 18 (179), 408.

Evans, Kenneth R., Richard G. McFarland, Bart Dietz, and Fernando Jaramillo (2012), "Advancing Sales Performance Research: A Focus on Five Underresearched Topic Areas," Journal of Personal Selling \& Sales Management, 32 (1), 89-105.

Fan, Yan, Niall W. Duncan, Moritz de Greck, and Georg Northoff (2011), "Is There a Core Neural Network in Empathy? An fMRI Based Quantitative MetaAnalysis," Neuroscience \& Biobehavioral Reviews, 35 (3), 903-911.

Fox, Peter T., Lawrence M. Parsons, and Jack L. Lancaster (1998), "Beyond The Single Study: Function/Location Metanalysis in Cognitive Neuroimaging," Current opinion in neurobiology 8 (2), 178-187.

Freud, Sigmund (1981), "Repression. The Standard Edition of the Complete Psychological Works of Sigmund Freud. Volume XIV," On the History of the Psycho-analytic Movement, Papers on Meta psychology and Other Works.

Ganesan, Shankar (1994), "Determinants of Long-Term Orientation in Buyer-Seller Relationships," The Journal of Marketing, 1-19.

Gill, Harjinder, Kathleen Boies, Joan E. Finegan, and Jeffrey McNally (2005), "Antecedents of Trust: Establishing a Boundary Condition for the Relation Between Propensity to Trust and Intention to Trust," Journal of Business and Psychology, 19 (3), 287-302.

Guenzi, Paolo, and Laurent Georges (2010), "Interpersonal Trust in Commercial Relationships: Antecedents and Consequences of Customer Trust in the Salesperson," European Journal of Marketing, 44 (1), 114-138.

Hamamura, Takeshi, and Liman Man Wai Li (2012), "Discerning Cultural Identification from a Thinly Sliced Behavioral Sample," Personality and Social Psychology Bulletin, 38 (12), 1697-1706.

Hamann, Stephan B., Timothy D. Ely, Scott T. Grafton, and Clinton D. Kilts (1999), "Amygdala Activity Related to Enhanced Memory for Pleasant and Aversive Stimuli," Nature neuroscience, 2 (3).

Hawes, Jon M., Kenneth E. Mast, and John E. Swan (1989), "Trust Earning Perceptions of Sellers and Buyers," Journal of Personal Selling \& Sales Management, 9 (1), 1-8. 
Hibbard, Jonathan D., Nirmalya Kumar, and Louis W. Stern (2001), "Examining the Impact of Destructive Acts in Marketing Channel Relationships," Journal of Marketing Research, 38 (1), 45-61.

Holzwarth, Martin, Chris Janiszewski, and Marcus M. Neumann (2006), "The Influence of Avatars On Online Consumer Shopping Behavior," Journal of Marketing, 70 (4), 19-36.

Jain, Shailendra Pratap, Pragya Mathur, and Durairaj Maheswaran (2009), "The Influence of Consumers' Lay Theories on Approach/Avoidance Motivation," Journal of Marketing Research, 46 (1), 56-65.

James, William (1890), The principles of psychology, New York: Holt and Company.

Jung, Carl Gustav (2014), Collected Works of CG Jung, Volume 6: Psychological Types, Vol. 6, Princeton University Press.

Kahneman, Daniel (2011), Thinking, fast and slow. Macmillan.

Kim, Hackjin, Min-Jo Choi, and In-Ji Jang (2012), "Lateral OFC Activity Predicts Decision Bias Due to First Impressions During Ultimatum Games," Journal of Cognitive Neuroscience, 24 (2), 428-439.

Kingshott, Russel PJ, and Anthony Pecotich (2007), "The Impact of Psychological Contracts on Trust and Commitment in Supplier-Distributor Relationships," European Journal of Marketing, 41 (9), 1053-1072.

Kraus, Michael W., and Dacher Keltner (2009), "Signs of Socioeconomic Status: A Thin-Slicing Approach," Psychological science, 20 (1), 99-106.

Lagace, Rosemary R., Robert Dahlstrom, and Jule B. Gassenheimer (1991), "The Relevance of Ethical Salesperson Behavior on Relationship Quality: The Pharmaceutical Industry," Journal of Personal Selling \& Sales Management, 11 (4), 39-47.

Laird, Angela R., P. Mickle Fox, Cathy J. Price, David C. Glahn, Angela M. Uecker, Jack L. Lancaster, Peter E. Turkeltaub, Peter Kochunov, and Peter T. Fox, "ALE Meta-Analysis: Controlling the False Discovery Rate and Performing Statistical Contrasts," Human brain mapping, 25 (1), 155-164.

Lewicki, Roy J., and Bunker, Barbara B. (1995), Trust in relationships: A model of development and decline, Jossey-Bass.

Lieberman, Matthew D., and William A. Cunningham. "Type I and Type II Error Concerns in fMRI Research: Re-Balancing the Scale," Social Cognitive and Affective Neuroscience, 4 (4), 423-428. 
Mattavelli, Giulia, Timothy J. Andrews, Aziz UR Asghar, John R. Towler, and Andrew W. Young (2012), "Response of Face-Selective Brain Regions to Trustworthiness and Gender of Faces," Neuropsychologia, 50 (9), 2205-2211.

McKnight, D. Harrison, Larry L. Cummings, and Norman L. Chervany (1998), "Initial Trust Formation in New Organizational Relationships," Academy of Management Review, 23 (3), 473-490.

Moorman, Christine, Rohit Deshpande, and Gerald Zaltman (1993), "Factors Affecting Trust in Market Research Relationships," The Journal of Marketing, 57 (1), 81-101.

Morgan, Robert M., and Shelby D. Hunt (1994), "The Commitment-Trust Theory of Relationship Marketing," The Journal of Marketing, 58(3), 20-38.

Mowen, John C., and Maryanne M. Mowen (1991), "Time and Outcome Valuation: Implications for Marketing Decision Making," The Journal of Marketing, 55 (4), 54-62.

North, Michael S., Alexander Todorov, and Daniel N. Osherson (2010), "Inferring the Preferences of Others from Spontaneous, Low-Emotional Facial Expressions," Journal of Experimental Social Psychology, 46 (6), 1109-1113.

Northoff, Georg, Alexander Heinzel, Moritz De Greck, Felix Bermpohl, Henrik Dobrowolny, and Jaak Panksepp (2006), "Self-Referential Processing in Our Brain—a Meta-Analysis of Imaging Studies on the Self," Neuroimage, 31 (1), 440-457.

Oda, Ryo, Takuya Naganawa, Shinsaku Yamauchi, Noriko Yamagata, and Akiko MatsumotoOda (2009), "Altruists Are Trusted Based on Non-Verbal Cues," Biology Letters, rsbl20090332.

Ortigue, Stephanie, Francesco Bianchi-Demicheli, Nisa Patel, Chris Frum, and James W. Lewis (2010), "Neuroimaging of Love: fMRI Meta-Analysis Evidence Toward New Perspectives in Sexual Medicine," The journal of sexual medicine, 7 (11), 3541-3552.

Palmatier, Robert W., Rajiv P. Dant, Dhruv Grewal, and Kenneth R. Evans (2006), "Factors influencing the effectiveness of relationship marketing: a meta-analysis," Journal of marketing 70 (4), 136-153.

Pessoa, Luiz, Sabine Kastner, and Leslie G. Ungerleider (2002), "Attentional Control of the Processing of Neutral and Emotional Stimuli," Cognitive Brain Research, 15 (1), 31-45.

Phan, K. Luan, Tor Wager, Stephan F. Taylor, and Israel Liberzon. "Functional neuroanatomy of emotion: a meta-analysis of emotion activation studies in PET and fMRI." Neuroimage 16, no. 2 (2002): 331-348.

Rosenthal, Robert. "The file drawer problem and tolerance for null results." Psychological bulletin 86, no. 3 (1979): 638. 
-------, and Robin M. DiMatteo (2002), “Meta-Analysis,” Stevens' Handbook of Experimental Psychology.

Said, Christopher P., Sean G. Baron, and Alexander Todorov (2009), "Nonlinear Amygdala Response to Face Trustworthiness: Contributions of High and Low Spatial Frequency Information," Journal of Cognitive Neuroscience, 21 (3), 519-528.

Scheer, Lisa K (2012), "18 Trust, Distrust and Confidence in B2B Relationships," Handbook on Business to Business Marketing, 332.

Sharpe, Donald (1997), "Of Apples and Oranges, File Drawers and Garbage: Why Validity Issues in Meta-Analysis Will Not Go Away," Clinical Psychology Review, 17 (8), 881901.

Simon, Joe J., Stephan Walther, Christian J. Fiebach, Hans-Christoph Friederich, Christoph Stippich, Matthias Weisbrod, and Stefan Kaiser (2010), "Neural Reward Processing is Modulated by Approach-and Avoidance-Related Personality Traits," Neuroimage, 49 (2), 1868-1874.

Sirdeshmukh, Deepak, Jagdip Singh, and Barry Sabol (2002), "Consumer Trust, Value, and Loyalty in Relational Exchanges," Journal of marketing, 66 (1), 15-37.

Swan, John E., Michael R. Bowers, and Lynne D. Richardson (1999), "Customer Trust in The Salesperson: An Integrative Review and Meta-Analysis of the Empirical Literature," Journal of Business Research, 44 (2), 93-107.

-------, I. Fred Trawick Jr, David R. Rink, and Jenny J. Roberts (1988), "Measuring Dimensions of Purchaser Trust of Industrial Salespeople," Journal of Personal Selling \& Sales Management, 8 (1), 1-10.

Stanley, Damian A., and Ralph Adolphs (2013), "Toward a Neural Basis for Social Behavior," Neuron 80 (3), 816-826.

Strotzer, Michael (2009), "One Century of Brain Mapping Using Brodmann Areas," Clinical Neuroradiology, 19 (3), 179-186.

Svoboda, Eva, Margaret C. McKinnon, and Brian Levine (2006), "The Functional Neuroanatomy of Autobiographical Memory: a Meta-Analysis," Neuropsychologia, 44 (12), 2189-2208.

Swan, John E., I. Fred Trawick Jr, David R. Rink, and Jenny J. Roberts (1988), "Measuring Dimensions of Purchaser Trust of Industrial Salespeople," Journal of Personal Selling \& Sales Management, 8 (1), 1-10.

Talairach, Jean, and Pierre Tournoux (2008), "Co-Planar Stereotaxic Atlas of the Human Brain. 3-Dimensional Proportional System: An Approach to Cerebral Imaging." 
Todorov, Alexander (2008), "Evaluating Faces on Trustworthiness," Annals of the New York Academy of Sciences, 1124 (1), 208-224.

-------, Sean G. Baron, and Nikolaas N. Oosterhof (2008), "Evaluating Face Trustworthiness: A Model Based Approach," Social Cognitive and Affective Neuroscience, 3 (2), 119-127.

-------, and Andrew D. Engell (2008), "The Role of the Amygdala in Implicit Evaluation of Emotionally Neutral Faces," Social Cognitive and Affective Neuroscience, 3 (4), 303-312.

-------, Guinevere F. Eden, Karen M. Jones, and Thomas A. Zeffiro (2002),"Meta-Analysis of the Functional Neuroanatomy of Single-Word Reading: Method and Validation," Neuroimage, 16 (3), 765-780.

Turkeltaub, Peter E., Simon B. Eickhoff, Angela R. Laird, Mick Fox, Martin Wiener, and Peter Fox (2012), "Minimizing Within-Experiment and Within-Group Effects in Activation Likelihood Estimation Meta-Analyses," Human Brain Mapping, 33 (1), 1-13.

Uttal, William R (2013), Reliability in cognitive neuroscience: A meta-meta-analysis, MIT Press.

Verosky, Sara C., and Alexander Todorov (2010), "Differential Neural Responses to Faces Physically Similar to the Self as a Function of Their Valence," NeuroImage, 49 (2), 16901698.

Vigneau, Mathieu, Virginie Beaucousin, Pierre-Yves Herve, Hugues Duffau, Fabrice Crivello, Olivier Houde, Bernard Mazoyer, and Nathalie Tzourio-Mazoyer (2006), "MetaAnalyzing Left Hemisphere Language Areas: Phonology, Semantics, and Sentence Processing," Neuroimage, 30 (4), 1414-1432.

Wager, Tor D., Martin Lindquist, and Lauren Kaplan (2007), "Meta-Analysis of Functional Neuroimaging Data: Current and Future Directions," Social Cognitive and Affective Neuroscience, 2 (2), 150-158.

Watabe, Motoki, Hiroshi Ban, and Hiroki Yamamoto (2011), "Judgments About Others' Trustworthiness: An fMRI Study," Letters on Evolutionary Behavioral Science, 2 (2), 2832.

Winston, Joel S., Bryan A. Strange, John O'Doherty, and Raymond J. Dolan (2002), "Automatic and Intentional Brain Responses During Evaluation of Trustworthiness of Faces," Nature Neuroscience, 5 (3), 277-283.

Wulf, Kristof De, Gaby Odekerken-Schröder, and Dawn Iacobucci (2001), "Investments in Consumer Relationships: A Cross-Country and Cross-Industry Exploration," Journal of Marketing, 65 (4), 33-50. 
Figure 1: Initial Trust Development Framework in the Buyer-Seller Relationship

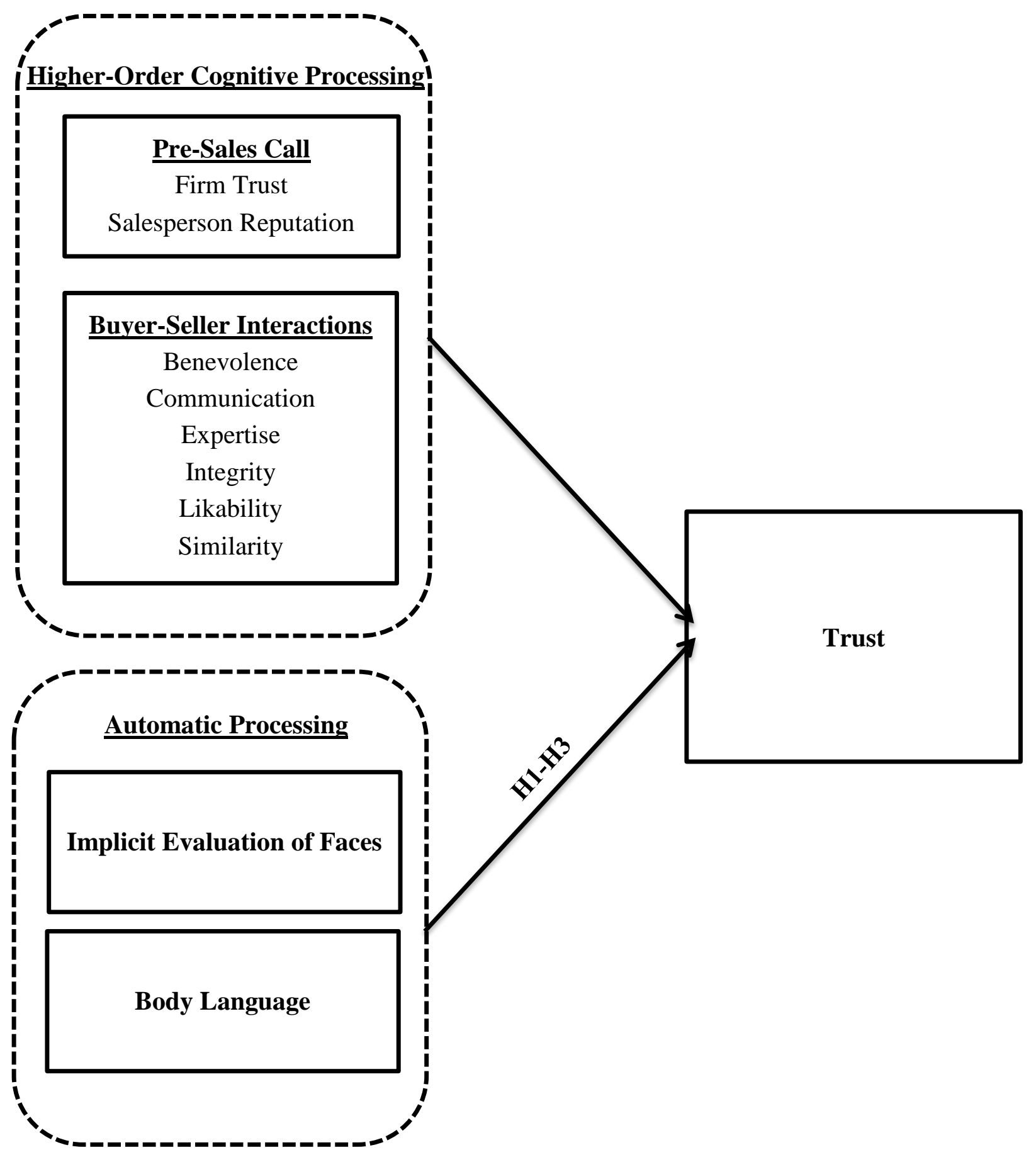


Figure 2: ALE Results for Implicit Evaluation of Faces

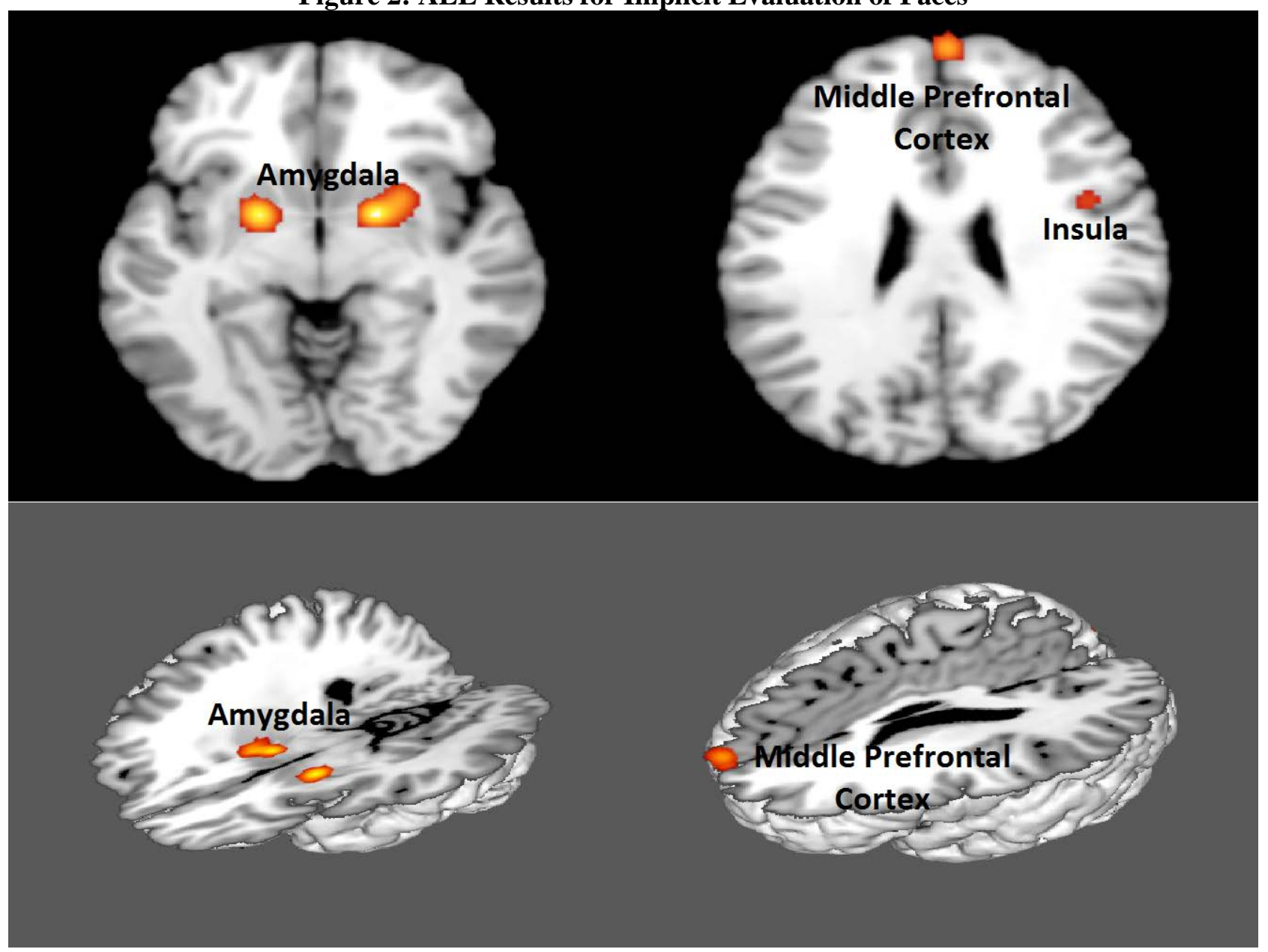


Table 1: Antecedents of Trust in Exchange Relationships

\begin{tabular}{|c|c|c|}
\hline Contructs & Definitions & Representative Papers \\
\hline Benevolence & $\begin{array}{l}\text { Caring about an exchange partner's } \\
\text { welfare and motivated to seek } \\
\text { mutually beneficial outcomes. }\end{array}$ & $\begin{array}{l}\text { Gill et al., 2005; Swan, Bowers, } \\
\text { and Richardson } 1999\end{array}$ \\
\hline Communication & $\begin{array}{l}\text { "Formal and informal sharing of } \\
\text { meaningful information" (Anderson } \\
\text { and Narus, p. 44) }\end{array}$ & $\begin{array}{l}\text { Anderson and Narus 1990; } \\
\text { Anderson and Weitz 1989; } \\
\text { Morgan and Hunt } 1994\end{array}$ \\
\hline Expertise & $\begin{array}{l}\text { Demonstrated competence that } \\
\text { typically manifest itself in the } \\
\text { information that is provided and in } \\
\text { the implementation of solutions. }\end{array}$ & $\begin{array}{l}\text { Crosby, Evans, and Cowles } \\
\text { 1990; Doney and Cannon 1997; } \\
\text { Lagace, Dahlstrom, and } \\
\text { Gassenheimer 1991; Moorman, } \\
\text { Deshpande, and Zaltman } 1993\end{array}$ \\
\hline Firm Trust & $\begin{array}{l}\text { An inference of the trustworthiness } \\
\text { of an organization based on past } \\
\text { action and the reputation that it has } \\
\text { established within the industry. }\end{array}$ & $\begin{array}{l}\text { Doney and Cannon 1997; Swan, } \\
\text { Bowers, and Richardson } 1999\end{array}$ \\
\hline Integrity & $\begin{array}{l}\text { "Perceived unwillingness to } \\
\text { sacrifice ethical standards to } \\
\text { achieve individual or organizational } \\
\text { objectives" (Moorman, Deshpande, } \\
\text { and Zaltman 1993, p. 84) }\end{array}$ & $\begin{array}{l}\text { Gill et al., 2005; Moorman, } \\
\text { Deshpande, and Zaltman } 1993\end{array}$ \\
\hline Likability & $\begin{array}{l}\text { A perception that an individual is } \\
\text { enjoyable to know. }\end{array}$ & $\begin{array}{l}\text { Hawes, Mast, and Swan 1999; } \\
\text { Swan et al. } 1988\end{array}$ \\
\hline Reputation & $\begin{array}{l}\text { A signal of future action based on } \\
\text { the behavior exhibited in other } \\
\text { relationships. }\end{array}$ & Ganesan 1994 \\
\hline Similarity & $\begin{array}{l}\text { A perception of shared interests and } \\
\text { values. }\end{array}$ & $\begin{array}{l}\text { Crosby, Evans, and Cowles } \\
\text { 1990; Doney and Cannon 1997; } \\
\text { Palmatier et al., } 2006\end{array}$ \\
\hline
\end{tabular}




\section{Table 2: Location and Function of Brain Regions}

Regions

Amygdala

Insula

Fusiform Gyrus Summary of Findings Illustrative Studies

The amygdala has been shown to be key in making valence determinations. It has been described as the driver of implicit evaluation of faces, and is also active in intentional trust decisions.

This region is associated with the processing of emotional information. It has been shown to be active in both facial trustworthiness studies and in intentional trust decisions.

This region is associated with the processing of stimuli, it is especially important in processing faces.
Adolphs, Tranel, and Damasio 1998; Dimoka 2010; Todorov 2008

Dimoka 2010; Phan et al. 2002; Winston et al. 2002

Baas et al. 2008; Winston et al. 2002 
Table 2: Differences Between Neurological Meta-Analysis and Traditional Meta-Analysis

Traditional Meta-Analysis

This is the concern that comparing dissimilar studies will produce incoherent results

Apples and Oranges (Rosenthal and DiMatteo 2001; Sharpe 1997).

File Drawer Problem

The file drawer problem states that there is a tendency for positive results to be published and that the omission of negative results artificially inflates effect size (Rosenthal and DiMatteo 2001; Sharpe 1997).

\section{Garbage In and Garbage Out}

\author{
Neurobiological \\ Variability, \\ Technical Artifacts, \\ and Cognitive \\ Variability
}

Garbage in and garbage out is the concern that including lower quality research in a meta-analysis will lead to a lower quality meta-analytic results (Rosenthal and DiMatteo 2001; Sharpe 1997).

These concerns are not applicable to traditional meta-analyses.

Neurological Meta-Analysis

Neuroimaging meta-analyses are not immune to this concern. In fact, the most challenging issue related to a neuroimaging meta-analysis is selecting the appropriate results to include in the meta-analysis (Fox, Parsons and Lancaster 1998).

This file drawer problem is not considered a serious risk because brain mapping meta-analyses are focused on the location of the effect instead of the size of the effect. "Selective omission of subsignificant effects strongly biases meta-analyses of effect size, but has a minimal and unbiased influence on effect location. Inclusion of subsignificant effects, on the other hand (to avoid a publication bias), would artificially inflate the estimate of location variance, with minimal influence on estimated mean location" (Fox, Parsons and Lancaster 1998, p. 180).

Fox, Parsons and Lancaster (1998) combat this concern by stating that neuroimaging meta-analyses should only use significant peer reviewed results that are combined using methods approved by the larger scientific community.

The issue of neurobiological variability is that there is inconsistency in human brain anatomy among subjects (Uttal 2013). Researches attempt to mitigate this through the use of three dimensional coordinate systems (Talairach and Tournoux 1988; Evans, Collins, and Milner 1992), but this is still not a perfect solution. Technical artifacts are biases caused by the MRI such as magnetic strength of the individual machine, noisy machines, the subjects' ability to stay motionless, and issues imaging all parts of the brain (e.g. orbito frontal cortexes because of sinuses) (Uttal 2013). While new technology and procedures attempt to correct for these potential issues; it is important to remember that these are still potential problems especially in earlier studies. Cognitive variability is the idea that a subject past experiences and current affective state make it almost impossible to simply measure the response to a stimuli without including noise (Uttal 2013). Since the meta-analytic researchers is unable to control these potential issues they are best served by enacting selection criteria which only include papers with high methodological rigor. 
Table 4: Summary of the Functional MRI Studies Used in the Meta-Analysis

\begin{tabular}{|c|c|c|c|c|c|}
\hline Authors & Year & Procedures & Evaluation & $\mathbf{N}$ & Key Findings \\
\hline $\begin{array}{l}\text { Winston et } \\
\text { al. }\end{array}$ & 2002 & $\begin{array}{l}\text { Subjects were shown } 60 \text { faces (displaying expression) that } \\
\text { were rated on trustworthiness and } 60 \text { faces that were rated } \\
\text { on age (college vs. high school student) }\end{array}$ & $\begin{array}{l}\text { Explicit } \\
\text { and } \\
\text { Implicit }\end{array}$ & 12 & $\begin{array}{l}\text { When evaluating faces for both age and trustworthiness there was bilateral } \\
\text { amygdala activation when an untrustworthy face was shown. This } \\
\text { demonstrates that the amygdala response automatically occurs when evaluating } \\
\text { an untrustworthy face. }\end{array}$ \\
\hline $\begin{array}{l}\text { Engell, et } \\
\text { al. }\end{array}$ & 2007 & $\begin{array}{l}\text { Subjects were shown } 66 \text { faces with neutral expressions and } \\
\text { asked if they had seen the face before in a previous portion } \\
\text { of the study. }\end{array}$ & Implicit & 16 & $\begin{array}{l}\text { This study showed that the amygdala is active when viewing untrustworthy } \\
\text { faces even when there is no expression and when they are not consciously } \\
\text { evaluating trustworthiness. }\end{array}$ \\
\hline $\begin{array}{l}\text { Todorov } \\
\text { and Engell }\end{array}$ & 2008 & $\begin{array}{l}\text { Subjects were shown } 66 \text { faces with neutral expressions and } \\
\text { asked if they had seen the face before in a previous portion } \\
\text { of the study. }\end{array}$ & Implicit & 15 & $\begin{array}{l}\text { This study demonstrated that trustworthiness evaluations were valence } \\
\text { decisions in which a determination was made on whether another individual } \\
\text { should be approached or avoided. }\end{array}$ \\
\hline Bass et al. & 2008 & $\begin{array}{l}\text { Subjects were shown } 120 \text { faces displaying neutral } \\
\text { expressions where } 60 \text { were rated on trustworthiness and } 60 \\
\text { faces were rated on age (over } 30 \text { vs. under 30). }\end{array}$ & $\begin{array}{l}\text { Explicit } \\
\text { and } \\
\text { Implicit }\end{array}$ & 21 & $\begin{array}{l}\text { Schizophrenic subjects* don't recruit areas such as the amygdala and the } \\
\text { insula as well as healthy adults when evaluating facial trustworthiness. }\end{array}$ \\
\hline Said et al. & 2008 & $\begin{array}{l}\text { Independent evaluations of forehead, eyes, nose, and mouth } \\
\text { were combined to produce } 20 \text { highly trustworthy faces (10 } \\
\text { of each gender) and } 20 \text { highly untrustworthy faces (10 of } \\
\text { each gender). }\end{array}$ & Explicit & 32 & $\begin{array}{l}\text { The results showed that the extremely trustworthy and extremely } \\
\text { untrustworthy faces produces similar amygdala reaction demonstrating that the } \\
\text { relationship between the amygdala and facial trustworthiness may not be } \\
\text { linear. The amygdala still seems to be more sensitive to negative } \\
\text { trustworthiness information. }\end{array}$ \\
\hline $\begin{array}{l}\text { Todorov } \\
\text { et al. }\end{array}$ & 2008 & $\begin{array}{l}96 \text { neutral faces were manipulated using computer software } \\
\text { to look more or less trustworthy (high inner eyebrows, } \\
\text { pronounced cheekbones, wide chins and shallow nose } \\
\text { sellion looked more trustworthy than faces with low inner } \\
\text { eyebrows, shallow cheekbones, thin chins and deep nose } \\
\text { sellion). }\end{array}$ & Implicit & 14 & $\begin{array}{l}\text { The results showed a curvilinear relationship between facial trustworthiness } \\
\text { and amygdala reaction similar to Said et al. (2008). }\end{array}$ \\
\hline $\begin{array}{l}\text { Verosky } \\
\text { and } \\
\text { Todorov }\end{array}$ & 2010 & $\begin{array}{l}\text { Neutral faces were manipulated to look more or less } \\
\text { trustworthy using facial software and faces were also } \\
\text { morphed ( } 20 \% \text { self, } 40 \% \text { self, } 50 \% \text { self, } 60 \% \text { self, and } 80 \% \\
\text { self) with the subjects own face. }\end{array}$ & Implicit & 30 & $\begin{array}{l}\text { Subjects were more likely to rate trustworthy morphs as looking like self than } \\
\text { untrustworthy morphs. }\end{array}$ \\
\hline $\begin{array}{l}\text { Kim, } \\
\text { Choi, and } \\
\text { Jang }\end{array}$ & 2012 & $\begin{array}{l}\text { Subjects were shown } 60 \text { faces that were manipulated to be } \\
\text { high, medium, and low in trustworthiness. Subjects were } \\
\text { ask to respond to offers after seeing pictures of these faces. }\end{array}$ & Implicit & 12 & $\begin{array}{l}\text { Facial trustworthiness impacted subsequent decisions with responses being } \\
\text { impacted based on the trustworthiness of the face. }\end{array}$ \\
\hline $\begin{array}{l}\text { Doallo et } \\
\text { al. }\end{array}$ & 2012 & $\begin{array}{l}\text { Subjects were shown pictures of two different races and } \\
\text { were asked to click a button when they saw one race and } \\
\text { not the other (counterbalanced). }\end{array}$ & Explicit & 12 & $\begin{array}{l}\text { Regardless of race, the faces which were not supposed to be selected were } \\
\text { rated as less trustworthy. }\end{array}$ \\
\hline
\end{tabular}


Table 5: ALE Results for Implicit evaluation of faces

\begin{tabular}{lcccccccc}
\hline \multirow{2}{*}{ Macroanatomical location } & $\begin{array}{c}\text { Broadman } \\
\text { Area }\end{array}$ & \multirow{2}{*}{ Cluster Size } & \multicolumn{5}{c}{ MNI Coordinates } \\
\cline { 3 - 8 } & & & \multicolumn{3}{c}{$\begin{array}{c}\text { Weighted Center } \\
\text { (x,y,z) }\end{array}$} \\
& & & & \multicolumn{3}{c}{$\begin{array}{c}\text { Unweighted Center } \\
\text { (x,y,z) }\end{array}$} \\
\hline Amygdala (R) & & 2384 & 20.56 & -2.62 & -13.38 & 18 & -6 & -12 \\
Amygdala (L) & & 2304 & -17.97 & -5.39 & -14.06 & -18 & -6 & -12 \\
Medial Prefrontal Cortex (R) & BA 10 & 968 & 1.80 & 56.21 & 15.39 & 2 & 56 & 16 \\
Fusiform Gyrus (R) & & 704 & 39.13 & -47.99 & -19.82 & 38 & -50 & -20 \\
Insula & BA 13 & 432 & 42.66 & -2.17 & 13.83 & 42 & -2 & 14 \\
Fusiform Gyrus (L) & & 408 & -19.07 & -31.21 & -20.68 & -20 & -32 & -22 \\
Pyramis (L) & & 344 & -24.12 & -58.55 & -26.40 & -24 & -60 & -28 \\
Cuneus (R) & BA 19 & 272 & 14.38 & -94.51 & 22.72 & 12 & -94 & 22 \\
Middle Occipital Gyrus (R) & BA 37 & 264 & 51.22 & -69.66 & 3.45 & 52 & -70 & 4 \\
Post Central Gyrus (R) & BA 40 & 248 & 40.00 & -26.82 & 45.58 & 40 & -28 & 44 \\
\hline
\end{tabular}




\section{CHAPTER 3: ESSAY 2 - Trust Recovery in the Buyer-Seller Relationship}

I think trust is the key aspect, the buyer believes not only in the products and services that are being sold, but at the end of the day they believe in the company. They trust the company, but ultimately, they trust you... if that is not there, then I don't think you're going to get a second look...if they don't trust you to know that you're thinking about their best interest and what's best for them the sale will never be made.

-Services Salesperson (25 years experience)

I think that [trust] is vital. I don't want to work with a salesperson if I don't have at least a base level of trust with them. If I thought that any of the salespeople were untrustworthy, I didn't want to deal with them.

-Buyer (9 years experience)

As these quotes reflect, in buyer-seller dyads, interpersonal trust drives loyalty and financial outcomes (Baumann and Le Meunier-FitzHugh 2014; Palmatier et al. 2006). Trust is vital, but also "is fragile because it takes time to build up [trust] and no time to destroy" it (Lewicki and Bunker, 1995, p. 161). One aspect of importance is what happens when salespeople violate buyer trust. Given the importance of trust and its fragile nature, it is surprising that more research doesn't exist which focuses on the nature of breaches of trust by salespeople and on salesperson trust repair strategies. I use the term breach of trust to indicate any violation (i.e., intentional issue) of trust or error (i.e., mistake, unintentional issue) which damages a buyer's trust in the salesperson, and a trust repair strategy is any effort performed by the salesperson to recover trust after a breach of trust.

In recent years, a small but growing amount of scientific interest has begun to develop on breaches of trust and the implementation of trust repair strategies (e.g., Ferrin et al. 2007; Kim et al. 2006; Kim et al. 2004; Nakayachi \& Watabe 2005; Schweitzer, Hershey, \& Bradlow 2006). I seek to increase that interest through systematically building theory on the breach of trust and the 
trust repair process. Given the importance of the breach of trust construct, it would be expected that it is well defined. Contrarily, the literature does not well define the breach of trust construct, but instead likens it to other more commonly used constructs like trust violations (i.e., intentional damage to trust) or adjacent constructs such as contract breaches (e.g., Atkinson 2007; Schilke et al. 2013; Schweitzer, Hershey, and Bradlow 2006). The first objective of this research is to better conceptualize and define this key construct.

The literature is also unclear in regard to determining the optimal trust repair strategies in buyer-seller relationships. The predominate view that has been tested in the literature is that when repairing trust in interpersonal relationships, verbal repair strategies (i.e., spoken repair attempts) should be used to change perceptions around the cause of the breach of trust. The most commonly studied verbal repair attempts are social accounts (e.g., apology, excuse, denial), though other verbal strategies such as taking ownership of an issue may also be important. Tomlinson and Mayer (2009) have called for additional research that advances theory on trust recovery by looking at how verbal and behavioral repair strategies work in conjunction. I answer this call by examining how behavioral repair strategies (i.e., actions) compliment verbal repair strategies in practice. Therefore, the second objective of this research is to build on the existing viewpoint in the literature on trust repair with the proposed viewpoint provided by insights from sales professionals and buyers.

Evidence suggests that trust is strongly affected by key events that change the trajectory (i.e., magnitude and direction) of trust over the course of a relationship. I propose that a breach of trust is one such key event that will negatively influence trust trajectory, while trust repairs allow salespeople the opportunity to correct the course of a relationship after a breach of trust. 
Accordingly, the third objective of this research is to develop a process model that provides insight as to how breaches of trust and trust repair strategies affect trust over time.

Given the early stage of research on this topic, I used a grounded theory approach to study these three objectives (Glaser and Strauss 2009). Following this approach I use interviews from salespeople, sales executives, and professional buyers along with an analysis of the popular business press (i.e., discourse analysis) and academic research to extend and verify existing theory. My research contributes to theory in three ways. First, I begin to resolve the inconsistencies around the conceptualization of the breach of trust construct, supporting the case that rather than being analogous with other constructs (e.g., trust violations, contract breaches), breach of trust is a broader construct [including violations or errors that will damage trust]. This is consistent with theory in the error management literature that makes the case violations and errors are distinct constructs (Frese and Keith 2015).

Second, it provides a more complete explanation of how behavioral repair strategies (i.e., actions, including solving the problem, financial compensation, etc.), can be coupled with verbal repair strategies (e.g., apologies, justifications) to repair trust. Previous scholarly research has focused primarily on identifying the correct verbal repair strategies with little or no consideration of accompanying behavioral repair strategies (e.g., Kim, Dirks, Cooper, Ferrin 2006; Lewicki and Wiethoff 2000; Tomlinson, Dineen, and Lewicki 2004; Tomlinson and Mayer 2009). It is important to consider both verbal and behavioral repair strategies because evidence from managerial practice suggests the importance of both in combination for restoring trust. The service repair literature would tend to support this view, which indicates that service failures are best repaired with a combination of both words and actions (Hess, Ganesan, and Klein 2003). Third, I develop a process model which depicts how a breach of trust and a trust repair attempt 
can affect trust over time. This extends research on trust trajectories (e.g., Palmatier et al. 2013). This research is also managerially relevant in outlining explicit strategies for how a salesperson can adapt trust repair strategies to both the situation and the characteristics of the buyer.

\section{METHODS}

Because of the limited research in this area and because theory building was the primary objective of this study, I utilize a grounded theory approach in developing the theoretical models described in this study (Strauss and Corbin 1998). I conducted interviews with business-tobusiness salespeople, sales executives, and professional buyers. I triangulate these interview data with the academic literature on breach of trust and trust repair, and a discourse analysis of the popular business press. Figure 1 provides an overview of the triangulation process used in this paper. Triangulation uses multiple methods to come to an understanding of a phenomenon by converging on congruent findings and uncovering discrepancies (Jick 1979).

$$
<<<<<\text { Insert Figure } 1 \text { Here }>>>>>
$$

\section{Academic Literature Review}

A review of the academic literature in marketing uncovered a dearth of research on breach of trust and on the trust repair process. Though the organizational behavior and psychology literatures have given the topic meaningful consideration, this work has primarily focused on using verbal repair strategies to recover from a breach of trust. While this research provides insights into the breach of trust and repair processes, it offers little theoretical guidance on how and why behavioral repair strategies should be coupled with verbal repair strategies. This is important because behavioral strategies have been shown to be key to repairing relationships in other settings, such as the service provider-customer relationship (e.g., Hess et al. 2003). Additionally, Gillespie and Dietz (2009) make the case that behavioral repair strategies are an 
understudied, but important, component to the trust repair process, and that most studies have a limited focus on trust repairs to a single response when multiple complimentary steps are necessary. I answer this call by using interviews to uncover the steps in an often complex trust repair process. This allowed for a three-step strategy that uses both verbal and behavioral components to be revealed.

\section{In-depth Interviews}

In-depth interviews were conducted with nineteen professional salespeople, four sales executives, and seven professional buyers. This research is exploratory in nature with the aim of theory development. Following Kohli and Jaworski’s (1990) recommendation, I used an interview sampling frame using individuals with varied backgrounds. As such, a theoretical sampling plan was used to produce a diverse group of informants with different perspectives and experiences (Bendapudi and Leone 2003; Kohli and Jaworski 1990; Tuli Kohli, and Bharadwaj 2007; Weiss 1994). I ensured that informants came from both industrial and services industries. Individuals were interviewed from firms that specialize in a variety of areas such as technology, industrial automation, professional sports, procurement services, the rental car business, marketing research, health insurance, component manufacturing, and agricultural products, among others. Informants had a diverse educational backgrounds that ranged from high school diplomas to graduate degrees. Sales professionals were included with varying levels of experience ranging from 2-40 years. Informants were recruited through a university sales center, an industrial sales center, and social networking.

As is the case with in-depth interviews, question ordering was fluid in nature depending on the responses of the informants. After a brief discussion about the sales practitioners experience and general thoughts about trust, nine questions around breach of trust and trust 
repair were (typically) explored. These questions were based on a desire to understand and advance theory around breaches of trust and trust repair while also verifying existing theory within the context of creating an overarching framework on this process. Prior to finalizing the questions, two researchers that were independent of the project were asked to evaluate the questions and provide suggestions. One researcher possessed subject matter expertise while the other possessed methodological expertise. The following questions were the product of that process.

1. What does the term breach of trust mean to you?

2. What are different ways that a salesperson could breach a buyer's trust? Can you give me some examples of this?

3. Are there different levels of breach of trust?

4. Do you think buyers are concerned with matters such as: Who was at fault? Will it happen again? Could the salesperson have controlled the mistake?

5. Can a salesperson gain a buyer's trust back after it has been breached? How would the salesperson go about doing that?

6. Does the type of trust repair depend on the grievance?

7. Does your previous relationship with the buyer effect how he/she will react when trust is breached?

8. Are words or actions more effective in restoring a buyer's trust?

9. Is it a good idea to try to repair trust through generous actions such as taking a buyer out for drinks or to a ballgame or through price/service concessions?

To better facilitate open and non-defensive dialogue, questions of "how" were asked instead of "why" (Becker 1998; Weiss 1994). While the above questions provided the basic framework for the interview, it was often necessary to probe for additional examples or clarify thought processes. When necessary, additional questions were asked based on the flow of the conversation; this is consistent with Weiss' (1994) recommendation that interviews should be driven by the informants' train of thought and not rigid interview guides.

The interviews lasted just over 45 minutes on average and were audiotaped for the purpose of more accurate documentation. Analysis involved an open coding process that identified categories followed by axial coding in which relationships between the categories were 
uncovered (Strauss and Corbin 1998). Similar to procedures described in Ulaga and Reinartz (2011) and Challagalla, Murtha, and Jaworkski (2014), I used an expert judge to evaluate a portion of the transcripts for accuracy and reliability. The judge reviewed $20 \%$ of the total interviews. The participants showed support for the proposed framework. I took the generalized respondent approach to reporting where quotations and inferences are meant to represent the prevailing views of the informants (Weiss 1994). Since there was a large degree of convergence among the salesperson, sales executive, and buyer interviews, the term interview will refer to the majority view of all three groups. In cases where there were divergent views among or within the groups that will be noted. While numerous insights materialized as the result of the study, the most interesting and relevant topics are discussed in this manuscript.

\section{Discourse Analysis}

Discourse analysis is used to give an account of the general dialogue about a subject, or in other words, to describe what people are reading or saying about a particular topic. I used discourse analysis to describe the message presented by the popular business press to salespeople by examining two popular information vehicles (i.e., Wall Street Journal (WSJ) and the works of two bestselling business authors cited below). Exploring these texts helped synthesize the advice that is widely available to sales practitioners. A discourse can be defined as a socially constructed truth, so to analyze a particular discourse it is important to understand why it exists along with the actual message (Waller 2006). This is because both salespeople and buyers could be influenced by guidance on how to react when trust is breached by this practitioner literature. The general messages of this dialogue is clear; breach of a buyer's trust is common and a salesperson should try to earn that trust back with a combination of words and actions. 
A natural starting point for understanding this dialogue was to examine the WSJ which is the most widely read newspaper and business publication in the United States with an average readership well over 2 million (Statista magazine and newspaper circulation statistics). Articles on salesperson trust from the last thirty years were examined using a key word search. In addition, the works of bestselling business authors Ken Blanchard and Stephen Covey were included in the analysis. These books (i.e.,, Trust Works! Four Keys to Building Lasting Relationships, The SPEED of Trust: The One Thing That Changes Everything) provide practical guidance on the trust repair process. These books were included because they were mentioned in some of the executive interviews as being influential in how trust repair should be viewed, and for that reason are key to triangulating those executives’ approach. Taken together these newspaper articles and books help frame the business dialogue on trust because of their vast readership. In subsequent sections, I attempt to accomplish the primary function of this method, which is to accurately convey the communication around the subject and compare it with existing theory (Fairclough 2013).

In the following sections, I first define the breach of trust construct. Next, I demonstrate how the trust repair steps uncovered by the interviews, builds on the existing trust recovery literature. Third, I develop a conceptual model and propositions about how both verbal strategies and behavioral strategies impact trust recovery. I conclude with a discussion about how this research advances theory along with the strategic direction for sales practitioners.

\section{BREACH OF TRUST CONCEPTUALIZATION AND DEFINITION}

The term breach of trust is not well defined in the literature, but instead is typically described with synonyms and examples. These descriptions are sometimes inconsistent with breach of trust being likened to a violation of trust (Schilke et al. 2013; Schweitzer, Hershey, and 
Bradlow 2006) or damaged trust (Lount et al. 2008), or presented as analogous to a contract breach (Atkinson 2007). Trust violation is more commonly used in the literature than breach of trust when describing instances in which trust is damaged. An examination of the error management literature demonstrates the problem with using the term trust violation for any type of trust damaging actions. Violations are intentional deviations from a standard while errors are unintentional deviations (Frese and Keith 2015). This indicates that a construct is necessary, which more precisely accounts for intentional and unintentional actions that damage trust. I propose that breach of trust is that construct.

I developed a formalized definition that clearly conceptualizes a breach of trust by interpreting the interviews within the context of the existing literature. In this attempt to provide a better definition, I began with a definition of trust, which has been thoroughly examined in the marketing literature. Trust can be defined as confidence in an exchange partner's credibility and benevolence (Doney and Cannon 1997, p. 36; Ganesan 1994; Kumar, Scheer, and Steenkamp 1995). For example, in the buyer-seller relationship, if the buyer makes a purchase from a salesperson, that buyer is showing confidence in the salesperson by accepting the risk associated with that purchase (e.g., criticism from peers and management; failure). Trust is given by buyers based on an assessment of the credibility and benevolence of the salesperson. "Credibility of an exchange partner, is an expectancy that the partner's word or written statement can be relied on. Benevolence is the extent to which one partner is genuinely interested in the other partner's welfare and motivated to seek joint gain” (Doney and Cannon 1997, p. 36).

The interviews with sales professionals and buyers helped illuminate what makes up a breach of trust. Consistently mentioned in their breach of trust examples were indications that 
confidence had been lost in the salesperson. This loss of confidence deeply impacted the relationship.

It's the fact that I have taken advantage of them or that I deceived them and that I didn't act in their best interest and it really can shake the foundation of the relationship. -Services Salesperson (25 years experience)

You could say I've had a trust breach if a client has expected you to deliver on certain set of expectations based upon the relationship that you have built with them and they did not deliver.

-Sales Executive (22 years experience)

Some of these breaches of trust were intentional while others are not.

Looking at it, you could have done something that was accidental...or it could be where they want the business, and they tell them what they want to hear, but they're really aren't going to have the intention to do what they said they would do.

-Services Salesperson (15 years experience)

Common examples of these breaches of trust included sharing confidential information, over promising, not accurately understanding the buyer's needs, lying, providing late deliverables, and pushing products, which are not beneficial to the buyer. Taken in conjunction with the literature, I define breach of trust as the buyer's perception that a violation or error has occurred that reduces the buyer's confidence in the salesperson.

\section{TRUST RECOVERY}

There are three assumptions that are core to any trust recovery research: (1) trustees desire to be considered trustworthy; (2) trustors are less inclined to believe that the trustee is trustworthy; and (3) both parties have to be willing resolve these divergent beliefs (Kim et al. 2009). A growing body of research contends that the best way to resolve these divergent beliefs is to utilize verbal repair strategies, which attempt to change how buyers perceive the cause of the trust violation (e.g.; Dirks et al. 2009, Tomlinson and Mayer 2009). While the grounded theory that developed from my interviews and discourse analysis agree with the core 
assumptions in the academic literature, it explicates the importance of behavioral repair strategies. My proposed view expanded on the existing view in demonstrating that behavioral repair strategies are the natural complement to verbal repair strategies. In the following explanation, I detail how trust repair is better conceptualized as a four-step process focused on verbal strategies and behavioral strategies.

\section{Existing View}

The academic literature suggests that using a verbal repair strategy (e.g., apologies, denials, excuses) to change a buyer's attributions about a breach of trust is the optimal way to repair trust (e.g., Kim et al. 2004; Kim et al. 2006). An attribution is a buyer’s attempt to understand the cause of a particular event (Tomlinson and Mayer, 2009). Broadly speaking, attribution theory involves an individual's attempt to understand the cause of an event (Dixon, Spiro, and Jamil 2001). This more commonly follows a failure than a success (Folkes 1988; Weiner 2000). When making an attribution, individuals attempt to determine the specific cause of the failure through evaluating the dimensions of causality (Teas and McElroy 1986).

The three independent dimensions of causality are locus of causality, controllability, and stability (Fang, Evans, and Landry 2005; Johnson and Kim 1994; Sujan 1986; Weiner 1986). Locus of causality is a determination of whether a cause is internal or external to the individual. Controllability is how much the individual can regulate a situation. Finally, stability is whether or not the event is expected to be an anomaly or occur again. Kim et al., (2009) suggests that the priority in implementing trust repair strategies is to convince the injured party that the locus of causality is external or uncontrollable to the transgressor. If that is not possible, only then should the transgressor admit culpability and attempt to convince the injured party that the breach of trust will not reoccur. 
If this theory was applied to a buyer-seller context, it would suggest that the salesperson should use the verbal repair strategy that will influence a buyer's attributions in a way that is least damaging for salesperson trust. For example, if a product did not meet the quality standards promised by the salesperson, then the salesperson should make an excuse as to why that occurred (i.e., the breach is attributed to causes outside of the salespersons control). An apology that expresses contrition for the mistake and a desire for that mistake not to reoccur would only be employed if a denial or excuse could not be effectively executed by the salesperson. The rationale for this is that if the buyer believes that the salesperson is not at fault or could not have controlled the event, it will be less damaging to trust than if the salesperson admitted the mistake and expressed contrition. Table 1 provides a summary explanation for how verbal repair strategies can be used to change attributions after a breach of trust.

$<<<<<$ Insert Table 1 Here $>>>>>$

\section{Proposed View of Trust Repair}

Contrary to the dominant view in the literature, the interviews indicate that salespeople use verbal repair strategies that accept responsibility for a breach of trust in conjunction with behavioral repair strategies. Verbal responsibilities are used to accept responsibility for the breach of trust and to create an action plan to make sure the breach of trust does not reoccur. This is followed by actions that provide evidence that the verbal repair strategies are genuine and that the salespeople wants to "make things right with the buyer."

You apologize and you move on and you put a corrective course of action in place. -Sales Executive (21 years of experience)

Actions are more important, but the words have to align with the actions themselves. -Services Salesperson (4 years of experience) 
I propose a three-step process that represents the optimal trust repair strategy based on the results of my analysis. While this three-step process is a method for optimizing the trust repair process, all of these steps are not always followed in practice. For example, a salesperson might take action first before constructing a plan with the buyer or a salesperson might use any number of verbal repair strategies without ever taking action. While this section explains a three-step optimized trust repair strategy, the next section will look at the impact of each of these steps separately on trust recovery. The steps that were mentioned by the majority of salespeople include (1) providing a social account (2) agreeing to action, and (3) taking action. In the following discussion, I further discuss these three-steps in greater detail.

$<<<<<$ Insert Figure 2 Here $>>>>>$

\section{Providing a Social Account}

A social account is a type of reparative effort after a negative occurrence for the purpose of mending social issues (Cody and McLaughlin, 1990). Social accounts can be used to influence another individual's perception of a negative event (Bies, 1987). This is accomplished by providing information about responsibility and motives for the negative event (Sitkin and Bies 1993). Some accounts attempt to shift responsibility for the negative event by denying blame for the negative event or through explaining that uncontrollable circumstance were the cause of the negative event. Other accounts accept responsibility for negative event in a manner that expresses contrition or that the negative occurrence was not intended. The goal of social accounts is to mitigate the negative reaction of the injured party (Frey and Cobb 2010). When used after a breach of trust, the goal is increase the level of trust perceived by the injured party.

In trust recovery research, the typically examined social accounts are apologies, excuses, denials, and justifications (Kim et al., 2009; Tomlinson and Mayer 2009). Using social accounts 
to influence the attributions of the injured party has been shown to be a successful strategy in the organizational behavior literature (e.g., Kim et al. 2004; Kim et al. 2006). The interviews suggested that this may not be as effective in buyer-seller relationships.

The interviews overwhelmingly supported social accounts that accept responsibility for a breach of trust, such as apologies and justification. Specifically, the majority of the interviews suggested that apologies are often the best verbal repair strategies because this strategy shows remorse for what has been done. Contrarily, the interviews contended that shifting responsibility is typically ineffective in buyer-seller relationships because as the face of the organization, there is little benefit in making excuses for mistakes that were made by other members of the salesperson’s organization. For example, if the salesperson’s manufacturing team makes a mistake that breaches a buyer's trust, there is no value in blaming that part of the organization. Regardless of whether the issue was with the salesperson or the selling firm, it is generally suggested that the salesperson be willing to accept responsibility.

To me there is nothing more frustrating than someone making excuses and pointing the finger. That goes back to what I said before about being a problem solver. If someone proactively calls me and tells me the situation and offers ways to remedy it. That is someone who has my best interest in mind.

- Industrial Salesperson (19 years of experience)

You have to be totally honest. Don't make excuses, own up to it. Let them know that it won't happen again, and then don't let it happen again.

- Industrial Salesperson (20 years of experience)

With people, you apologize, you fall on your sword, and say, hey, we screwed up and we're going to make this right

-Sales Executive (21 years experience)

\section{Agreeing to Action}

Most of the interviewees mentioned agreeing to action as an integral part of the trust repair process. This is a verbal agreement between the buyer and the salesperson on the actions 
necessary to repair trust. Often, the salesperson listens to the buyer's assessment of what went wrong, and proposes a solution. The salesperson then should check in with the buyer to make sure that the plan is acceptable. Agreeing to action can include proposed behavior changes that will help correct the current breach of trust and proposed behavior changes that will prevent the reoccurrence of that breach of trust in the future. For example, if a salesperson failed to deliver a product on time that might demonstrate a lack of ability to the buyer. If caught soon enough, the salesperson can ask the buyer if having the order overnighted will help solve the current breach of trust. The salesperson might also suggest ways in which the logistics process can be improved to prevent that breach of trust in the future, and then check with the buyer to determine if that is an acceptable plan of action.

You get an action plan in place. You say, here is what I'm going to do and I'm going to check back in with you in two days on this or whatever it is. Or, if we need to call some people, make some outreach, do whatever, whatever the impact is...You apologize and you move on and you put a corrective course of action in place.

- Sales Executive (21 years of experience)

\section{Taking Action}

The interviews and discourse analysis state that an action plan is meaningless if it is not well executed. Resolving the trust breach by following through on an action plan that was agreed upon by both the buyer and salesperson can be helpful in mitigating the damage done by this breach of trust. Implementing an action plan that prevents a reoccurrence of a breach of trust is helpful in building back trust by demonstrating to the buyer that the salesperson is still reliable, and showing the buyer that the breach of trust is unlikely to happen again. This is consistent with equity theory that if negative actions can be balanced with positive actions, then the relationship can be restored.

That's where the communication and action plan come in to play, as far as, okay this is what happened, I deeply apologize for this and here is what we put in place as a result of 
that and it will never happen again....then, if you're not going to follow up with it from an action perspective and what you're going to do on an ongoing basis then that trust will not be repaired at all.

- Services Salesperson (25 years of experience)

\section{FACTORS AFFECTING TRUST RECOVERY EFFECTIVENESS}

The interviews suggest that the three components in an optimal trust repair strategy are (1) providing a social account, (2) agreeing to action, and (3) taking action. These components all have a role in trust recovery that is obtained by the salesperson. The first two components are verbal repair strategies with the last component being a behavioral repair strategy. Trust recovery is the difference between post-breach trust and post-repair trust levels in the salesperson. In other words, this measures the difference between the buyer's trust level of the salesperson immediately after the breach and after the trust repair attempt is completed. In the following section, propositions are developed which link the three components of trust repair with trust recovery. The definitions for the verbal and behavioral repair strategies that are discussed in this section are found in Table 2.

$<<<<<$ Insert Figure 3 and Table 2 Here $>>>>>$

\section{Verbal Repair Strategies}

Though the literature has shown that in some instances it is better not to take responsibility for a breach of trust, but instead shift the blame to another source (e.g., Kim et al. 2004; Kim et al. 2006), the interviews take a contrasting view. While it is tempting shift blame elsewhere, even if lying to do so, the salespeople interviewed in this study were adamant that accepting responsibility for a breach of trust was the appropriate course of action. Paramount to this approach is providing an honest account of the salesperson role in what happened. This signals that the salesperson has integrity and wants to "do the right thing." This corresponds with earlier trust recovery research, which suggests that when an individual damages trust that the 
violator should assume at least some responsibility for his/her actions (e.g. Lewicki and Bunker 1995).

A good salesperson understands how to have some really tough discussions and be upfront and honest. You never just want to cover things up and pretend it didn't happen. - Sales Executive (21 years of experience).

\section{The Relationship between Social Account Strategies and Trust Recovery}

The interviews overwhelmingly suggest that the salespeople should apologize when the salesperson is at least partially to blame for the breach of trust. This agrees with research indicating that apologies are the most effective way to resolve interpersonal disputes because it shows the individual feels guilty and acknowledges that he/she will not repeat the action (e.g., Takaku, 2001; Hodgins et al., 1996; Ohbuchi et al., 1989). This strategy indicates to the buyer that the breach of trust is unlikely to reoccur.

Try to apologize, that is one of the best ways to fix the damage that has been done -Industrial Salesperson

P1: Apologies have a positive relationship with trust recovery.

Justifications are a strategy where instead of trying to lessen the salesperson's perceived accountability or involvement, the salesperson "accepts responsibility while attempting to reframe their behavior as in accordance with some type of superordinate goal or value, or by providing a more positive interpretation of the negative outcome” (Tomlinson and Mayer, 2009, p. 99). While not mentioned as frequently as apologies, justifications were described as an effective strategy in the interviews. This is because it allowed the salesperson to accept responsibility while also communicating that there was no negative intent behind the salesperson's actions. 
Excuses and justification are two different things. Trying to explain or justify why something took place certainly has value, excuses are just bad and you are just trying to cover up something you knowingly did wrong.

-Services Salesperson (25 years of experience)

P2: Justifications have a positive relationship with trust recovery.

It can be uncomfortable to accept responsibility for a breach of trust, which often makes individuals reluctant to do so. Denials provide an option where blame can be shifted to another source. If the denial is accepted, it has been shown to be effective in trust recovery (e.g., Kim et al., 2004). The interviews consistently suggest that salespeople should not try to shift responsibility away from themselves. The contention behind this is that if the buyer's trust is breached the salesperson and/or selling firm typically bear at least partial responsibility, and that should be acknowledged by the salesperson.

You have to take responsibility for the [breach of trust], being the face of the organization you are the one who is going to take the heat locally for any decision made. Taking accountability for that has helped me in several instances.

-Services Salesperson (25 years of experience)

P3: Denials have a negative relationship with trust recovery.

Excuses "ask not to be held accountable, claiming that mitigating circumstances attenuate his or her culpability” (Tomlinson and Mayer 2009). The goal of an excuse is to convince the buyer that the breach of trust was outside of the salesperson's control. The interviews took a very negative viewpoint towards excuses because salespeople, as the face of the firm, should not try to shift blame to another source. Excuses were viewed in the interviews as a mechanism that unethical salespeople use to not take accountability for a mistake.

You have to be totally honest because you could lose a lot of business all together. You can't make excuses. I guess that is the main point. Just own up and say you made a mistake and don't let it happen again. -Industrial Salesperson (20 years of experience)

P4: Excuses have a negative relationship with trust recovery. 


\section{The Relationship between Agreeing to Action and Trust Recovery}

Agreeing to action occurs when a buyer and a seller develop a plan for resolving a breach of trust. The interviews indicate that agreeing to action with a buyer signals that the salesperson is seeking a just resolution and is worthy of trust. Justice can be described as individual perceptions of what is fair or right (Colquitt et al. 2001). In the buyer-seller dyad, the buyer is the arbiter of justice. An individual will use the sources available to determine if he/she is being treated justly by another individual (Lind, Kray, and Thompson 2001). Justice has been shown to act as a signal when making a determination about whether to trust another individual (Colquitt and Rodell 2011). For that reason, it is expected that agreeing to action may indicate that salesperson is trying to be just and reduce the loss of trust that typically accompanies a breach of trust.

P5: Agreeing to action has a positive relationship with trust recovery.

\section{Behavioral Repair Strategies}

The interviews indicated that behavioral repair strategies are important to trust recovery. The behavioral repair strategies mentioned in the interviews include: fixing the problem, offering a price or service concession, and employing generous actions (e.g., getting a buyer out on the golf course or giving them tickets to a concert). Each of these strategies is discussed in more detail in the following section. Throughout the interviews, the need to "rebalance the scales" was mentioned as a useful mechanism for trust recovery. Fixing the problem and offering a price/service concessions focus on restoring balance professionally. Generous actions attempt to restore balance through bestowing personal reward on the salesperson. The behavioral strategies that focused on acting to restore the professional relationship were more successful in practice. 


\section{The Relationship between Resolving the Current Issue and Trust Recovery}

The interviews suggest that if the salesperson can resolve the issue which caused the breach of trust, he/she should do so. For example, if the salesperson had the wrong type of product delivered, the correct product should be delivered as soon as possible. In the interviews, salespeople described driving all night to get orders fixed for customers and calling manufacturing while still in the buyers building to take swift action to fix issues. This swift, corrective action does not allow an issue to fester and is helpful in repairing trust.

P6: Taking action to resolve the issue has a positive relationship with trust recovery. The Relationship between Generous Actions and Trust Recovery

There was some discrepancy in the interviews as to whether generous actions (e.g. taking the buyer out to a ballgame) are an appropriate trust repair strategy. Generous actions can be described as providing time and/or gifts to the buyer. Generous actions attempt to ingratiate the salesperson with the buyer through providing gifts of personal relevance to the buyer or through attempting to rebuild the relationship through shared time together. Some common examples of this in a buyer-seller relationship include golfing, paying for drinks, and purchasing concert tickets.

The majority of the interviews suggest that while generous actions can be helpful in trust development, it is not an effective trust repair strategy. This is because generous actions are considered either an ineffective or an unethical way to repair trust. As this strategy does not address the actual issue that led to a breach of trust, and is perceived by many as the equivalent of a "bribe.” Until the issue is resolved, generous actions are considered irrelevant and will not be accepted. 
If you take someone out to lunch or to an event together that is building the relationship...if something went wrong and you dropped the ball taking someone to a ballgame will not fix you dropping the ball. You have to address the issue and plan for how to make sure it doesn't happen again in the future.

- Services Salesperson (15 years of experience)

P7: Generous actions have a negative relationship with trust recovery.

\section{The Relationship between Price/Service Concessions and Trust Recovery}

There was also mixed support for price and service concessions. Price/Service concessions are similar in theory to hostage posting, which is "a self-sanctioning system in an uncertain situation” (Nakayachi and Watabe 2005, p. 2). This self-imposed sanction for making a mistake indicates to the buyer that the salesperson is unlikely to repeat that mistake because it is costly to do so. Some sales professionals were hesitant to use concessions because they believed that it could turn into an expectation where any minor issue is met with request for price reductions. Others were comfortable employing them in severely damaged relationships or when there was a direct cost to the buyer.

It is worth exploring reimbursement if we cost them money, but we want to make sure that we do not devalue the service by giving it away for free.

- Services Salesperson (10 years of experience)

While some of the interviews suggested that they were hesitant to employ a price or service concession because of the expectations that it set, none mentioned being concerned that such a concession would be detrimental to the trust recovery effort. In fact, the majority view was that it would likely help the relationship.

P8: Price/Service Concessions have a positive relationship with trust recovery.

\section{The Interaction between Verbal Repair Strategies and Behavioral Repair Strategies}

A common theme throughout the interviews is that words and actions work in conjunction to repair trust. For that reason, I contend that there will be an interaction between 
verbal repair strategies and behavioral repair strategies on trust recovery. In the following discussion, I provide examples of how apologies have a positive interaction with price/service concessions and how agreeing to action has a positive interaction with resolving the issue. These combinations are common in practice and illustrate the usefulness of combining verbal and behavioral repair strategies. This is designed to start the conversation on how verbal repair strategies and behavioral repair strategies work together to restore trust.

You can talk somebody down from the ledge after you've broken their trust...then if you're not going to follow up with it from an action perspective...then that trust will not be repaired at all.

- Services Salesperson (25 years of experience)

When repairing trust in the buyer-seller relationship, apologizing for a breach of trust provides evidence to the buyer that the salesperson has character through demonstrating a willingness to be honest even when there is cost to the salesperson (e.g., esteem, reputation). This can be enhanced with a behavioral strategy, which further demonstrates to the buyer that the salesperson wants to make the situation right through corrective action. Often this behavioral repair strategy is a price/service concession. For example, if a salesperson pushes a solution that is not in the buyer's best interest it can be perceived as a breach of trust. The salesperson can begin by apologizing. This is an acknowledgement by the salesperson of not making a proper recommendation and feeling contrition for that. This acknowledgement of fault not only humbles the salesperson, but also indicates an understanding of negative behavior and a desire to rebalance the relationship. This could be coupled with financial compensation that reimburses the buyer for the lost time and effort that was caused by the poor recommendation. This behavior repair strategy would enhance the effectiveness of apologizing because it tangibly reinforces the message that the salesperson wants to make things right with the buyer. 
Agreeing to action is an effective verbal repair strategy because it sends a positive signal to the buyer. This strategy will not be effective if the agreed upon action is not followed. This is consistent with the literature on post-sales service, which suggests that requesting buyer feedback and then not acting upon it can be extremely detrimental to the relationship (Challagalla, Venkatesh, and Kohli 2009). In fact, agreeing to action without executing it has a stronger negative impact than not agreeing to action in the first place. Agreeing to action and then following through on it does not only reduce the negative effect of the breach of trust; it also demonstrates reliability, which helps build trust even further. This suggests a positive interaction between agreeing to action and taking action to resolve the issue.

P9: There is an interactive relationship between verbal repair strategies and behavioral repair strategies on trust recovery.

\section{DISCUSSION}

Interpersonal trust has long been examined as a critical factor in the success of relationships between salespeople and buyers (e.g., Doney \& Cannon, 1997). However, as noted by Palmatier, et al. (2013), research has predominantly examined trust at a single period of time, rather than taking a dynamic view of trust. Yet, trust evolves over time and can ebb and flow (Dwyer, Schurr \& Oh, 1987). Of particular interest in sales is the process by which trust evaluations are updated after a breach of trust has occurred and what actions salespeople can undertake to repair trust. This research builds on the existing viewpoint in the literature on trust repair by incorporating insights from sales professionals and buyers to develop a model of the optimized trust repair process. This research also provides a more complete explanation of how behavioral repair strategies (e.g., solving the problem, financial compensation), can be coupled with verbal repair strategies (e.g., apologies and justifications) to recover trust. This advances previous scholarly research that has focused primarily on identifying verbal repair strategies with 
little or no consideration of accompanying behavioral repair strategies (e.g., Kim et al., 2006; Tomlinson, Dineen, and Lewicki, 2004; Tomlinson \& Mayer, 2009).

\section{Theoretical Implications}

I attempt to provide clarity around the trust repair literature by fully explicating the breach of trust construct and by providing a holistic model of the trust recovery process. This was accomplished through employing a grounded theory approach to trust recovery. Key to the model is an assertion that behavioral repair strategies are necessary to recovery from a breach of trust. This was largely absent from previous research on the process, which focuses primarily on verbal repair strategies and did not empirically examine the importance of combining verbal repair strategies with behavioral repair strategies. This research also provides new theory about an optimized three-step trust repair procedure.

\section{Managerial Implications}

In the early stages of a buyer-seller relationship, the salesperson must be even more vigilant in building and protecting buyer trust. The salesperson does not yet have the relational capital to withstand a breach of trust. When a breach of trust occurs, buyers may attempt to understand the cause of the breach of trust. This will affect the perceptions surrounding the severity of the breach. To optimize the trust recovery effort, the salesperson should employ a three-step process that consists of (1) providing a social account, (2) agreeing to action, and (3) taking action. These strategies are tried and tested by successful sales professional and were validated through speaking with professional buyers. The key to properly utilizing these strategies is utilize integrity. Salespeople should not use these strategies to further breach a buyers trust (e.g., lying as part of the repair attempt), but should use these strategies to salvage an otherwise fruitful relationship. 


\section{Future Research}

Interpersonal trust repair strategies are largely absent in the marketing literature. This study proposed a three-step process for repairing trust in the buyer-seller relationship. The effectiveness of this process can be further validated in the sales literature and tested in other contexts. I clarified the breach of trust construct and provided a definition, which could set the foundation for future measurement development. Additionally, the factors surrounding the breach of trust and trust repair process are integrated using a process model. The propositional framework is an attempt to build theory though a triangulated approach, which may be validated through future research.

Other potential research could examine how trust repair strategies could be matched to individual buyer characteristics to further enhance trust recovery. While not explicitly discussed in this paper, executive interviews indicated that understanding and adapting to buyer difference during trust repair attempts will impact the effectiveness of those attempts. Specifically, it was suggested that buyer learning orientations, thinking styles, and communication styles could be the key in adapting trust repair strategies. In addition, while outside of the scope of this paper, the interviews suggested that executive action (sanctioning the salesperson) is detrimental to salesperson trust recovery, but can positively impact firm trust recovery. Future research should examine trust recovery at multiple levels and determine the conditions under which executive action should be employed in the trust repair process. 


\section{REFERENCES}

Atkinson, Carol (2007), "Trust and the Psychological Contract," Employee Relations, 29 (3), 227-246.

Baumann, Jasmin, and Kenneth Le Meunier-FitzHugh (2014), "Trust as a Facilitator of CoCreation in Customer-Salesperson Interaction-An Imperative for the Realization of Episodic and Relational Value?," AMS review, 4 (1-2), 5-20.

Becker, Howard S (1998), "Tricks of the Trade," Chicago, IL: University of Chicago(1998). Pp (153-54)

Bendapudi, Neeli, and Robert P. Leone (2003), "Psychological Implications of Customer Participation in Co-Production," Journal of Marketing, 67 (1), 14-28.

Challagalla, Goutam, Brian R. Murtha, and Bernard Jaworski (2014), "Marketing Doctrine: a Principles-Based Approach to Guiding Marketing Decision Making in Firms," Journal of Marketing, 78 (4), 4-20.

-------, R. Venkatesh, and Ajay K. Kohli (2009), "Proactive Postsales Service: When and Why Does it Pay Off?," Journal of Marketing, 73 (2), 70-87.

Cody, Michael J., and Margaret L. McLaughlin (1990), "The Psychology of Tactical Communication." In The Chapters in This Book Are a Portion of the Papers Presented at the" Third International Conference on Social Psychology and Language," held in Bristol, England on Jul 20-24, 1987. Multilingual Matters.

Colquitt, Jason A., and Jessica B. Rodell (2011), "Justice, Trust, and Trustworthiness: A Longitudinal Analysis Integrating Three Theoretical Perspectives," Academy of Management Journal, 54 (6), 1183-1206.

Dirks, Kurt T., Roy J. Lewicki, and Akbar Zaheer (2009), "Reparing Relationships Within and Between Organizations: Building a Conceptual Foundation," Academy of Management Revie, 34 (1), 68-84.

Dimoka, Angelika (2010), "What Does The Brain Tell Us About Trust and Distrust? Evidence From a Functional Neuroimaging Study," Mis Quarterly, 373-396.

Fairclough, N. (2013). Critical discourse analysis: The critical study of language. Routledge.

Ferrin, Donald L., Peter H. Kim, Cecily D. Cooper, and Kurt T. Dirks (2007), "Silence Speaks Volumes: The Effectiveness of Reticence in Comparison to Apology and Denial For Responding to Integrity-and Competence-Based Trust Violations," Journal of Applied Psychology, 92 (4), 893. 
Frese, Michael, and Nina Keith (2015), "Action Errors, Error Management, and Learning in Organizations," Annual Review of Psychology, 66, 661-687.

Gillespie, Nicole, and Graham Dietz (2009), "Trust Repair After an Organization-Level Failure," Academy of Management Review, 34 (1), 127-145.

Gill, Harjinder, Kathleen Boies, Joan E. Finegan, and Jeffrey McNally (2005), "Antecedents of Trust: Establishing a Boundary Condition For the Relation Between Propensity to Trust and Intention to Trust," Journal of Business and Psychology, 19 (3), 287-302.

Glaser, Barney G., Anselm Leonard Strauss (2009), The discovery of grounded theory: Strategies for qualitative research, Transaction Publishers.

Hawes, Leonard C (1999), "The Dialogics of Conversation: Power, Control, Vulnerability," Communication Theory, 9 (3), 229-264.

Hess Jr, Ronald L., Shankar Ganesan, and Noreen M. Klein (2003), "Service Failure and Recovery: the Impact of Relationship Factors On Customer Satisfaction," Journal of the Academy of Marketing Science, 31 (2), 127-145.

Hodgins, Holley S., Elizabeth Liebeskind, and Warren Schwartz (1996), "Getting Out of Hot Water: Facework in Social Predicaments," Journal of Personality and Social Psychology, 71 (2), 300.

Jick, Todd D (1979), "Mixing Qualitative and Quantitative Methods: Triangulation in Action," Administrative Science Quarterly, 24 (4), 602-611.

Kim, Peter H., Kurt T. Dirks, and Cecily D. Cooper (2009), "The Repair of Trust: A Dynamic Bilateral Perspective and Multilevel Conceptualization," Academy of Management Review, 34 (3), 401-422.

-------, -------, -------, and Donald L. Ferrin (2006), "When More Blame is Better Than Less: The Implications of Internal vs. External Attributions For The Repair of Trust After a Competence-vs. Integrity-Based Trust Violation," Organizational Behavior and Human Decision Processes, 99 (1), 49-65.

-------, Donald L. Ferrin, Cecily D. Cooper, and Kurt T. Dirks (2004), "Removing The Shadow of Suspicion: The Effects of Apology Versus Denial for Repairing Competence-Versus Integrity-Based Trust Violations," Journal of Applied Psychology, 89 (1), 104.

Kohli, Ajay K., and Bernard J. Jaworski (1990), "Market Orientation: The Construct, Research Propositions, and Managerial Implications," The Journal of Marketing, 1-18.

Lewicki, Roy J., and Barbara B. Bunker (1995), Trust in relationships: A model of development and decline, Jossey-Bass. 
-------, Edward C. Tomlinson, and Nicole Gillespie (2006), "Models of Interpersonal Trust Development: Theoretical Approaches, Empirical Evidence, and Future Directions," Journal of Management, 32 (6), 991-1022.

------- and Carolyn Wiethoff (2000), "Trust, Trust Development, and Trust Repair," The Handbook of Conflict Resolution: Theory and Practice, 1, 86-107.

Lount Jr, Robert B., Chen-Bo Zhong, Niro Sivanathan, and J. Keith Murnighan (2008), "Getting Off on the Wrong Foot: The Timing of a Breach and The Restoration of Trust," Personality and Social Psychology Bulletin, 34 (2008), 1601-1612.

Mayer, Roger C., James H. Davis, and F. David Schoorman (1995), "An Integrative Model of Organizational Trust," Academy of Management Review, 20 (3), 709-734.

Morrison, Elizabeth Wolfe, and Sandra L. Robinson (1997), "When Employees Feel Betrayed: A Model of How Psychological Contract Violation Develops," Academy of Management Review, 22 (1), 226-256.

Nakayachi, Kazuya, and Motoki Watabe (2005), "Restoring Trustworthiness After Adverse Events: The Signaling Effects of Voluntary Hostage Posting on Trust," Organizational Behavior and Human Decision Processes, 97 (1), 1-17.

Ohbuchi, Ken-ichi, Masuyo Kameda, and Nariyuki Agarie (1989), "Apology as Aggression Control: Its Role in Mediating Appraisal of and Response to Harm," Journal of Personality and Social Psychology, 56 (2), 219.

Palmatier, Robert W., Rajiv P. Dant, Dhruv Grewal, and Kenneth R. Evans (2006), "Factors Influencing the Effectiveness of Relationship Marketing: a Meta-Analysis," Journal of Marketing, 70 (4), 136-153.

-------, Mark B. Houston, Rajiv P. Dant, and Dhruv Grewal (2013), "Relationship Velocity: Toward a Theory of Relationship Dynamics," Journal of Marketing, 77, 13-30.

Pritchard, Robert D (1969), "Equity Theory: A Review and Critique," Organizational Behavior and Human Performance, 4 (2), 176-211.

Rousseau, Denise M., Sim B. Sitkin, Ronald S. Burt, and Colin Camerer (1998), "Not So Different After All: A Cross-Discipline View of Trust," Academy of Management Review, 23 (3), 393-404.

Scheer, Lisa K (2012), "18 Trust, Distrust and Confidence in B2B Relationships," Handbook on Business to Business Marketing, 332.

Schilke, Oliver, Martin Reimann, and Karen S. Cook (2013), "Effect of Relationship Experience on Trust Recovery Following a Breach," Proceedings of the National Academy of Sciences, 110 (38), 15236-15241. 
Schweitzer, Maurice E., John C. Hershey, and Eric T. Bradlow (2006), "Promises and Lies:

Restoring Violated Trust," Organizational Behavior and Human Decision Processes, 101 (1), 1-19.

Singh, Jagdip, and Deepak Sirdeshmukh (2000), "Agency and Trust Mechanisms in Consumer Satisfaction and Loyalty Judgments," Journal of the Academy of marketing Science, 28 (1), 150-167.

Strauss, Anselm, and Juliet Corbin (1998), "Basics of Qualitative Research: Procedures and Techniques for Developing Grounded Theory."

Takaku, Seiji (2001), "The Effects of Apology and Perspective Taking on Interpersonal Forgiveness: A Dissonance-Attribution Model of Interpersonal Forgiveness," The Journal of Social Psychology, 141 (4), 494-508.

Tomlinson, Edward C., and Roger C. Mryer (2009), "The Role of Causal Attribution Dimensions in Trust Repair," Academy of Management Review, 34 (2009), 85-104.

-------, Brian R. Dineen, and Roy J. Lewicki (2004), "The Road to Reconciliation: Antecedents of Victim Willingness to Reconcile Following a Broken Promise," Journal of Management, 30 (2), 165-187.

Tuli, Kapil R., Ajay K. Kohli, and Sundar G. Bharadwaj (2007), "Rethinking Customer Solutions: From Product Bundles to Relational Processes," Journal of Marketing, 71 (3), $1-17$.

Ulaga, Wolfgang, and Werner J. Reinartz (2011), "Hybrid Offerings: How Manufacturing Firms Combine Goods and Services Successfully," Journal of Marketing, 75 (6), 5-23.

Waller, Lloyd G (2011), "Introducing Fairclough's Critical Discourse Analysis Methodology For Analyzing Caribbean Social Problems: Going Beyond Systems, Resources, Social Action, Social Practices and Forces of Structure or Lack Thereof as Units of Analysis."

Weiner, Bernard (1986), "An Attributional Theory of Achievement Motivation and Emotion," In An Attributional Theory of Motivation and Emotion, Springer US, 159-190.

Weiss, Robert S (1995), Learning from strangers: The art and method of qualitative interview studies. Simon and Schuster. 
Figure 1

Overview of the Triangulation Process

\section{9 interviews with salespeople}

Four interviews with sales vice presidents

Seven interviews with professional buyers 
Figure 2

Proposed View for Optimized Trust Repair Process in Buyer-Seller Relationships

\begin{tabular}{|c|c|c|}
\hline $\begin{array}{c}\text { Provide a } \\
\text { Social } \\
\text { Account }\end{array}$ & $\begin{array}{c}\text { Agree to } \\
\text { Action }\end{array}$ & Take Action \\
\hline
\end{tabular}


Figure 3

Trust Repair Model

\section{Verbal Repair Strategies}

$\mathrm{P}_{1}$ : Apologizing $(+)$

$\mathrm{P}_{2}$ : Justifications $(+)$

$\mathrm{P}_{3}$ : Denial (-)

$\mathrm{P}_{4}$ : Excuses (-)

$\mathrm{P}_{5}$ : Agreeing to action $(+)$

Behavior Repair Strategies

$\mathrm{P}_{6}$ : Resolving the Issue $(+)$

$\mathrm{P}_{7}$ : Generous Actions (-)

$\mathrm{P}_{8}$ : Price/Service Concessions

$(+)$ 
Tables 1: Attribution Theory Perspective of Social Accounts

\begin{tabular}{|c|c|c|c|c|}
\hline $\begin{array}{l}\text { Trust Repair } \\
\text { Strategy }\end{array}$ & How it is intended to work & $\begin{array}{l}\text { Nature of the } \\
\text { Repair } \\
\text { Strategy }\end{array}$ & $\begin{array}{l}\text { Core } \\
\text { Message }\end{array}$ & $\begin{array}{l}\text { Intended } \\
\text { Attribution } \\
\text { Change }\end{array}$ \\
\hline Denial & $\begin{array}{l}\text { Convince the injured party that } \\
\text { there was no wrong doing (the } \\
\text { transgressor is innocent) }\end{array}$ & Verbal & $\begin{array}{l}\text { Blame } \\
\text { Shifting }\end{array}$ & $\begin{array}{l}\text { Innocent } \\
\text { (external } \\
\text { causality) }\end{array}$ \\
\hline Excuse & $\begin{array}{l}\text { Convince the injured party that } \\
\text { the breach of trust could not have } \\
\text { been controlled by the } \\
\text { transgressor }\end{array}$ & Verbal & $\begin{array}{l}\text { Blame } \\
\text { Shifting }\end{array}$ & $\begin{array}{l}\text { Situational } \\
\text { (Uncontrollable) }\end{array}$ \\
\hline Justification & $\begin{array}{l}\text { Acknowledge to the injured party } \\
\text { that the transgressor is } \\
\text { responsible for the breach of trust, } \\
\text { but also indicate that the } \\
\text { transgressor had did not have } \\
\text { negative motives. }\end{array}$ & Verbal & $\begin{array}{l}\text { Blame } \\
\text { Accepting }\end{array}$ & $\begin{array}{l}\text { Situational } \\
\text { (Uncontrollable) }\end{array}$ \\
\hline Apology & $\begin{array}{l}\text { Assuming responsibility and } \\
\text { expressing remorse indicating } \\
\text { that a transgressor is more likely } \\
\text { to correct his or her shortcomings } \\
\text { in the future. }\end{array}$ & Verbal & $\begin{array}{l}\text { Blame } \\
\text { Accepting }\end{array}$ & $\begin{array}{l}\text { Unlikely to } \\
\text { reoccur } \\
\text { (unstable) }\end{array}$ \\
\hline
\end{tabular}


Table 2: Definitions of Salesperson Trust Repair Strategies

\begin{tabular}{|c|c|c|}
\hline $\begin{array}{l}\text { Trust Repair } \\
\text { Strategy }\end{array}$ & Definition & $\begin{array}{c}\text { Nature of the } \\
\text { Repair Strategy }\end{array}$ \\
\hline Denial & $\begin{array}{l}\text { "a statement whereby an allegation is explicitly declared to } \\
\text { be untrue (i.e., the statement acknowledges no } \\
\text { responsibility and hence no regret" (Kim et al., 2004) }\end{array}$ & Verbal \\
\hline Excuse & $\begin{array}{l}\text { "Asks not to be held accountable claiming that mitigating } \\
\text { circumstances attenuate his or her culpability.... [excuses] } \\
\text { communicate causes for the negative outcome were } \\
\text { uncontrollable" (Tomlinson and Mayer 2009) }\end{array}$ & Verbal \\
\hline Justification & $\begin{array}{l}\text { an explanation that attempts to convey that the intentions } \\
\text { behind an action were appropriate while attempting to shift } \\
\text { responsibility to a situational factor. (Kim et al., 2009) }\end{array}$ & Verbal \\
\hline Apology & $\begin{array}{l}\text { "conveys an admission of responsibility and regret on the } \\
\text { part of the offender for the violation and its concomitant } \\
\text { harm on the victim" (Tomlinson et al. 2004). }\end{array}$ & Verbal \\
\hline Resolving the Issue & Taking action to correct a mistake or solving a problem & Behavioral \\
\hline $\begin{array}{l}\text { Price/Service } \\
\text { Concessions }\end{array}$ & Providing a price discount or a free service & Behavioral \\
\hline Generous Actions & $\begin{array}{l}\text { Providing gifts and/or time to the buyer. Some examples of } \\
\text { this may include taking a buyer out to a ballgame, paying } \\
\text { for lunch, or performing an activity together (e.g., } \\
\text { racquetball). }\end{array}$ & Behavioral \\
\hline
\end{tabular}




\section{Chapter 4: Essay 3 - An Equity Theory Perspective on Trust Recovery}

Even the best salespeople can damage the buyer's trust. Specifically, it is estimated that $50 \%$ lie on sales calls, $34 \%$ make unrealistic promises, and $22 \%$ sell buyers unneeded products (Marchetti 1997; Strout 2002). This can produce outcomes that are perceived to be negative in the buyer's mind. Sales researchers therefore have a substantial stake in understanding the consequences of those negative outcomes on trust and how to implement successful trust repair strategies that recover trust and allow the exchange relationship to continue. In this chapter, I examine how a salesperson's choice of trust repair strategies can ameliorate a buyer's reaction to a negative outcome and positively affect trust recovery.

Implementing a suboptimal trust repair strategy can lead to a failure to recover trust which is detrimental to both the buyer and the salesperson. Damaged trust that goes unrepaired often manifests itself through the termination of a relationship or through the deterioration of a relationship in the form of neglect and opportunism (Anderson and Jap 2005). This can interfere with an otherwise successful collaboration that yields returns for both parties. When using appropriate trust repair strategies, salespeople can view damaged trust as an opportunity to engage in a substantive repair effort that may ultimately bolster the relationship and allow for the development of higher levels of trust.

The trust recovery literature to date has been primarily examined in intra-organizational settings and through the lens of attribution theories (Tomlinson, in-press). A variety of attribution theories have been used to explain trust recovery, including Heider's attribution theory (e.g., Dirks et al. 2011), correspondence inference theory (e.g., Basford, Offerman, and Behrend 2014), Kelley’s discounting principles (Kim et al. 2006), schematic model of dispositional attribution (Kim et al., 2004), and causal attribution theory (Tomlinson and Mayer 
2009). The common principle interwoven in this research is that verbal repair strategies (i.e., social accounts or words) are effective through changing perceptions about a negative outcome and the likelihood of its reoccurrence. From an attribution theories perspective, verbal repair strategies are often more effective than behavioral repair strategies (i.e., actions), because they can be used to shift responsibility for a negative outcome to another source or situation, which is more effective than accepting responsibility and "fixing" the issue that led to damaged trust (Kim et al., 2009). It is expected that this guidance will not extend to marketing exchange relationships as I theorize that accepting responsibility and "making things right” will be the optimal way to recover trust that has been damaged.

There is a dearth of trust recovery research in the marketing exchange literature, this dissertation chapter explores two critical research issues that are pertinent to both marketing researchers and practitioners. The lack of research in these areas is likely due to the difficulty of collecting trust recovery data in actual business-to-business exchange relationships. First, although there is some empirical evidence supporting claims from the attribution theories literature that trust can be recovered by shifting responsibility for the damaged trust to another source (e.g., Kim et al. 2004; Ferrin et al., 2007), this strategy may be less prudent in buyer-seller relationships. When a negative outcome occurs, the buyer is often able to make accurate attributions as to its cause. For example, when a new product underperforms, it is apparent to the buyer whether or not the salesperson overpromised during the sales presentation. In circumstances where the cause of the negative outcome is less evident, the buyer still expects the salesperson to act as the face of the organization, taking responsibility for any negative outcomes caused by the sales firm and perform actions of remediation. Second, while verbal repair strategies have been the focus of the trust recovery literature (Kim et al. 2004; Ferrin et al. 2007; 
Tomlinson and Mayer 2009), there is a divergent perspective in marketing practice that suggests, "actions speak louder than words." Clearly, there is a lack of theoretical explanation and strategic guidance for that perspective in the literature. This void in the literature is critical as salespeople remain deprived of clear strategic guidance on how they should respond when trust is damaged.

Therefore, the purpose of this research is to develop and empirically test a conceptual model that provides insights into the process of how salespeople can use trust repair strategies to recover trust after it has been damaged. In doing so, this research makes three key contributions to the literature. First, this study challenges the contention that trust recovery is primarily achieved through changing a buyer's attributions about the cause of the negative outcome, and instead proposes that increasing perceptions of fairness (i.e., equity) serves as the bridge between trust repair strategies and trust recovery. This view of trust recovery is based on the exchange principle that a buyer's rewards should be proportionate to his/her investments in the relationship. Thus, it is expected that demonstrating fairness through a salesperson's actions is a surer path to trust recovery than trying to persuade the buyer that the negative outcome should not be attributed to the salesperson. In demonstrating this, the study provides empirical evidence that fairness is an important missing mediator to the extant trust recovery models. Next, this research demonstrates the importance of salesperson action in trust recovery by identifying and testing the impact of four behavioral repair strategies. These behavioral strategies are developed from the four dimensions of equity and provide strategic guidance on the actions that salespeople should take when attempting to recover the trust of a buyer. As behavioral repair strategies tangibly affect equity while verbal repair strategies do not, this marks a clear change in perspective, which suggests in trust recovery, "actions do speak louder than words.” Finally, existing trust recovery research uses experiments and trust games to empirically examine the 
effectiveness of verbal and behavioral repair strategies. While this research has been foundational to our understanding of trust recovery this paper is the first to examine the effectiveness of trust repair strategies in actual business-to-business exchange relationships adding to the external validity of trust recovery theory. This is important because the effectiveness of repair strategies in the real world is somewhat different than what is found in lab based experiments (Tucker et al., 2016).

In developing this framework, this research first defines trust and negative outcomes, followed by a brief review of the trust recovery literature. Next, the theoretical framework for trust recovery examines verbal and behavioral repair strategies through the lens of equity theory. With these foundations in place, a conceptual model and hypotheses examine the interactive nature of verbal and behavioral repair strategies on trust recovery, as mediated by perceptions of fairness. Hayes' (2013) regression based conditional process analysis is utilized to test the moderated mediation model that is suggested in the hypotheses from a longitudinal experiment with 320 consumers and a critical incident technique study of 200 professional buyers. In the final section, the theoretical implications and strategic relevance is discussed.

\section{PRIOR THEORY AND RESEARCH}

\section{Trust}

The focus of this paper is on buyer's perceptions of trust in a salesperson and the strategies required for recovering these perceptions after being damaged by negative outcomes. Consistent with past research in marketing, I define trust as confidence in an exchange partner's credibility and benevolence (Doney and Cannon 1997, p. 36; Ganesan 1994; Kumar, Scheer, and Steenkamp 1995). Credibility refers to a positive expectation that an exchange partner's word can be relied upon, based on the integrity and competence of that exchange partner. 
Benevolence refers to caring about the best interest of an exchange partner with a desire to produce mutually beneficial solutions. Neurological research supports this conceptualization of trust suggesting that credibility is determined through a calculative process driven by whether the exchange is expected to be rewarding in the future with benevolence being determined through an emotional response to inferences about the exchange partner's intentions (Dimoka 2010). Trust is believed to develop through accumulated experience with an exchange partner (e.g., Doney and Cannon 1997; Lewicki and Bunker 1996). When this experience results in a negative outcome attributed to the other exchange partner there is often a reduction in trust (Tomlinson and Mayer 2009).

\section{Negative Outcomes}

Negative outcomes can be defined as the perception of disconfirming evidence about expectations or beliefs (Tomlinson and Mayer 2009). Buyers' expectations of salespeople have increased substantively, and when the salesperson or a member of the salesperson's firm does not meet those expectations, the salesperson is often implicated as being responsible (Koppitsch et al., 2013). In a buyer-seller exchange, there are a variety of ways that a salesperson may be perceived to be the cause of a negative outcome by the buyer. Common examples of behaviors that result in negative outcomes include: lying to the buyer; pushing products that are not in the buyer's best interest; overpromising either on a product or on a unrealistic delivery date; sharing a buyer's confidential information; missing a deadline; failing to accurately understand a buyer's needs; or sending an incorrect shipment. When there is a negative outcome, salespeople can implement repair strategies for the purpose of trust recovery. 


\section{Trust Recovery}

The empirical studies on trust recovery focus on the conditions under which trust can be damaged and the strategies used in the process of repairing trust. A repair strategy is a salesperson's attempt to regain trust after it has been damaged. These strategies can be verbal or behavioral. The intended result of these strategies is trust recovery. Trust recovery can be defined as the level of perceived reparation to trust after a negative outcome. Existing research has focused primarily on verbal repair strategies designed to influence perceptions about damaged trust (Dirks et al., 2011; Gillespie and Dietz 2009).

Early trust recovery research focused on the verbal repair strategy of accepting responsibility for negative outcomes (e.g., Lewicki and Bunker 1996; Tomlinson, Dineen, and Lewicki 2004). A responsibility-accepting strategy is a verbal response following a negative outcome by the transgressor in an attempt to regain trust with the injured party. It is defined as an admission of accountability for the negative outcome by the transgressor that includes an expression of remorse and a statement about having positive intentions towards the injured party (taking accountability, showing contrition, and providing information about motivations). Elements of this strategy can be found in common social accounts such as apologies (accountability and contrition) and justifications (accountability and information about motivations). The purpose of this strategy is for the transgressor to humble his/herself while showing esteem for the injured party in an attempt to reduce inequity in the relationship through creating a rewarding experience for the injured party. In the buyer-seller relationship, this strategy may be chosen to show respect to the buyer through accepting personal accountability and displaying remorse while also providing context for the buyer to understand the motivation behind the salesperson's actions. 
Contrarily, subsequent research has suggested that shifting responsibility for a negative outcome can often be an effective verbal repair strategy (Ferrin et al. 2007: Kim et al. 2004; Kim et al. 2006). A responsibility-shifting strategy is a verbal response following a negative outcome by the transgressor in an attempt to regain trust with the injured party. It is defined as the transgressor claiming that the negative outcome is due to an external cause (blaming someone or something else). This claim is predicated upon the contention that the transgressor is not the actual perpetrator or that the transgressor was unable to control the cause of the negative outcome. This strategy is often expressed in the form of a denial or an excuse. The purpose of this strategy is to convince the injured party that the transgressor did not actually act unfairly in an attempt to negate the injured party's perceptions of inequity. In the buyer-seller relationship, this strategy may be chosen to indicate that the salesperson is not to blame for the negative outcome. This contradiction in findings in the literature, on whether responsibility-accepting strategies or responsibility-shifting strategies are the optimal strategy in trust recovery, indicates that improved theory is needed.

Three primary behavioral repair strategies have emerged from the literature. One effective behavioral mechanism for trust recovery is sanctions, in the form of reduced outcomes, against the party that damaged trust (e.g., Nakayachi and Watabe 2005). A second behavioral trust repair strategy is to apply regulatory controls or guidelines for future inputs into the buyerseller exchange (e.g., Dirks et al., 2011). Recent scholarship has suggested that regulatory controls are the "most common and substantive [behavioral] strategy for repairing trust" (Yu, Yang, Jing 2017, p. 235). A third behavioral trust repair strategy is restoration of material outcomes. This strategy is effective when there is a significant financial component of the broken trust, and includes providing actual restitution to the exchange partner (e.g., Desmet, de Cremer, 
and van Dijk 2011; Haesevoets, Folmer, and Van Hiel 2015).

Although the existing literature provides valuable insights into the trust recovery process, there is not a strong framework for explaining the effectiveness of behavioral repair strategies in trust recovery. Without this framework, it is unknown whether the three behavioral repair strategies, as empirically tested, are sufficient for understanding trust recovery or if there are undiscovered behavioral strategies absent from the literature. Additionally, without a framework, it is difficult to integrate more established verbal repair strategies with behavioral repair strategies. To fill this gap, I propose the following theoretical framework to integrate the use of verbal and behavioral repair strategies in trust recovery. While either the injured party or the transgressor may initiate or suggest the use of verbal and behavioral strategies, this framework’s strategic focus on the transgressors role in trust recovery (e.g., the strategies a salesperson can implement to recover a buyer’s trust.).

\section{A THEORETICAL FRAMEWORK FOR TRUST RECOVERY}

Verbal repair strategies have been shown to be useful in producing trust recovery (e.g., Ferrin et al., 2007; Kim et al. 2004; Tomlinson et al. 2004). This is because verbal repair strategies provide an opportunity for the transgressor to give a social account of what occurred after a negative outcome, as social accounts can be understood as a persuasive communication designed to change the attitudes of the harmed party. Specifically, a social account can be defined as "a verbal strategy employed by a person to minimize the apparent severity of the predicament or to convince the audience that the wrongful act is not a fair representation of what the actor is like as a person” (Bies, 1987, p. 294). This is primarily a process of influencing the impressions of the harmed party where the transgressor provides an account of what occurred while the injured party attempts to interpret this information in the context of the other 
information that is available (Tucker et al. 2016). The acceptability of the verbal repair strategy is evaluated by the harmed party through comparing it to any counter arguments (Frey and Cobb 2010). There are four broad types of social accounts: (1) those that attempt to shift responsibility to another source (e.g., denial, excuse), (2) those that accept responsibility and provide an ideological reason for the action (e.g., justification), (3) those that provide a referential account to indicate that "you are better off than others," and (4) remorseful account that shows contrition (e.g., apology) (Bies 1987).

The primary verbal repair strategies that are studied in the trust recovery literature are apologies, denials, excuses, and justifications as the referential account is not expected to increase perceptions of trust after a negative outcome (e.g., Kim et al., 2009; Tomlinson et al., 2009). See Table 1 for definitions of verbal strategies most commonly employed in trust recovery research. A fundamental difference in these verbal repair strategies is that inherent to an apology or justification is accepting responsibility for a negative outcome while denials and excuses shift responsibility for a negative outcome. The existing literature on trust recovery, using attribution theories, largely prioritizes accounts that shift responsibility to another source after a negative outcome for the purpose of attempting to maintain an identity of character and integrity (e.g., Ferrin et al., 2007; Kim et al. 2006; Kim et al., 2009). The problem with this is that injured parties often do not accept accounts that shift responsibility for negative outcomes due perceptions that those accounts are inaccurate or dishonest (Tomlinson et al., 2004). Instead, the social accounting literature has emphasized using social accounts to increase fairness in the relationship (e.g., Cobb and Wooten 1998; Frey and Cobb 2010; Sitkin and Bies 1993). $<<<<<$ Insert Table 1 about here $>>>>>$ 
Unfortunately, an emphasis on managing perceptions of fairness can lead to a focus on being believed to be fair over actually being fair (Greenberg 1990; Hong 2016). This is based on the transgressor's desire to protect his or her social identity from being damaged (Bies 1987; Goffman 1971; Tetlock \& Manstead, 1985). Instead, effective verbal repair strategies are those that provide an explanation of untoward behavior and bridge the gap as to why the transgressor did not meet expectations, expressing a desire to return to "status quo ante" through meeting expectations in the future (Scott and Lyman 1968). This type of restoration often necessitates the use of behavioral repair strategies that tangibly restore fairness (i.e., equity) ${ }^{2}$ to a relationship. Fairness is a summary concept of the input/outcome comparisons found in equity theory where fairness is achieved when the inputs/outcomes of both parties are roughly proportional (Swan and Oliver 1991). Combining verbal and behavioral repair strategies can be useful for accurately managing perceptions of fairness through supporting contentions of fairness with actions that demonstrate that those contentions are true.

Equity theory can be used to explain the mental calculation that the injured party makes when evaluating the verbal and behavioral repair strategies, which ultimately leads to a decision about whether the transgressor is fair and if the transgressor should be trusted. In the following discussion, I explicate this process more fully in the context of buyer-seller relationships focusing on instances in which the salesperson is perceived to be the cause of a negative outcome for the buyer. This discussion begins with a brief explanation of equity theory from a buyer's perspective. Next, I discuss the process of recognizing and addressing perceived buyer inequity, which is the crux of this theory. Finally, I explain why restoring equity is vital to trust recovery.

\footnotetext{
${ }^{2}$ From an equity theory perspective, fairness is a function of the equality of buyer outcome and input combinations and salesperson input and output combinations (Oliver and Swan 1989). So, for the remainder of this research, the terms fairness and equity will be used interchangeably (e.g., Sheppard, Lewicki, and Minton 1992).
} 
In support of that premise, I examine how each of the three primary behavioral repair strategies examined in the literature function through impacting a unique dimension of equity and discuss a key missing behavioral repair strategy. I then explicate the typology that I developed categorizing verbal and behavioral strategies, while discussing how these verbal strategies are also useful in restoring equity.

\section{Understanding Equity}

Before specifically examining the role of equity in trust recovery, it is important to describe the central premises of this theory. Equity is established on a central exchange tenant, that an individual's rewards should be proportional to his/her investments in an exchange relationship (Oliver and Swan 1989). More specifically, “equity theory postulates that persons in social exchange relationships compare with each other the ratios of their inputs into the exchange to their outcomes from the exchange” (Huppertz, Arenson, and Evans 1978, p. 250; Adams 1963). These dimensions of equity (i.e., the inputs and outcomes of both parties) can be either tangible (e.g., money, effort, time) or psychological (e.g., esteem, power, caring) in nature (Lapidus and Pinkerton 1995). Equity perceptions may not be the same for both individuals, and may differ based on the eye of the beholder. In this research, equity is examined from the buyer's perspective as the focus of this manuscript is on the strategies salespersons use to influence a buyer's equity evaluation, making the buyer the arbiter of equity in this case. From a buyer's perspective, inequity exists when the perceived inputs and/or outcomes in an exchange relationship are inconsistent with the perceived inputs and/or outcomes of the salesperson. Perceptions of salesperson fairness should increase as perceptions of inequity decrease (Oliver and Swan 1989). 


\section{Addressing Inequity for the Purpose of Trust Recovery}

Buyer inequity must be addressed when either a salesperson experiences distress for exploiting the buyer or inequity reaches a threshold that is unacceptable to the buyer with the buyer demanding for equity to be restored. This may be the result of one large negative outcome or the cumulative effect of multiple smaller negative outcomes. Inherent to this concept of a threshold of inequity is a prediction that people develop different standards of comparison for evaluating outcomes within a relationship, with varying ranges of inequity being acceptable. When an event "exceeds a given threshold (zone of indifference)” for that individual, it prompts a reinterpretation of the relationship (Harmeling et al., 2015). For example, a salesperson could deliver a solution that did not quite fulfill the promised specifications, one buyer may deem that it is close enough and that the relationship with the salesperson is still an equitable one (has not reached threshold of inequity), while another buyer could deem that not delivering on a promise makes the relationship inequitable (reached the threshold of inequity). Another example is a salesperson being late to a meeting once and the buyer not thinking about that action as being inequitable. The second time the salesperson is late to a meeting the buyer might decide that the salesperson is not acting fairly by wasting the buyer's time, which exceeds the threshold of inequity.

A buyer's threshold of inequity will be dependent on the equity sensitivity of the individual buyer. The equity sensitivity of the buyer is both a trait variable and a function of environmental factors (e.g., previous relationship and dependence). Individuals with a higher equity sensitivity trait are those who tend to be less tolerant of receiving inequitable treatment from others in general (Huseman, Hatfield, and Miles 1987). Thus, buyers with a higher equity sensitivity trait will reach the threshold necessary for reacting to inequity more rapidly than 
buyers with a lower equity sensitivity trait. Additionally, buyers in long standing relationships tend to have a higher threshold for inequity because of experience suggesting that equity will be restored over time (Heide and Miner 1992). Finally, dependence will impact the threshold for responding to inequity as a more dependent exchange partner will accept a level of inequity in his or her own mind due to a lack of available substitutes (Griffith et al., 2017) while still feeling hostility towards the inequitable exchange partner (Scheer, Kumar, and Steenkamp 2003).

Regardless of when the buyer's threshold of inequity is reached, it may behoove the salesperson to attempt to restore equity to the relationship. Individuals tend to trust as a result of equitable treatment because it provides an indication about whether the relationship will be rewarding in the future (DeConinck 2010; Wat and Shaffer 2005). Equity can be used as a valuable heuristic as to whether a relationship with a given salesperson should continue (Lind 2001). This is because equity acts like an ongoing ledger for an exchange relationship that can be easily readily audited based upon what both parties put into the relationship and receive from it. It is a calculative assessment of where the relationship is currently. Trust is a prediction of how another individual will act in the future, which is not as easily assessed. Thus, restoring equity can be a useful mechanism for trust recovery in buyer-seller relationships.

\section{Equity Dimensions as Framework for Behavioral Repair Strategies}

Restoring buyer's equity is accomplished through influencing one of the four dimensions of equity: 1) increasing the buyer's outcomes; 2) reducing the buyer's inputs; 3) reducing the salesperson's outcomes; and 4) increasing the salesperson's inputs. Existing behavioral repair strategies affect a unique dimension of equity. Specifically, a restoration strategy improves buyer outcomes; a sanctions strategy reduces salesperson outcomes; and a regulatory controls strategy increases salesperson inputs. This suggests a fourth missing behavioral repair strategy -- one that 
works through decreasing buyer inputs, which I identify as future concessions. The four

behavioral repair strategies: restoration, future concessions, sanction, and regulatory controls are

more formally defined below in terms of working through a dimension of tangible equity.

A restoration strategy is a behavioral response following a negative outcome that is an attempt to regain trust with the injured party. It is defined as problem solving activities designed to offset the harm caused by the negative outcome (immediate action to resolve the problem) (Desmet, de (Cremer, and van Dijk 2011). The purpose is to increase the benefits that the injured party receives from the relationship in an effort to reduce the inequity in that relationship (Walker 2006). In the buyer-seller relationship, this strategy may be chosen by the salesperson based on a desire to immediately "balance the ledger" with the buyer following a negative outcome.

A concessions strategy is a behavioral response following a negative outcome that is an attempt to regain trust with the injured party. It is defined as offering future compensation for a negative outcome (future tangible compensation). The purpose is to reduce the resources that the injured party needs to enter into the relationship in an effort to reduce the inequity in that relationship. In the buyer-seller relationship, this strategy may be chosen by the salesperson based on a desire to incentivize the buyer to continue the relationship after a negative outcome through a discount or a complimentary service on a future order.

A sanctions strategy is a behavioral response following a negative outcome that is an attempt to regain trust with the injured party. It is defined as paying a price for committing a negative outcome through incurring a meaningful penalty (personal punishment of the transgressor) (Gillespie and Dietz 2009). The purpose is to reduce the benefits that the transgressor receives from the relationship in an effort to reduce the inequity in that relationship. In the buyer-seller relationship, this strategy may be chosen by the salesperson to satiate the anger of the buyer through accepting punishment after a negative outcome.

A regulatory controls strategy is a behavioral response following a negative outcome that is an attempt to regain trust with the injured party. It is defined as "setting up a system to assure trustworthy behavior" by the transgressor after a negative outcome (developing rules or procedures to fix flawed relational behavior) (Dirks et al., 2011). The purpose is to increase the resources that the transgressor enters into the relationship in an effort to reduce the inequity in that relationship (Bottom et al. 2002). In the buyer-seller relationship, this strategy may be chosen by the salesperson to reassure the buyer that the salesperson will put in an agreed upon amount of resources into the relationship going forward without the salesperson incurring an immediate monetary cost.

\section{A Typology of Verbal Repair Strategies}

Restoring equity to a relationship can move beyond tangibly affecting inputs and outcomes to increasing the injured party’s psychological well-being (Folger and Cropanzano 
2001). Restoring a buyer's psychological equity can occur through minimizing the perception that inequity occurred or through impacting the psychological rewards/costs of the injured party (Walster, Berscheid, and Walster 1973). Social accounts have been found to reduce perceptions of inequity in a relationship (Cobb and Wooten 1998). This occurs through interpreting the harm or loss caused by an event with a desire to be fair to the injured party and communicating that in a way that will be accepted by the injured party (Bies 2013; Hong 2016). Social accounting states that accepting or shifting responsibility can play a large role in how inequity is reduced (Bies 1987). As such, I create a typology of verbal repair strategies that categorizes social accounts based on whether responsibility is accepted for a negative outcome or whether it is shifted to another source. I start by describing three key factors which are found in social accounts, which are expected restore the psychological equity of the buyer, and go on to explain how these factors are expected to impact the effectiveness of responsibility-shifting and responsibility-accepting strategies.

Restoring psychological equity is affected by three primary factors: (a) the salesperson’s apparent responsibility for the negative outcome; (b) the extent to which the salesperson appears to possess contrition; and (c) the perceived intentions of the salesperson (Bies 1987). Each of these factors is subjective in nature and is based on the buyer's perceptions. Therefore, if the salesperson is able to influence the buyer's perception of any of these factors using a verbal repair strategy, then there should be a reduction in psychological inequity. Responsibilityshifting strategies work through assigning blame for the negative outcome to another source in attempt to persuade the buyer that the salesperson did not behave inequitably and was not responsible for the negative outcome. Responsibility-accepting strategies work through admitting responsibility for the negative outcome and then expressing contrition and positive intentions 
towards the buyer, which increase the psychological rewards of the buyer and can also increase the psychological costs of the salesperson, which reduces inequity.

Responsibility-shifting strategies. The primary purpose of a responsibility-shifting strategy is to mitigate a salesperson's responsibility for a negative outcome. This is commonly accomplished through denying being the cause of the negative outcome or using an excuse to claim that mitigating circumstances influenced behavior (Bies 1987; Fincham and Jaspars 1980). The purpose of the responsibility-shifting strategy is to convince the buyer that the salesperson did not do anything wrong and/or that anyone else would have acted in a similar fashion in that situation. Contrition is not employed with this strategy because the salesperson is making the case that he or she acted appropriately towards the buyer with the negative outcome being caused by an external source or was a function of something the salesperson can not control. While responsibility-shifting strategies have been found to effective in restoring perceptions of fairness after acting inequitably (e.g., Bies and Shapiro 1987) other studies have shown these strategies to be relatively ineffective in that regard (Colquitt \& Chertkoff, 2002; Gilliland, 1994; Schaubroeck et al., 1994).

Responsibility-accepting strategies. A responsibility-accepting strategy is designed to convince the buyer that the negative outcome does not represent what the salesperson is "really like” as a person. It typically begins with acknowledging responsibility for the negative outcome and expressing contrition for the actions that caused the negative outcome (i.e., apology). It may also include explaining the positive motives or intentions behind an action (i.e., justification) (Cody and McLaughlin 1990). To increase the effectiveness of an apology it is necessary to reestablish benevolent intent through coupling it with an explanation (Tomlinson, Lewicki, and Wang 2012). Thus, I describe a responsibility-accepting strategy as (1) acknowledging 
responsibility for a negative outcome, (2) showing contrition for that negative outcome, and (3) providing an explanation of intent. Acknowledging responsibility and showing contrition will restore psychological equity to the buyer through redistributing esteem to the buyer (Roschk and Kaiser 2013), while the explanation of intent works through expressing caring to the harmed party (Tomlinson, Lewicki, and Wang 2012).

\section{CONCEPTUAL MODEL AND HYPOTHESES}

The following model and set of hypotheses provide a framework for considering how behavioral repair strategies (restoration, future concessions, penance, and regulatory controls) and verbal repair strategies (responsibility-accepting and responsibility-shifting) influence trust recovery through changing the perceptions of fairness (equity) in a buyer-seller relationship. Behavioral repair strategies are carefully conceived actions implemented by the salesperson for the purpose of trust repair. Each of the behavioral repair strategies shown in Figure 1 work through changing one of the four dimensions of equity. Each of these strategies impacts a tangible outcome or input in the exchange relationship.

$<<<<<$ Insert Figure 1 about here $>>>>>$

Salespeople may attempt to use verbal repair strategies to complement the use of behavioral repair strategies in changing fairness perceptions. Specifically, verbal repair strategies can aid in the reduction of inequity in two fundamentally different ways: (1) a blame accepting strategy works through the redistribution of esteem accomplished through humility and contrition and (2) a responsibility-shifting strategy attempts to persuade the buyer that the salespersons actions were appropriate (Walster, Walster, and Berscheid 1978). Verbal repair strategies work through a psychological reduction of inequity. 
This psychological reduction of inequity may be used to complement strategies that impact the tangible reduction of inequity (Walster, Walster, and Berscheid 1978). Behavioral repair strategies show the buyer that the salesperson can be relied upon through taking action to restore equity after a negative outcome leading to increased perceptions of credibility. Additionally, behavioral repair strategies can demonstrate benevolence in that the salesperson takes an action that is in the interest of the buyer.

Unfortunately, without a verbal strategy the behavioral strategy may be misconstrued with the buyer ascribing the salesperson's actions to a desire not to lose the sale instead of being motivated by benevolence. This is important because when the intentions behind actions are perceived to be benevolent, they are more beneficial to the relationship and are expected to recover trust more effectively (Gillespie and Dietz 2009; Palmatier et al., 2009). The following hypotheses describe the relationship between behavioral repair strategies and perceptions of fairness, the moderating relationship of verbal repair strategies on the relationship between behavioral repair strategies and fairness perceptions, and the mediating role of fairness perceptions on the relationship between verbal and behavioral repair strategies and trust repair.

\section{The Impact of Behavioral Repair Strategies on Fairness}

In buyer-seller exchanges, the equity process is thought to progress when the buyer forms a perception based upon his or her outcomes and inputs as compared to the salesperson's outcomes and inputs. The buyer then cognitively integrates perceptions of these four equity dimensions (Farkas and Anderson 1979). If the buyer determines that the salesperson's ratio of outcomes to inputs is more favorable than the buyer's ratio, then inequity exists. Fairness increases as inequity decreases, so increasing the buyer's outcomes, reducing the buyer's inputs, reducing the salesperson's outcomes, or increasing the salesperson's inputs all affect perceptions 
of fairness. The behavioral strategies of restoration, future concessions, sanctions, and regulatory controls all work through influencing a dimension of equity, and consequently, are expected to improve perceptions of fairness.

Restoration Strategy. A restoration strategy positively affects buyer outcomes. These positive outcomes are material in the form of resolving the problem and/or compensating for the issue, which increases perceptions of fairness. This strategy is typically implemented in conjunction with the buyer to establish sufficient equity restoration. Restoration is a collaborative problem solving approach to increasing perceptions of fairness where the individual that has been harmed has input into the plan used to make amends (McCold and Wachtel 2003). In this process, the priorities and potential outcomes for both parties are examined to reach a solution that meets both parties requirements (Ganesan 1993).

A restoration strategy works through correcting the issue that resulted in a negative outcome for the injured party (Kidder 2007). In exchange relationships, mistakes must be corrected and problems must be resolved to restore equity (McColl-Kennedy and Sparks, 2003). This is accomplished through identifying a solution that is satisfactory to the buyer and the salesperson, exchanging information about the goals and priorities in the relationship, and evoking alternative solutions until one is agreed upon (Dant and Schul 1992). By implementing this agreed upon solution, the salesperson addresses the inequity in the relationship through improving the buyer's outcomes in a way that is mutually agreed upon. Examples of using a restoration strategy in a sales context include driving all night to get the product to a buyer on time because the order was not shipped when it was promised or switching the buyer to a new product or service at no cost when the salesperson over promised on a sub-optimal product. 
If there was a loss of profit due to the issue, the restoration strategy will include financial compensation for that loss. "Receiving compensation for a monetary loss would be a sufficient response for victims of distributive harm” (Desmet, De Cremer, and van Dijk 2011). Exchange relationships are often driven by tangible outcomes, so a financial compensation facilitates the process of restoring equity to a relationship. A financial compensation that covers economic loss is effective in trust recovery (Desmet, De Cremer, and van Dijk 2011).

$\mathrm{H}_{1}$ : Restoration that is implemented by the salesperson increases the buyer's perceptions of relationship fairness.

Future Concession. During the negotiation and closing stages of the sales process, a buyer will often request a reduction in the quoted price of a product or to receive a free service. Salespeople are trained to request something in return for this concession in order to maintain the fairness of the exchange (Keiser 1988). So, there is a norm of reciprocity that suggests that when a concession is granted the salesperson should receive a proportionate outcome (Cronin 1994). In a trust recovery situation, the salesperson already possesses a disproportionately superior outcome, so a future concession can be used to reduce the buyer's inputs rebalancing the relationship.

A future concession occurs when a salesperson offers a financial discount or an additional level of complementary service on a future order. An example of this is providing a $10 \%$ discount off the next order or providing an additional level of complementary service moving forward. Future concessions work primarily through reducing the time, money, or effort that a buyer invests into a future order. This reduction of buyer inputs increases perceptions of fairness.

A future concession strategy carries the additional benefit of increasing the probability of future orders and encouraging continued trust. While this strategy has not been studied in the 
trust recovery literature, it has been found to be an effective strategy in service recovery (e.g., Grewal, Roggeveen, and Tsiros 2008; Hoffman, Kelley, and Rotalsky 1995). The rationale for this is two-fold. First, during the next exchange, the buyer will put less resources into the exchange making it advantageous to continue the relationship. Secondly, if there is another issue that arises, there is a precedent that the salesperson will take action to restore equity to the relationship through reducing buyer inputs. This creates an expectation that a salesperson will act fairly in the future, which can yield the benefit of higher present fairness perceptions.

$\mathrm{H}_{2}$ : Future concessions provided by the salesperson increase the buyer's perceptions of relationship fairness.

Sanctions. An effective strategy for restoring equity in the relationship is to reduce one's own outcomes (Walster, Berscheid, and Walster 1973). In an exchange relationship, this can be accomplished through a sanctions strategy in which the salesperson is penalized through the reduction of material outcomes (Smith, Bolton, and Wagner 1999). This type of strategy can be voluntarily initiated by the salesperson or insisted upon by the buyer. This type of punishment oriented strategy has been found to be effective in trust recovery (Dirks et al., 2011).

Sanctions are effective because this strategy acknowledges that the salesperson took advantage of the buyer and accepts a penalty in an effort to restore equity with the buyer. This tit-for-tat exchange penalizes the salesperson for the wrongdoing in accordance to the severity of the salesperson's harm to the buyer reducing the salesperson's outputs. An example of this is the salesperson offering or accepting a financial penalty that is greater than the damage caused to the buyer. Thus, the primary purpose of a sanction is to reduce the salesperson's outcomes after trust has been damaged so that perceptions of fairness increase.

$\mathrm{H}_{3}$ : Sanctions on the salesperson increase the buyer's perceptions of relationship fairness. 
Regulatory Controls. Regulatory controls apply regulations, rules, and contracts to constrain the salesperson's inputs by establishing a minimum level of inputs that the salesperson must be enter into the relationship. Regulatory controls are often an effective trust repair strategy because it helps ensure reliable behavior (e.g., Sitkin and Roth 1993). This allows the buyer to be confident that the salesperson will enter an appropriate amount of time, effort, and capital into the relationship. For example, if the salesperson made a sub-optimal product recommendation to the buyer, a regulatory control could be that the salesperson agrees to spend a specified amount of time/effort on researching solutions specific to the firm along with bringing in an engineer to all future product recommendation meetings. Another potential regulatory control for a suboptimal product recommendation is a salesperson committing to spend a documented amount of money on testing the effectiveness of a product in an environment similar to the buyer's company before implementing a recommendation. This decreases perceptions of inequity through increasing salesperson inputs moving forward. This has the secondary benefit of effectively protecting the buyer against future negative outcomes that can damage trust.

A regulatory control acknowledges acting in a way that was unfair to the buyer with the salesperson agreeing to have his or her actions controlled so that it will not reoccur. These controls typically are enforced with substantive penalties if violated, making it advantageous to adhere to the agreement (Nakayachi and Watabe 2005). This provides assurances to the buyer that the salesperson's future action will be fair through an agreement that the salesperson's inputs into the relationship will increase.

$\mathrm{H}_{4}$ : Regulatory controls on the minimum inputs provided by the salesperson increase the buyer's perceptions of relationship fairness.

\section{The Moderating Role of Verbal Repair Strategies}

While behavioral repair strategies are effective through tangibly affecting equity 
perceptions by changing inputs and outcomes, a responsibility-accepting strategy complements these actions through improving perceptions of psychological equity. A responsibility-accepting strategy increases perceptions of psychological equity by redistributing esteem in the exchange relationship (Bramel et al., 1968; Smith, Bolton, and Wagner 1999). The salesperson accomplishes this by accepting accountability for a negative outcome that damaged trust and attempts to convince the buyer that the salesperson did not have negative intent. This puts the salesperson in a position of vulnerability and uncertainty regarding how the buyer will respond. The salesperson may lose the buyer's esteem by admitting responsibility for the negative outcome. This potential sacrifice of salesperson esteem is worthwhile because of the importance of showing a buyer respect after a negative outcome. Receiving positive regard and esteem from others is paramount to increasing perceptions of fairness (McColl-Kennedy and Sparks 2003).

A responsibility-accepting strategy acts as psychological compensation to the buyer for being treated unfairly (Tax, Brown, Chandrashekaran 1998). In fact, acknowledging responsibility for a negative outcome and expressing regret for the damaging trust is often necessary in trust recovery (Lewicki and Wiethoff 2000). This is because a responsibilityaccepting strategy acts as “down payment” for reducing inequity (Tomlinson 2012). It also provides context for behavioral repair strategies in that accepting responsibility shows contrition and indicates to the buyer that the salesperson's actions stem from valuing the partnership with the buyer enough to possess the intent to restore balance to the relationship. Thus, it is expected that a responsibility-accepting strategy will enhance the positive relationship of behavioral repair strategies on fairness perceptions regardless of which behavioral strategy is employed.

A responsibility-shifting strategy does little to improve perceptions of fairness (e.g., Colquitt \& Chertkoff, 2002; Gilliland, 1994; Schaubroeck et al., 1994). This is because a 
salesperson's unwillingness to take responsibility for his or her role in the negative outcome does not show respect for the buyer, and actually demonstrates a lack of esteem if this verbal repair strategy is inaccurate. Ineffective repair strategies further exacerbate the damage to trust through failing to meet expectations a second time (Basso and Pizzutti 2016). The goal of this strategy is to persuade the buyer that the negative outcome had its genesis from a source that is external to the salesperson. Responsibility-shifting strategies carry the risk of being perceived as being deceptive, ineffectual, or self-absorbed (Kim et al., 2009; Schlenker, Pontari, and Christopher 2001). Thus, if the responsibility-shifting strategy is not accepted by the buyer it may diminish the positive effect of behavioral repair strategies on perceptions of fairness. If the responsibilityshifting strategy is accepted by the buyer, it is likely to increase perceptions of fairness (e.g., Frey and Cobb 2010). Even so, a responsibility-shifting strategy is expected to be less psychologically rewarding to the buyer than a responsibility-accepting strategy. This is because the focus of a responsibility-shifting strategy is on persuading the buyer that the salesperson is not at fault instead of looking for ways to be fair to the buyer by framing the account around an acknowledgement of the salesperson's role in the negative outcome. If the victim says that trust is broken, then trust is broken and shifting responsibility is not going to change this (Lewicki and Bunker 1996).

Typically, when there is a negative outcome, the salesperson bears some responsibility and it shows more respect to the buyer to acknowledge that responsibility, show contrition, and explain intent than to try to persuade the buyer that it is not really the salesperson's fault. The following is an example where there is very limited, if any, salesperson fault, but the responsibility-accepting strategy is still expected to be more psychologically rewarding to the buyer: A component manufacturer sends a late shipment to a buyer, which results in the buyer 
having reduced trust in the salesperson from the component manufacturer. The salesperson has a choice of strategies to employ. The salesperson can employ a future concession strategy to restore tangible equity to the relationship or the salesperson can also provide a responsibilityshifting strategy that indicates that the late shipment was due to poor road conditions that were uncontrollable by the salesperson. While the responsibility-shifting strategy would likely be accepted as fair, it would be more psychologically rewarding to the buyer for a salesperson to provide a responsibility-accepting strategy that acknowledges that the delivery was not made on time. The responsibility-accepting strategy, coupled with a behavioral repair strategy of a future concession, demonstrates acceptance that the delay caused issues for the buyer, that the salesperson was sorry that he or she did not honor the delivery commitment and will look for new solutions not to repeat that mistake. It also conveys that the salesperson intended for the delivery to be on time, but that road conditions caused the shipment to be delayed. With the behavioral repair strategy remaining the same, a responsibility-accepting strategy will enhance the effectiveness of that behavioral strategy more than using a responsibility-shifting strategy due to the greater positive impact of responsibility-shifting strategies on psychological equity.

Alternatively stated,

$\mathrm{H}_{5}$ : There is a greater positive interaction between a responsibility-accepting strategy and the behavioral repair strategies of (a) restoration, (b) future concession, (c) sanction, and (d) regulatory controls on perceptions of fairness than a responsibility-shifting strategy will have on perceptions of fairness when employing the same behavioral repair strategy.

\section{The Mediating Role of Fairness on Trust Recovery}

Verbal and behavioral repair strategies are used to positively affect a buyer's perceptions of fairness in the relationship, which is hypothesized to lead to trust recovery. When the buyer believes that his/her outcomes and inputs are equivalent to that of the salesperson then the buyer will perceive the relationship to be fair. The buyer will then use that perception of fairness as a 
surrogate or heuristic as to whether the salesperson should be trusted. This is because fairness is an indicator as to whether the relationship is currently rewarding for the buyer, so it is a useful predictor of whether a relationship will continue to be rewarding in the future.

Negative outcomes can result in a buyer's perceptions of inequity in the relationship. Inequity will result in reduced trust within a relationship (De Ruyter and Wetzels 2000; Smith 1990). This is because trust (in particular, calculative trust) relies on a cost-reward determination (Dimoka 2010; Lewicki and Bunker 1996). Inequity provides evidence that the relationship is not currently rewarding. In addition to this cost-reward determination, trust can also include an interpersonal attachment based on caring for the other individual (Lewicki et al., 1998; Lewicki, Tomlinson, and Gillespie 2006; Rousseau et al., 1998). Inequity can indicate that the salesperson does not care about the buyer. Inequity can be tangibly mitigated by adjusting individual outcomes or inputs for either buyer or salesperson. I contend that this can be accomplished through the implementation of a behavioral repair strategy to increase perceptions of fairness that will positively influence trust recovery. This can be complemented with verbal strategies that can be psychological rewarding for the buyer and also provide information about the level of caring for the buyer based on the salesperson's intentions towards that buyer. This is expected to provide context to the actions taken by the salesperson in a way that explains that the salesperson wants to "do right” by the the buyer increasing the positive relationships between behavioral repair strategies on perceptions of fairness. Trust recovery requires a perception of fairness in the relationship from the buyer's perspective. As the salesperson implements strategies to effect balance restoration in the equity relationship, the perception of fairness returns and trust levels increase.

$\mathrm{H}_{6}$ : Perceptions of fairness will positively mediate the relationship between behavioral repair strategies and trust recovery. 
$\mathrm{H}_{7}$ : There is a positive interaction between verbal and behavioral repair strategies and trust recovery that is positively mediated by perceptions of fairness.

In the next section, I discuss the research methods used to test these hypotheses. This discussion revolves around two empirical studies: (1) a B2C experiment designed to test the impact of each of the verbal and behavioral strategies in a controlled environment, examining how trust recovery unfolds over time; and (2) a B2B critical incident study that I use to examine how verbal and behavioral strategies are employed in marketing practice. A primary purpose of the B2C experiment is to test causality while the B2B critical incident study will be used to provide evidence of external validity. This two study format will also allow for an examination as to whether the theory is generalizable from a B2C to a B2B context.

\section{METHODS}

\section{Overview}

I used two empirical studies (Study 1 and Study 2) to test the proposed conceptual framework and hypotheses empirically, both of which evaluated: (1) the effect of individual behavioral repair strategies on perceptions of fairness and (2) the interaction of verbal and behavioral repair strategies on trust recovery as mediated through perceptions of fairness. The

first study established a foundation for verbal and behavioral repair strategies based on equity theory by testing their impact on perceptions of fairness. Conducting the first study in this experimental setting provided the requisite control that was necessary to establish internal validity and provided a causal test as to whether verbal and behavioral repair strategies caused an increase in perceptions of fairness and determined whether fairness was a key mediating variable between verbal and behavioral repair strategies and trust recovery. 
To enhance external validity, I conducted a second study with professional purchasing agents across industries in ongoing business-to-business exchange relationships. I utilized a critical incident technique (CIT) approach as this technique has been shown to provide a "rich source of data” related to key relational events (Gremler 2004). Specifically, CIT has been used in marketing to examine relational repair efforts (e.g., Bitner, Booms, and Tetreault 1990; Harmeling et al., 2015). The addition of the CIT study provided evidence the model possessed external validity through examining real, ongoing buyer-seller relationships and outcomes, while also demonstrating that the results generalize from a business-to-consumer to a business-tobusiness context. Before discussing the two empirical studies in more depth, I first describe the pretest, which proceeded them.

\section{Pretest}

To ensure the effectiveness of the experimental manipulations in study 1 and to validate the adapted trust recovery and increased perceptions of fairness scales in study 2, a pilot study was conducted. This pilot study employed the manipulations and measures used in study 1 along with the trust recovery and increased perceptions of fairness measures from study 2 . This was conducted with a sample of 102 participants from the Amazon Mechanical Turk panel that were screened to ensure that they currently purchase insurance, as this is the context of the study 1 experiment. Before administering the pretest, I asked a sales executive (recently retired) and a senior level professional purchasing agent, both from the same Fortune 100 firm, to review the materials for both studies. This was to ensure that the experimental scenarios were realistic and that all questions were unambiguous and clear. Manipulation checks were run to test the validity of the manipulations and slight wording adjustments were made based on the results of the pretest. 
The pretest was also used to validate the adapted measures for study 2: trust recovery (adapted from Doney and Cannon 1997) and increased perceptions of fairness (adapted from Oliver and Swan 1989). The pretest was longitudinal in nature measuring both trust and fairness before and after a trust repair attempt. This was designed to capture the change in fairness and trust that occur when a salesperson makes a repair attempt after trust has been damaged. As study 2 is cross-sectional in nature, the variables of increased perceptions of fairness and trust recovery were correlated to the actual changes in fairness and trust that were measured during the pretest to determine the efficacy of the study 2 variables. Increased perceptions of fairness had a moderately high correlation with the actual change in fairness ( $r=.67)$, and trust recovery had a moderately high correlation with the actual change in trust $(\mathrm{r}=.71)$.

\section{Study 1: Business-to-Consumer Experiment}

Design and sample. In this study, I targeted responses from Amazon Turk Prime participants as part of a longitudinal experiment for a small inducement of $\$ 1.75$. This research followed a disclosure based sampling procedure designed to ensure sufficient sample size while minimizing the risk of false positives (Simmons et al., 2011). The predetermined sampling rule was to include 40 respondents per cell with 12 cells include in the experiment for a desired final sample size of 480 . This provides the requisite sample size that is necessary to conduct the desired data analysis (Hair et al., 2006), and is consistent with the sample sizes of 35-50 respondents per cell that is typical of trust recovery experiments (e.g., Desment et al., 2011; Dirks et al., 2011; Kim et al., 2004).

A separate pre-screening survey was used to ensure that participants have experience purchasing insurance in a consumer setting as this was the scenario used in the experiment. The 
screening survey was separate from the actual experiment, and was disguised as a consumption of common services survey. Participants that purchased insurance services were invited to participate via email in the actual experiment.

Participants that chose to take the experiment were then randomly assigned to one of twelve between-subjects treatment conditions: 3 verbal repair strategies (responsibility-shifting, responsibility-accepting, none) x 4 behavioral repair strategies (restoration, future concessions, sanctions, regulatory controls). Consistent with previous trust recovery research, the experiment was set up as a role-play scenario (e.g., Ferrin et al., 2007; Kim et al., 2004; Kim et al., 2013). The participants were asked to react to a role-play scenario that unfolded over the course of three hypothetical sequential interactions with an insurance agent (salesperson). As in previous research, distractor questions/tasks were used between interactions to reduce demand artifacts (e.g., Harmeling et al., 2015; Venkatraman et al., 2015). The distractor tasks that were used are listed in Appendix A.

Manipulations. Multiple hypothetical, sequential interactions were used to perform a longitudinal, scenario based experiment (Harmeling et al., 2015). The experiment began with interaction 1 that was designed to show that the salesperson is trustworthy based on past interactions. After the interaction, respondents were asked to answer scale questions about the dependent variable (trust) and the mediating variable (fairness). After the question block, respondents were given a distractor task designed to last 2-3 minutes. Respondents then viewed interaction 2 that is designed to convey that the salesperson may have been the cause of a negative outcome. After the interaction, trust and fairness were measured for the second time followed by another distractor task designed to last 2-3 minutes. Respondents then viewed interaction 3 that was a description of the verbal and behavioral repair strategy that the 
salesperson implemented. That was followed by a question block where trust, fairness, manipulation checks for the repair strategies, and the control variables were measured. See Figure 2 for a visual depiction of the experimental procedures.

The purpose of having three sequential interactions was to measure actual changes in fairness and trust as they occur. The change in perceptions between interaction 1 and interaction 2 were expected to demonstrate that trust and fairness are damaged by the salesperson's negative actions. The difference in perceptions between interactions 2 and 3 was used to examine whether the verbal and behavioral repair strategies cause increases in perceptions of fairness and trust recovery. Full manipulation descriptions were provided in Appendix B. Each interaction is described in more detail below.

\section{$<<<<<$ Insert Figure 2 about here $>>>>>$}

Interaction 1 was used to stimulate perceptions of trust in the salesperson. A positive description of salesperson attributes was provided to elicit perceptions of trust in the salesperson based on the results of Doney and Cannon (1997). This scenario described a salesperson that has a longstanding, positive relationship with the buyer. Interaction 1 was the same for all respondents.

To promote realism in the experiment a common cause of damaged trust was chosen. It has been estimated that $22 \%$ of salespeople sell buyers products that are not in the buyer's best interest (Marchetti 1997; Strout 2002). When the buyer begins to suspect that the salesperson should not have recommended the product, trust can be damaged. Interaction 2 suggests that the salesperson may have recommended a product that was not in the best interest of the buyer. There is no concrete evidence provided about the salesperson's guilt or innocence in this matter. Interaction 2 was the same for all respondents. 
For the third interactions, respondents were randomly assigned into one of twelve between-subjects treatment conditions: 3 verbal repair strategies (responsibility-shifting, responsibility-accepting, none) x 4 behavioral repair strategies (restoration, future concessions, sanctions, regulatory controls). The third interaction began with the salesperson responding by providing one of the three verbal repair strategies. In the responsibility-accepting strategy condition, the salesperson admitted culpability for making the bad recommendation, expressed remorse, and let the buyer know that it would never happen again. In the responsibility-shifting strategy condition, the salesperson denied responsibility for the recommendation explaining that there was no way to know that the recommendation would not be effective based on the current information. In the reticence (i.e., no verbal repair strategy) condition, the salesperson said nothing about the recommendation. ${ }^{3}$

The verbal repair strategy was followed by a description of one of the four behavioral repair strategies. In the restoration strategy condition, the salesperson replaces the product with a higher quality product at no additional charge. In the future concessions condition, the salesperson offers the buyer a rebate of $20 \%$ off the next order. In the sanctions condition, the salesperson forfeits his or her commission on the sale. This is verified by the sales manager providing the buyer with a letter documenting the reprimand of the salesperson, which includes a statement declaring that the salesperson did not receive a commission for the sale. In the regulatory controls condition, the salesperson agrees to provide a written statement about the merits of any future recommendations with a substantial penalty against the salesperson if the agreed upon procedure is not followed.

\footnotetext{
${ }^{3}$ The reticence strategy (no verbal repair strategy) is not part of the theoretical framework, but is included in the experiment for potential post hoc analysis.
} 
In Study 1, 493 respondents, who were identified as having purchased insurance in a separate screening survey, participated in the experiment. Twelve respondents were removed from the analysis for failing an attention check and/or providing straight line responses. This left 481 respondents for the final analysis. In this study, the respondents were $50 \%$ male and had an average age of 36 . There were $46 \%$ of the respondents that reported having a college education or higher and the average amount of full time work experience was 28 years. Manipulation checks revealed that the manipulations were successful as $91 \%$ of the manipulation checks were answered correctly. The manipulation for the verbal strategies was "the salesperson used his or her words to...(accept responsibility, shift responsibility, did not discuss responsibility).” The manipulation for the behavioral strategies was "the salesperson took the following action...(restoration, future concessions, sanctions, and regulatory controls)." Definitions were provided for each of the verbal and behavioral repair strategies.

Measurement. Participants responded to two measures: trust (Doney and Cannon 1997) and fairness (Oliver and Swan 1989). Participants then responded to manipulation checks designed to assess whether they recognized the nature of the repair strategy. As controls, I included gender, age, perceived typicality of the event, and propensity to trust. There is evidence to suggest that there are neurological differences in how people tend to make trust decisions based on the gender of the individual with women tending to be less trusting, which may be attributed to women having an "inclination toward a heightened level of risk perception” (Reidl et al., 2010, p. 415). Age can differentially impact trust with some evidence that younger adults are less trusting (Clark and Eisenstein 2013). The perceived typicality of the event can change how buyers process encounters with business personnel (Hess, Ganeson, and Klein 2007). Propensity to trust is a trait variable that captures an individual's stable tendencies towards 
trusting that can be inherently different among individuals (Mayer et al. 1995). All measurement scales, manipulation checks, and control variables are listed in Appendix C.

Measurement reliability and validity. I used a confirmatory factor analysis to evaluate the fit and construct validity of the proposed measurement model. As the independent variables were based on dummy coding the experimental manipulations, the latent variables of trust recovery and increased perceptions of fairness were included in the model. The measurement model indicated an acceptable fit and supported convergent validity for a two-factor model, chisquare $=169.70(\mathrm{p}<.001), \mathrm{df}=34, \mathrm{CFI}=.976, \mathrm{RMSEA}=.09$ and all item-factor loadings $>|.8| . \mathrm{A}$ chi-square difference test demonstrated that this model possessed a better fit than a unidimensional model using the same items (see Table 2). The AVE for both latent variables was above |.5| providing additional evidence for convergent validity (Fornell and Larker 1981; Hair et al., 2006). Composite reliability exceeded Nunnally’s 1978 acceptability criteria of .70 with trust recovery (operationalized as the change in trust between interactions 2 and 3) having an CR=.94 and increased perceptions of fairness (operationalized as the change in fairness between interactions 2 and 3) having an $\mathrm{CR}=.96$. The factor loadings and standard error results from the confirmatory factor analysis are depicted in Table 3, while Table 4 displays the correlation table for the measurement items of the latent variables. Cronbach's alpha for all scales can be found in Appendix C.

$<<<<<$ Insert Tables 2, 3, and 4 about here $>>>>>$

A test for discriminate validity is to ensure that all AVE values are greater than the corresponding squared correlation estimates (Fornell and Larcker 1981). This is also the case for increased perceptions of fairness (.86), but trust recovery (.74) is lower than the corresponding squared correlation estimate (.81). This led me to conduct an alternative discriminant validity test 
prescribed by Bagozzi and Yi (1988), that examines whether or not the factors are distinct using a chi square difference test to see if the measurement model has a significantly better fit where the latent variables are not constrained (free) than when the correlation between the two latent factors is constrained to unity. This test provided evidence for discriminately validity as the chisquare value of the nested comparison (i.e., chi-square difference test) $=145.09, \mathrm{df}=1, \mathrm{p}<.001$.

To mitigate concerns of non-response bias, design and empirical procedures were followed. On the design side, respondents were assured that their responses would be anonymous, that there were no right or wrong answers, the survey was kept to an appropriate length, and an appeal was made to the respondent's ego (Erdogan and Baker 2002; Podsakoff et al. 2003; Tyagi 1989). As an empirical test, the time trend-based extrapolation method was used to assess non-response bias consistent with previous sales research (e.g., Gonzalez et al. 2010; Jackson Jr. et al. 2010; Johnson and Friend 2015). The data was split in half based on when the study was completed where data was classified as either early or late responders. Hotelling’s $\mathrm{T}^{2}$ was conducted on the means of the latent variables, and there was not a significant difference in the results for early vs. late responders. Hotelling's $\mathrm{T}^{2}$ was employed because it addresses the problem of inflating the Type I error rate that comes from running a series of $t$ tests (Hair et al., 2006). Together this provides evidence that non-response bias is not a concern in this study.

Table 5 shows the means, standard deviations, and correlations for the Study 1 variables. Also included in Table 3 are the relevant construct reliability coefficients, AVEs, and squared multiple correlations.

$<<<<<$ Insert Table 5 about here $>>>>>$

Data Analysis and Results for Study 1. A multiple regression analysis was used to test the hypotheses that stemmed from the conceptual model. A hierarchical regression approach was 
performed in accordance with the recommendation from Cohen (1978). The results of the hypothesis tests are provided in Table 6.

Hypothesis 1, 2, 3, and 4 examined the direct effect of behavioral repair strategies on perceptions of fairness. Specifically, $\mathrm{H}_{1}$ posits that restoration strategies positively impact a buyer's perceptions of fairness. This hypothesis is supported $(\mathrm{b}=.67, \mathrm{p}<.01) .{ }^{4}$ There was not support for the main effects of the other behavioral repair strategies: future concessions ( $b=-.16$, $\mathrm{p}>.05)$, sanctions $(\mathrm{b}=-.18, \mathrm{p}>.05)$, and regulatory controls $(\mathrm{b}=.00, \mathrm{p}>.05)$, suggesting that these repair strategies do not increase a buyer's perceptions of fairness. Thus, $\mathrm{H}_{2}-\mathrm{H}_{4}$ were not supported. While not explicitly hypothesized, the verbal repair strategies of responsibilityaccepting $(\mathrm{b}=.61, \mathrm{p}<.01)$ and responsibility-shifting $(\mathrm{b}=1.38, \mathrm{p}<.01)$, had a positive relationship with perceptions of fairness.

Hypothesis 5 assessed the moderating role of verbal repair strategies (responsibilityaccepting strategies and responsibility-shifting strategies) on the relationships between each of the four behavioral repair strategies and increased perceptions of fairness. This was estimated with a single equation using the moderated regression approach that is described in Cohen et al. (2002). Restoration $(\mathrm{b}=-.11, \mathrm{p}>.05)$, future concessions $(\mathrm{b}=.04, \mathrm{p}>.05)$, sanctions $(\mathrm{b}=-.21, \mathrm{p}>.05)$, and regulatory controls $(b=-.18, \mathrm{p}>.05)$ were not moderated by responsibility accepting. Additionally, restoration ( $\mathrm{b}=1.01, \mathrm{p}>.05)$, future concessions $(\mathrm{b}=.52, \mathrm{p}>.05)$, and regulatory controls ( $b=-.55, p>.05)$ were not moderated by responsibility shifting. There was a positive interaction between sanctions and responsibility shifting $(b=1.63, \mathrm{p}<.05)$ on increased perceptions of fairness. The standardized coefficient $(\beta=.36, \mathrm{p}<.01)$ for responsibility shifting

\footnotetext{
${ }^{4}$ Unstandardized coefficients are reported for all of the hypotheses, so that the regression equation could be recreated if desired. As all scales use a seven-point agreement scale, there is limited benefit in providing the standardized coefficients.
} 
was larger than the standardized coefficient for the interactive effect of responsibility shifting and sanctions $(\beta=.24, \mathrm{p}<.01)$. This indicates that the use of sanctions actually diminished the positive effect of responsibility shifting on increased perceptions of fairness in this study. As the hypothesis predicted that responsibility accepting strategies would be a more effective moderator than responsibility shifting strategies, the results of this moderation analysis provided evidence that $\mathrm{H}_{5}$ was not supported.

$<<<<<$ Insert Table 6 about here $>>>>>$

The indirect effect of each of the behavioral repair strategies on trust recovery through perceptions of fairness was examined in Hypothesis 6. Hayes' (2013) conditional PROCESS model (template - Model 4) was used to test $\mathrm{H}_{6}$. A bootstrap analysis based on 10,000 estimates with a 95\% bias-corrected confidence interval was used to test the significance of the mediation analysis. The results of the mediation analysis are as follows: restoration $\rightarrow$ increased perceptions of fairness $(b=.74, \mathrm{p}<.01)$; increased perceptions of fairness $\rightarrow$ trust recovery $(b=.78, p<.01)$; restoration $\rightarrow$ trust recovery $(\mathrm{b}=-.02, \mathrm{p}>.05)$. These results support $\mathrm{H}_{6}$ as fairness completely mediates the relationship between restoration and trust recovery. See Figure 3 for a depiction of the mediation results including confidence intervals for the coefficients.

Hypothesis 7 posited that there will be a positive interaction between verbal and behavioral repair strategies and trust recovery that is positively mediated by perceptions of fairness. (i.e., first-stage moderated-mediation). As sanctions and responsibility shifting were previously shown to have a positive interactive effect on increased perceptions of fairness, this interaction was tested using using Hayes’s (2013) PROCESS model 7 with 10,000 boot-strapped samples with a 95\% bias-corrected confidence interval (CI). The results of this analysis provide evidence that the relationship between the interactive effect and increased perceptions of fairness 
was significant $(\mathrm{b}=1.04 ; \mathrm{CI}=.17$ to $1.92 ; \mathrm{p}<.05)$ and that the relationship between increased perceptions of fairness and trust recovery was also significant $(b=.81 ; \mathrm{CI}=.77$ to $.85 ; \mathrm{p}<.01)$ providing evidence for mediation. ${ }^{5}$ This suggests that $\mathrm{H}_{7}$ was supported. None of the control variables tested in the model were shown to be significant indicating that in Study 1 that age, gender, propensity to trust and typicality of the event did not affect trust recovery.

In summary, there were positive main effects of responsibility accepting, responsibility shifting, and restoration on increased perceptions of fairness. There was evidence that increased perceptions of fairness mediates the relationship between these verbal and behavioral repair strategies on trust recovery.

$<<<<<$ Insert Figure 3 about here $>>>>>$

\section{Study 2: Business-to-Business CIT Survey}

Design and sample. Purchasing agents across 36 industries (e.g., financial services, computer services, industrial manufacturing, healthcare, consulting) were surveyed using a reputable online business-to-business panel (i.e., Research Now). A CIT methodology was used to analyze key instances in which a salesperson damaged the trust of a buyer along with the salesperson's subsequent trust repair attempt. To determine the appropriate sample size for this study, I used the results from Dirks et al., (2011) to calculate the samples size necessary for this study and determined that a minimum sample size of 119 participants was necessary. Hair et al., (2006) recommends 15-20 respondents for every independent variable in a regression analysis. With six IVs in the model, that would require a sample size of 120 participants. To run a

\footnotetext{
${ }^{5}$ When the moderator is dichotomous, moderated-mediation is a test of the equality of the conditional indirect effects in the two groups, so the relationship between the interactive effect and trust recovery is not reported (Hayes 2013).
} 
measurement model a sample size of at least 150 is preferred. Thus, the final sample of 204 purchasing agents was sufficient for this study.

Purchasing agents have decision making responsibility with regards to purchasing and develop exchange relationships with salespeople. Surveying purchasing agents provides the opportunity to gather first-hand accounts of how perceptions of fairness and trust recovery are affected by trust repair strategies after trust has been damaged. In this study, respondents were $57 \%$ male and had an average age of 43 . In terms of annual firm revenue, $19 \%$ of respondents work in larger corporations (100 million +), 44\% work in moderate sized companies (1-99 million), and 38\% work for smaller companies (less than 1 million). Respondent have an average of 24 years of full time work experience.

Consistent with previous studies employing a critical incident technique, I asked the respondents to recall a memorable event in the relationship with an exchange partner (Bitner, Booms, and Tetreault 1990; Harmeling et al. 2015). Specifically, I asked them to recall one instance in which a salesperson attempted to repair the damaged trust caused by a negative outcome. Previous research has suggested that there is fundamental integrity to participants' reconstructions of memories and that these memories are retold with minor editorial revisions (Barclay 1986; Conway 1986). There is a limitation to these methods in that temporal details such as dates, frequencies, and specific time sequences are not remembered well, so only the central elements of the event(s) should be requested (Brewin, Andrews, and Gotlib 1993, p. 87). This use of reconstructed memories can be enhanced with the use of cued recall (Linton 1986).

In this research, participants were not asked to provide any details about the timing of events, but were cued to remember the single most memorable event in which a salesperson damaged trust. The respondents were then cued to remember the words and actions that the 
salesperson used to attempt to recover that trust. Additionally, acknowledging that trust may be held at multiple organizational levels (Fang, Palmatier, and Scheer 2008), I asked respondents to focus on instances in which a salesperson damaged his/her trust and the trust repair strategies that were implemented by the salesperson.

This design was used to focus the analysis on the buyer-seller dyad, while still creating variation in the types of trust repair strategies that were analyzed. The advantage of this type of retrospective account is that respondents were able to reflect in the way that they think, providing a detailed account of what they experienced (Gremler 2004; Stauss and Weinlich 1997). Potential respondents from a reputable nation-wide panel company were invited to participate via email. A copy of the solicitation that was used is included in Appendix D and a copy of the informed consent document was included in Appendix E. The invitation included a description of the study, a guarantee of anonymity, an assurance that there are no right or wrong answers, and a link to the survey. The invitation was developed using guidelines from Dillman (2007). The panel company screened respondents on professional purchasing being a primary job function.

Measurement. Participants responded to the following measures: trust recovery (adapted from Doney and Cannon 1997) and increased perceptions of fairness (adapted from Oliver and Swan 1989). In addition to the controls discussed in Study 1, I controlled for the following measures: outcome severity and dependence. These variables were expected to influence how individuals make sense of the intentions around a negative event that impacted trust (Tomlinson et al., 2004; Tomlinson 2011).

Before being asked to reflect on how the salesperson damaged and attempted to repair trust, participants were asked three opening questions that were not included in the conceptual 
model. The purpose of these questions were to ask broad, interesting, and easy to answer questions to help the respondent feel more comfortable with the survey (Churchill and Iacobucci 2005). This led into open-ended questions that was used to understand the trust-damaging event and uncover the verbal and behavioral repair strategies employed by the salesperson.

After the conclusion of the critical incident technique (CIT) questions, aided recall was used to assess whether each of the six types of repair strategies discussed in this study were employed using an agreement scale. See Appendix F for a list of the opening questions (Q1-Q3), CIT questions, and aided recall questions (i.e., single items measures for the trust recovery strategies).

Verbal and behavioral repair strategies were dummy coded based on whether they were included in the repair based on the buyer's account of that repair attempt as a back up to the aided recall measures. Coding was consistent with practices described in the recent literature (Latour and Latour 2010; Ng 2010; Qin, Wen, Dou 2016). Specifically, two judges, who were MBA students at a Mid-Atlantic university, were shown definitions and examples of the verbal and behavioral repair strategies discussed in this research, and were given instructions on how to code qualitative data. These judges coded participants' use of both verbal and behavioral repair strategies with disputes being settled through discussion. Inter-coder reliability was .96. Thirtyone of the 204 responses were listed as “other” because they did not fit within the coding scheme or there was not sufficient information to accurately code the response. As a quality check, I audited all of the judges' coding to make sure that they followed the coding instructions.

The aided recall measures, that assessed the degree to which each trust repair strategy was employed by the salesperson, were used in the as the independent variables in the final analysis. This approach had the advantages of additional variability (scale vs. dichotomous data) 
and the use of all 204 responses in the analysis. The qualitative data (i.e., coded data) did support the findings of the aided recall measures that responsibility-accepting strategies and regulatory controls were important to increasing perceptions of fairness and trust recovery.

Measurement reliability and validity. The data cleaning techniques described in the previous study was also applied to Study 2 . This was followed by an examination of the convergent and discriminant validity of the measurement model. Design and empirical procedures were implemented to address concerns of common method variance and nonresponse bias.

Hu and Benter (1999) suggest that multiple fit indices are used when evaluating models. Since the sample size is under 250 and there are less than six variables examined, I evaluated RMSEA and CFI along with chi square (Hair et al., 2006). The fit of the measurement model for the mediating and dependent variables for Study 2 proved acceptable, with chi square $=120.15$ $(\mathrm{p}<.001)$, CFI $=.975$, RMSEA $=.094$, and $\mathrm{df}=43$. A chi square difference test was run to see if the more parsimonious model (i.e., unidimensional model) should be used instead of the two factor solution. The chi-square difference test showed a significant difference between the two factor model and the one factor model where the two factor model had the better fit (see Table 7).

$<<<<<$ Insert Table 7 about here $>>>>>$

The next step in the analysis was to assess the reliability of the constructs. The composite reliability is above the .7 cutoff suggested by Nunnally (1979) for both trust recovery (CR=.94) and increase in perceptions of fairness $(\mathrm{CR}=.98)$. Construct validity was measured next by examining convergent validity and discriminant validity of these variables. In assessing convergent validity, I first looked at the factor loadings. All unstandardized loadings were 
significant and above the .5 cutoff. All AVE values were above |.5|, which indicates convergent validity (Fornell and Larker 1981; Hair et al., 2006). As was previously discussed, the two factor model has a better fit than the unidimensional model, which is also another indicator of convergent validity. The factor loadings and standard error results from the confirmatory factor analysis are depicted in Table 8, while Table 9 displays the correlation table for the measurement items of the latent variables.

$<<<<<$ Insert Tables 8 and 9 about here $>>>>>$

To demonstrate discriminant validity all AVE values should be greater than the corresponding squared correlation estimates (Fornell and Larker 1981. This is the case for both increased perceptions of fairness ( $\mathrm{AVE}=.91$ ) and trust recovery ( $\mathrm{AVE}=.70$ ), which are higher than the corresponding squared correlation estimate (.46), indicating that there is not an issue with discriminant validity. As an additional verification step, an alternative discriminant validity test prescribed by Bagozzi and Yi (1988) was performed that examines whether or not the factors are distinct using a chi square difference test to see if the existing measurement model where the latent variables are not constrained (free) has a significantly better fit than when the correlation between the two latent factors is constrained to unity. This test also provided evidence for discriminately validity as the chi-square value of the nested comparison (i.e., chi-square difference test result $)=221.32, \mathrm{df}=1, \mathrm{p}<.001$. Taken in conjunction, $\mathrm{I}$ determined the two factor model is the superior solution both theoretically and based on the data.

As a first step in mitigating concerns of common method variance and non-response bias through design procedures, respondents were assured that their responses were anonymous, that there were no right or wrong answers, the survey length was kept to an appropriate length, 
reminder emails were sent, and an appeal was made to the respondent's ego (Erdogan and Baker 2002; Podsakoff et al. 2003; Tyagi 1989).

To reduce concerns about common method variance, two tests were performed. First, Harman's single factor test was performed. When conducting an exploratory factor analysis using the recommendations from Hair et al., (2006), a review of the scree plot (Figure 4) and the change in the percentage of explained variance (Table 10) indicated that more than a single factor was needed. Next, a marker variable that is theoretically unrelated to a key study variable was included in the study (Podsakoff et al. 2003). Any observed relationship between the marker variable and the study variable was assumed to be an artifact of the method and was used to determine method variance. I included work-family conflict as the marker variable as it was expected to be theoretically unrelated to salesperson fairness. The shared variance between the marker variable and both increased perceptions of fairness and trust recovery were was not significant using the partial correlation method.

$<<<<<$ Insert Figure 4 and Table 10 about here $>>>>>$

The time trend-based extrapolation method was used to assess non-response bias consistent with previous sales research (e.g., Gonzalez et al. 2010; Jackson Jr. et al. 2010; Johnson and Friend 2015). The data was split based on survey completion date with respondents classified as either early or late responders. Hotelling's $\mathrm{T}^{2}$ was conducted to determine if there was a significant difference between the means of the latent variables for the early vs. late responders. The t-tests were non-significant further assuaging concerns of non-response bias.

Data Analysis and Results for Study 2. I employed moderated regression procedures (Cohen et al. 2002) and mediation procedures (Hayes 2013) to analyze the data. Single item measures were used to measure each of the independent variables, as is common in critical 
incident technique research. Variables were entered into the model using a hierarchical regression approach (Cohen 1978). Each of the independent variables (responsibility accepting, responsibility shifting, restoration, future concessions, sanctions, and regulatory controls) was mean centered prior to forming the interaction term (Aiken and West 1991). The mediating (perceptions of fairness) and dependent variable (trust recovery) were also mean centered. Descriptive statistics for this study are displayed in Table 11.

$<<<<<$ Insert Table 11 about here $>>>>>$

The results for the field study are fairly similar to the experimental results (see Table 4 for a full comparison of the coefficients, t-values, and significance levels of both studies). Specifically, I find support for $\mathrm{H}_{\mathrm{l}}$ that restoration has a positive relationship with increases in perceptions of fairness $(b=.15, \mathrm{p}<.01)$. Neither future concessions $(\mathrm{b}=-0.05 ; \mathrm{p}>.05)$ nor sanctions $(b=-0.04 ; p>.05)$ had a relationship with increased perceptions of fairness, which provided evidence that $\mathrm{H}_{2}$ and $\mathrm{H}_{3}$ were not supported. Contrary to the experiment, the field study provides evidence that regulatory controls have a positive impact on perceptions of fairness $(b=0.13$; $\mathrm{p}<.05$ ), which provides support for $\mathrm{H}_{4}$. While not hypothesized, responsibility accepting had a significant positive relationship with increased perceptions of fairness $(b=0.14 ; p<.05)$, while responsibility shifting did not $(b=-0.01 ; p>.05)$. Hypothesis 5 suggested that responsibility accepting would increase the positive relationship between behavioral repair strategies and increased perceptions of fairness $(b=-0.07 ; \mathrm{p}<.01)$. There was evidence for an interaction between restoration and responsibility accepting on increases in perceptions of fairness, but it was not in the hypothesized direction. As there were no other significant interactions, $\mathrm{H}_{5}$ was not supported. 
Increases in perceptions of fairness were shown to mediate the relationship between both restoration and regulatory controls on trust recovery providing evidence for $\mathrm{H}_{6}$. The results of the mediation analysis are as follows: (1) restoration $\rightarrow$ increased perceptions of fairness ( $b=.15$, $\mathrm{p}<.05)$; increased perceptions of fairness $\rightarrow$ trust recovery $(\mathrm{b}=.63, \mathrm{p}<.01)$; restoration $\rightarrow$ trust recovery ( $\mathrm{b}=-.02, \mathrm{p}>.05)$ and (2) regulatory controls $\rightarrow$ increased perceptions of fairness $(\mathrm{b}=.02$, $\mathrm{p}<.05)$; increased perceptions of fairness $\rightarrow$ trust recovery $(\mathrm{b}=.63, \mathrm{p}<.01)$; regulatory controls $\rightarrow$ trust recovery $(\mathrm{b}=.03, \mathrm{p}>.05)$. See Figure 5 for a depiction of these mediation results including confidence intervals for the coefficients. Mediation was tested using Hayes's (2013) PROCESS Model 4 with 10,000 boot-strapped samples with a 95\% bias-corrected confidence interval.

Hypothesis 7 suggested that verbal repair strategies increased the effectiveness of behavioral strategies on trust recovery as mediated by increased perceptions of fairness. As there were no significant positive interactions between verbal and behavioral trust repair strategies on increased perceptions of fairness then $\mathrm{H}_{7}$ was not supported. The control variables of age, gender, propensity to trust, typicality of the event, and severity of the event did not affect trust recovery. Dependence was the only control variable tested in this model that was shown to be significant $(\mathrm{b}=.47, \mathrm{p}<.01)$. This indicates that when a buyer is dependent on a salesperson, that buyer's perceptions of fairness is likely to increase after a trust repair attempt.

In summary, there were positive main effects of responsibility accepting, restoration, and regulatory controls on increased perceptions of fairness. There was evidence that increased perceptions of fairness mediates the relationship between these verbal and behavioral repair strategies on trust recovery.

$<<<<<$ Insert Figure 5 about here $>>>>>$ 


\section{DISCUSSION}

Despite the frequency that salespeople damage the trust of buyers, research investigating a buyer's response to a salesperson's trust repair strategies has been sparse. In investigating this, I find evidence from two studies, a business-to-consumer experiment and a business-to-business panel study, that trust is recovered through increasing the buyer's perceptions of fairness through either words or actions. Four behavioral repair strategies were tested in these studies with restoration and regulatory controls being shown to be the behavioral strategies that are effective in trust recovery. In both studies, accepting responsibility (e.g., apology) for the negative outcome that damaged trust was shown to be an effective strategy. Responsibility-shifting strategies (e.g., excuse) were found to be effective with buyers in the consumer experiment, but ineffective with professional buyers in the business field study. It is important to note that increased perceptions of fairness completely mediates the relationship between these repair strategies and trust recovery suggesting that increasing perceptions of fairness is necessary for achieving trust recovery.

While the interaction between verbal and behavioral repair strategies was examined, evidence suggests that both verbal and behavioral repair strategies were more effectively used in isolation. For example, a responsibility-accepting strategy was shown to be an effective strategy and restoration was shown to be an effective strategy, but combining the strategies did not increase the effectiveness of the repair attempt. Surprisingly, in the business-to-business study, the use of a responsibility accepting strategy actually diminished the positive effect of restoration on increasing a buyer's perceptions of salesperson fairness. Moreover, in the consumer study, responsibility shifting had a positive relationship with increased perceptions of fairness. Responsibility shifting was less effective when combined with a sanctions strategy. 
The individual characteristics of the buyer, the circumstances surrounding the trust damaging event, and the dependence of the buyer on the salesperson were examined to see if these factors impacted trust. While it was expected that individual buyer characteristics such as age, gender, and propensity to trust would influence the effectiveness of verbal and behavioral repair strategies on trust recovery, this was not the case. Additionally, the perceived typicality of the trust damaging event and the event's severity did not change the effectiveness of the trust repair strategies. The dependence of the buyer on the salesperson did increase the buyer's perceptions of fairness after a trust repair strategy was implemented. This could be because the dependent buyer views the salesperson's repair attempt more favorably when the buyer knows that it is beneficial for the relationship to continue. This could occur because the increased level of trust that stems from choosing to accept the trust repair strategy alleviates the cognitive dissonance that occurs from a continued working relationship with a salesperson that is not trusted. It could also be that it is worth trusting the salesperson again based on the potential reward that the salesperson brings to the relationship.

\section{Theoretical Implications}

The existing research in trust recovery largely focuses on managing the attributions of the injured party (Tomlinson in-press). The emphasis of trust repair strategies is on convincing the injured party that the transgressor should not be blamed by shifting responsibility to another source (e.g., Kim et al., 2009). This essay takes a divergent perspective suggesting that reducing the inequity of the injured party is more important than managing perceptions about the negative event that led to damaged trust. This is not to say that the stream of attribution theory research, which focuses on helping injured parties to accurately make sense of negative events through the use of social accounts (e.g., Tomlinson and Mayer 2009) is incompatible with the perspective 
espoused in this essay. I merely contend that a shift in focus is necessary towards employing trust repair strategies that "make things right with the injured party” through increasing psychological or tangible equity. The need for a shift in focus is evident in the contributions that this essay makes to trust recovery research.

The results of this essay offer four primary theoretical contributions to the literature. First, while previous research has focused primarily on changing attributions of the harmed party to recover trust, this essay has shown that reducing the inequity (i.e., increasing perceptions of fairness) is also key to trust recovery. This can be accomplished through using verbal repair strategies to reduce the psychological inequity that is felt after a negative outcome or to use behavioral repair strategies such as restoration or regulatory controls to tangibly improve equity for the buyer. This increases the buyer's perceptions of fairness, which is a key missing mediating variable in the current trust recovery literature. The importance of this mediator is evident as it completely mediated the relationship between both restoration and regulatory controls on trust recovery.

Next, while behavioral strategies have been somewhat undervalued in the current literature, I find that two behavioral strategies are effective in trust recovery. A restoration strategy, which improve a buyer's outcomes after trust has been damaged, can be used to "make things right” with the buyer so that trust can be restored. Regulatory controls can be used to formalize the salesperson's inputs into the relationship moving forward providing the buyer with confidence that the salesperson can be trusted. These strategies tangibly reduce the inequity that is felt by the buyer after trust has been damaged. This essay provides evidence that behavioral repair strategies are not subordinate to verbal repair strategies, but merely work through the previously unexplored mechanism of perceptions of fairness. 
Third, verbal and behavioral repair strategies are often used in combination in practice. While this research provides evidence that there is not an interactive effect between verbal and behavioral repair strategies, there is an additive effect. As noted previously, the behavioral repair strategies of restoration and regulatory controls are effective in increasing perceptions of fairness in marketing exchange relationships. Using both a responsibility accepting strategy and either a restoration or regulatory controls strategy is expected to increase trust recovery.

Finally, the empirical trust recovery research to date has tested theory using experiments. My research consists of two separate studies, an experiment and a field study, partially for the purpose of determining if the same theory that is effective in experimental settings still holds in marketing practice. The results of my experiment are consistent with previous research that a responsibility-shifting strategy is effective in trust recovery (e.g., Kim et al. 2004; Ferrin et al., 2007). Contrary to these results, the field study provided evidence that accepting responsibility is effective in trust recovery in business-to-business relationships while responsibility-shifting is not. This is of fundamental importance because it calls into question the external validity of theory suggesting that responsibility shifting strategies are an effective trust recovery strategy in marketing exchange relationships. A potential explanation for this finding is that when there is actual risk to trusting the salesperson again after trust is damaged, the buyer is not willing to trust that salesperson that is unwilling to admit culpability for a mistake. Additionally, in marketing exchange practice, the buyer is better positioned to evaluate the accuracy of the claims that are being made.

\section{Managerial Implications}

As this is the first study to explicitly examine the effectiveness of trust repair strategies in actual marketing exchange relationships, there are multiple managerial implications that arise 
from this study. The first involves the words that salespeople should use when attempting to recover trust after it has been damaged. While much of the existing research on trust recovery suggests that it is effective to shift responsibility to another source when trust is damaged, this does not seem to be effective in actual exchange relationships. Purchasing agents see salespeople as the face of the firm, and expect salespeople to take accountability for any negative outcomes that are caused by the salesperson's firm. When the salesperson accepts responsibility for a negative outcome they are perceived as being fairer by the buyer.

While there are multiple actions that salespeople utilize in practice, restoration and regulatory controls seem to be the most effective for trust recovery. Restoration can be implemented by taking a present action to try to find a solution for the buyer that improves the buyer's outcomes. An example of this is replacing an ineffective product with a better performing product at no additional charge to the customer. Another option is for the salesperson to implement regulatory controls that formalize the salesperson's behavior to the buyer moving forward, so that the salesperson will put the appropriate level of time, effort, and resources into the relationship moving forward. While concessions, such as future discounts, are common in sales practice, there was no evidence that this strategy increases perceptions of fairness or aides in trust recovery. Similarly, the salesperson's use of self-punishment (e.g., forfeiting a commission) was also not effective in restoring trust.

Finally, while previous research has focused on influencing the perceptions of the harmed party after trust has been damaged, this research suggests that the focus of a salesperson's trust repair strategy should be on increasing the buyer's perceptions of fairness. This can often be accomplished verbally through accepting responsibility for the negative outcome, showing contrition for the mistake, and stating an intention not to repeat the mistake again. When there is 
tangible harm to the buyer, a restoration strategy can be used to restore fairness to the relationship. If it is not possible to provide restitution in the present, regulatory controls can be used to rebalancing the equity in the relationship moving forward through increasing what the salesperson puts into the relationship.

\section{Limitations and Future Research Directions}

While the critical incident technique approach allowed for the collection of actual trust repair data in marketing exchange relationships, the methodology does possess limitations. Namely, there is a risk that respondents will not accurately recall the memory associated with the salesperson damaging trust and subsequently attempting to recover trust. I tried to mitigate this concern with techniques that aided in recall and through asking respondents to recall an incident that was salient to them. Additionally, as is common with critical incident technique studies due to time the respondent spends recalling and describing the key event, single item measures were used for used to examine the independent variables in this study. Finally, this methodology is cross sectional in nature. To help overcome this limitation, I conducted an experiment that was longitudinal in nature to examine the causal elements explored in this essay in a more controlled setting.

The experiment that was run in this essay also has limitations. The role-playing method, while essential to the manipulation, elicits a lower level of respondent involvement than would occur if an actual salesperson damaged the buyer's trust. Thus, it is possible that a weaker response to damaged trust than would actually occur in practice. The use of the insurance context for the experiment may limit the generalizability of the findings. The previously described critical incident technique field study was designed to help offset these concerns through examining actual negative outcomes and trust repair attempts in a variety of industries. 
Future research should build off of this work by taking a longitudinal approach to examining a salesperson damaging and repairing trust in a field setting. This approach could be augmented through the development of scales for the trust repair strategies that are commonly used in marketing exchange relationships. Future research should also examine the factors that enhance or decrease the effectiveness of the verbal and behavioral repair strategies that were examined in this study, such as the speed, quality, and sincerity of the trust repair attempts. Additionally, this study suggests that buyer dependence plays a large role in trust recovery, but theory in this area needs further development. Future research should explore this in greater detail, examining whether buyer dependence gives salespeople the necessary time to recover trust or if dependent buyers have a psychological need to trust the individual that he or she is working with and thus choose to continue to trust that individual.

\section{Conclusion}

Trust is the cornerstone of marketing exchange relationships, and salespeople are prone to damaging the trust of the buyer. It is critical for salespeople to implement verbal and behavioral strategies to recover that trust, so that the relationship with the buyer can continue. While previous research has suggested that persuasive techniques that shift blame to other sources is the key to trust recovery, this does not seem to be the case. Instead, salespeople should focus on acting fairly towards the buyer. This can be accomplished through accepting responsibility for the negative outcome that damaged trust or through taking actions, such as restoration and regulatory controls that restore equity to the buyer. While both of these actions are effective, restoration has the benefit of improving the buyer's outcomes in the present, while regulatory controls formally regulate what the salesperson gives to the relationship. Combining words (accepting responsibility) and actions (restoration, regulatory controls) increases trust 
recovery. While either words or actions can be effective in recovering trust, they are more effective when used in conjunction. It is important for the salesperson to choose the correct words and actions because commonly employed strategies such as shifting blame to other sources, providing future discounts, and self-sanctions were not effective in trust recovery. 


\section{REFERENCES}

Aiken, Leona S. and Stephen G. West (1991), Multiple regression: Testing and interpreting interactions. Thousand Oaks: Sage Publications Inc.

Adams, J. Stacy (1963), “Towards an Understanding of Inequity,” The Journal of Abnormal and Social Psychology, 67 (5), 422-36.

Anderson, Erin and S.D Jap (2005), “The Dark Side of Relationships,” MIT Sloan Management Review, 46 (3).

Barclay, Craig R. (1986), "Schematization of Autobiographical Memory,” Autobiographical Memory, 82-99.

Basford, Tessa E., Lynn R. Offermann, and Tara S. Behrend (2014), "Please Accept My Sincerest Apologies: Examining Follower Reactions to Leader Apology," Journal of Business Ethics, 119 (1), 99-117.

Basso, Kenny and Cristiane Pizzutti (2016), "Trust Recovery Following a Double Deviation," Journal of Service Research, 209-23.

Bies, Robert J. (1987), "The Predicament of Injustice: The Management of Moral Outrage," Research in Organizational Behavior.

------ (2013),"The Delivery of Bad News in Organizations: A Framework for Analysis," Journal of Management, 39 (1), 136-162.

------- and Debra L. Shapiro (1987),"Interactional Fairness Judgments: The Influence of Causal Accounts," Social Justice Research, 1 (2), 199-218.

Bitner, Mary Jo, Bernard H. Booms, and Mary Stanfield Tetreault (1990), "The Service Encounter: Diagnosing Favorable and Unfavorable Incidents," The Journal of Marketing, 71-84.

Bramel, Dana, Barry Taub, and Barbara Blum (1968), "An Observer's Reaction to the Suffering of His Enemy," Journal of Personality and Social Psychology, 8(4), p1 384.

Brewin, Chris R., Bernice Andrews, and Ian H. Gotlib (1993), "Psychopathology and Early Experience: A Reappraisal of Retrospective Reports," Psychological Bulletin, 113(1), 82.

Clark, April K. and Marie A. Eisenstein (2013), "Interpersonal Trust: An Age-Period-Cohort Analysis Revisited," Social Science Research, 42(2), 361-375.

Cobb, A. T. and K. C. Wooten (1998), "The Role Social Accounts Can Play in a Justice Intervention," Research in Organizational Change and Development, 11, 73-115. 
Cody, Michael J. and Margaret L. McLaughlin (1990), "The Psychology of Tactical Communication," In The Chapters in this Book are a Portion of the Papers Presented at the "Third International Conference on Social Psychology and Language," held in Bristol, England on Jul 20-24, 1987, Multilingual Matters.

Cohen, Jacob, Patricia Cohen, Stephen West, and Leona Aiken (2002), Applied Multiple Regression/Correlation Analysis for the Behavioral Sciences. Mahwah, NJ: Routledge.

Colquitt, Jason A. and Jerome M. Chertkoff (2002), "Explaining Injustice: The Interactive Effect of Explanation and Outcome on Fairness Perceptions and Task Motivation," Journal of Management, 28 (5), 591-610.

Colquitt, Jason A. and Jessica B. Rodell (2011), "Justice, Trust, and Trustworthiness: A Longitudinal Analysis Integrating Three Theoretical Perspectives," Academy of Management Journal, 54 (6), 1183-1206.

Conway, Martin A. (1996), "Autobiographical Memory," Memory 2, 165-194.

Dant, Rajiv P. and Patrick L. Schul (1992), "Conflict Resolution Processes in Contractual Channels of Distribution," The Journal of Marketing, 38-54.

De Ruyter, Ko and Martin Wetzels (2000), "Customer Equity Considerations in Service Recovery: A Cross-Industry Perspective," International Journal of Service Industry Management, 11(1), 91-108.

DeConinck, James B (2010), "The Effect of Organizational Justice, Perceived Organizational Support, and Perceived Supervisor Support on Marketing Employees' Level of Trust," Journal of Business Research, 63 (12), 1349-1355.

Desmet, Pieter TM, David De Cremer, and Eric van Dijk (2011), "In Money We Trust? The Use of Financial Compensations to Repair Trust in the Aftermath of Distributive Harm." Organizational Behavior and Human Decision Processes, 114 (2), 75-86.

Dillman, Don A. (2000), Mail and Internet Surveys: The Tailored Design Method, 2nd ed., New York: John Wiley \& Sons.

Dimoka, Angelika (2010), "What Does the Brain Tell Us About Trust and Distrust? Evidence from a Functional Neuroimaging Study," Mis Quarterly, 373-396.

Dirks, Kurt T., Roy J. Lewicki, and Akbar Zaheer (2009), "Reparing Relationships Within and Between Organizations: Building a Conceptual Foundation," Academy of Management Review, 34 (1), 68-84.

Doney, Patricia M. and Joseph P. Cannon (1997), "Trust in Buyer-Seller Relationships," Journal of Marketing, 61, 35-51. 
Fang, Eric, Robert W. Palmatier, Lisa K. Scheer, and Ning Li (2008), "Trust at Different Organizational Levels," Journal of Marketing, 72(2), 80-98.

Farkas, Arthur J. and Norman H. Anderson (1979), "Multidimensional Input in Equity Theory," Journal of Personality and Social Psychology, 37 (6), 879.

Ferrin, Donald L., Peter H. Kim, Cecily D. Cooper, and Kurt T. Dirks (2007), "Silence Speaks Volumes: The Effectiveness of Reticence in Comparison to Apology and Denial for Responding to Integrity-and Competence-Based Trust Violations," Journal of Applied Psychology, 92 (4), 893.

Fincham, Frank D. and Joseph M. Jaspars (1980), "Attribution of Responsibility: From Man the Scientist to Man as Lawyer," Advances in Experimental Social Psychology, 13, 81-138.

Folger, Robert and Russell Cropanzano (2001), "Fairness Theory: Justice as Accountability," Advances in Organizational Justice, 1, 1-55.

Fornell, Claes and David F. Larcker (1981), "Structural Equation Models with Unobservable Variables and Measurement Error: Algebra and Statistics," Journal of Marketing Research, 382-388.

Frey, Francis M. and Anthony T. Cobb (2010), "What Matters in Social Accounts? The Roles of Account Specificity, Source Expertise, and Outcome Loss on Acceptance," Journal of Applied Social Psychology, 40 (5), 1203-1234.

Ganesan, Shankar (1994), "Determinants of Long-Term Orientation in Buyer-Seller Relationships," The Journal of Marketing, 1-19.

Gillespie, Nicole and Graham Dietz (2009), "Trust Repair After an Organization-Level Failure," Academy of Management Review, 34 (1), 127-145.

Gilliland, Stephen W (1994), "Effects of Procedural and Distributive Justice on Reactions to a Selection System," Journal of Applied Psychology, 79 (5), 691.

Goffman, Erving (1971), "Relations in Public: Microstudies of the Social Order," London: Allen Lane. PMid 16059101.

Greenberg, Jerald (1990), "Looking Fair vs. Being Fair: Managing Impressions of Organizational Justice," Research in Organizational Behavior, 12 (1), 111-157.

Gremler, Dwayne D. (2004), "The Critical Incident Technique in Service Research," Journal of Service Research, 7(1), 65-89.

Grewal, Dhruv, Anne L. Roggeveen, and Michael Tsiros (2008), "The Effect of Compensation on Repurchase Intentions in Service Recovery," Journal of Retailing, 84 (4), 424-434. 
Griffith, David A., Jessica J. Hoppner, Hannah S. Lee, and Tobias Schoenherr (2017), "The Influence of the Structure of Interdependence on the Response to Inequity in BuyerSupplier Relationships," American Marketing Association.

Haesevoets, Tessa, Chris Reinders Folmer, and Alain Van Hiel (2015), "Is Trust for Sale? The Effectiveness of Financial Compensation for Repairing Competence- Versus IntegrityBased Trust Violations," PLOS ONE, 1-13.

Harmeling, Colleen M., Robert W. Palmatier, Mark B. Houston, Mark J. Arnold, and Stephen A. Samaha (2015), "Transformational Relationship Events," American Marketing Association.

Hawes, Leonard C (1999), "The Dialogics of Conversation: Power, Control, Vulnerability," Communication Theory, 9 (3), 229-264.

Hayes, Andrew F (2013), "Introduction to Mediation, Moderation, and Conditional Process Analysis: A Regression-Based Approach,” Guilford Press.

Heide, Jan B. and Anne S. Miner (1992), "The Shadow of the Future: Effects of Anticipated Interaction and Frequency of Contact on Buyer-Seller Cooperation," Academy of Management Journal, 35 (2), 265-291.

Hess Jr, Ronald L., Shankar Ganesan, and Noreen M. Klein (2003), "Service Failure and Recovery: The Impact of Relationship Factors on Customer Satisfaction," Journal of the Academy of Marketing Science, 31 (2), 127-145.

Hoffman, K. Douglas, Scott W. Kelley, and Holly M. Rotalsky (1995), "Tracking Service Failures and Employee Recovery Efforts," Journal of Services Marketing, 9(2), 49-61.

Hong, Michelle Chiawei. "Social Accounting and Unethical Behavior: Does Looking Fair Undermine Actually Being Fair?." PhD diss., Virginia Tech, 2016.

Hu, Li-tze and Peter M. Bentler (1999), "Cutoff Criteria for Fit Indexes in Covariance Structure Analysis: Conventional Criteria Versus New Alternatives," Structural Equation Modeling: A Multidisciplinary Journal, 6(1), 1-55.

Huppertz, John W., Sidney J. Arenson, and Richard H. Evans (1978), "An Application of Equity Theory to Buyer-Seller Exchange Situations," Journal of Marketing Research, 250-260.

Huseman, Richard C., John D. Hatfield, and Edward W. Miles (1987), "A New Perspective on Equity Theory: The Equity Sensitivity Construct," Academy of Management Review, 12 (2), 222-234. 
Kaynak, Ramazan and Tuba Sert (2012), "The Impact of Service Supplier's Unethical Behavior to Buyer’s Satisfaction: An Empirical Study," Journal of Business Ethics, 109(2), 219226.

Keiser, Thomas C. (1988), Negotiating with a Customer You Can't Afford to Lose, Harvard Business School.

Kidder, Deborah L. (2007), "Restorative Justice: Not 'Rights', but the Right Way to Heal Relationships at Work," International Journal of Conflict Management, 18, 4-22.

Kim, Peter H., Kurt T. Dirks, and Cecily D. Cooper (2009), "The Repair of Trust: A Dynamic Bilateral Perspective and Multilevel Conceptualization," Academy of Management Review, 34(3), 401-422.

-------, ------, ------, and Donald L. Ferrin (2006), "When More Blame is Better than Less: The Implications of Internal vs. External Attributions for the Repair of Trust After a Competence-vs. Integrity-Based Trust Violation," Organizational Behavior and Human Decision Processes, 99 (1) 49-65.

-------, Donald L. Ferrin, Cecily D. Cooper, and Kurt T. Dirks (2004), "Removing the Shadow of Based Trust Violations," Journal of Applied Psychology, 89 (1), 104.

Koppitsch, Steven, Valerie S. Folkes, Deborah MacInnis, and Christine Porath (2013), "The Way A Salesperson Manages Service Providers Influences Customers’ Anger about Problems," Journal of Personal Selling \& Sales Management, 33 (1), 67-77.

Kumar, Nirmalya, Lisa K. Scheer, and Jan-Benedict EM Steenkamp (1995), "The Effects of Perceived Interdependence on Dealer Attitudes," Journal of Marketing Research, 348356.

Lapidus, Richard S. and Lori Pinkerton (1995), "Customer Complaint Situations: An Equity Theory Perspective," Psychology \& Marketing, 12 (2), 105-122.

Latour, Kathryn A. and Michael S. Latour (2010), "Bridging Aficionados’ Perceptual and Conceptual Knowledge to Enhance How They Learn from Experience," Journal of Consumer Research, 37(4), 688-697.

Lewicki, Roy J. and Barbara B. Bunker (1996),"Developing and Maintaining Trust in Work Relationships," Trust in organizations: Frontiers of Theory and Research, 114, 139.

-------, Edward C. Tomlinson, and Nicole Gillespie (2006), "Models of Interpersonal Trust Development: Theoretical Approaches, Empirical Evidence, and Future Directions," Journal of management, 32 (6), 991-1022.

-------, Roy J. and Carolyn Wiethoff (2000), "Trust, Trust Development, and Trust Repair," The handbook of Conflict Resolution: Theory and Practice, 1 (1), 86-107. 
-------, Roy J., Daniel J. McAllister, and Robert J. Bies (1998), "Trust and Distrust: New Relationships and Realities," Academy of Management Review, 23(3), 438-458.

Lind, E. Allan (2001), "Fairness Heuristic Theory: Justice Judgments as Pivotal Cognitions in Organizational Relations," Advances in Organizational Justice, 56, 88.

Linton, Marigold (1986), "Ways of Searching and the Contents of Memory," Autobiographical Memory, 50-67.

Lount Jr, Robert B., Chen-Bo Zhong, Niro Sivanathan, and J. Keith Murnighan (2008), "Getting Off on the Wrong Foot: The Timing of a Breach and the Restoration of Trust," Personality and Social Psychology Bulletin, 34 (12), 1601-1612.

Mayer, Roger C., James H. Davis, and F. David Schoorman (1995), "An Integrative Model of Organizational Trust," Academy of Management Review, 20 (3), 709-734.

McCold, Paul and Ted Wachtel (2003), "In Pursuit of Paradigm: A Theory of Restorative Justice." In XIII World Congress of Criminology, 10-15.

McColl-Kennedy, Janet R., and Beverley A. Sparks (2003), "Application of Fairness Theory to Service Failures and Service Recovery," Journal of Service Research, 5 (3), 251-266.

Nakayachi, Kazuya and Motoki Watabe (2005), "Restoring Trustworthiness After Adverse Events: The Signaling Effects of Voluntary "Hostage Posting" on Trust," Organizational Behavior and Human Decision Processes, 97 (1), 1-17.

Ng, Sharon (2010), "Cultural Orientation and Brand Dilution: Impact of Motivation Level and Extension Typicality." Journal of Marketing Research, 47(1), 186-198.

Nunnally, Jum (1978), "Psychometric Methods." 464-465.

Oliver, Richard L., and John E. Swan (1989), "Consumer Perceptions of Interpersonal Equity and Satisfaction in Transactions: A Field Survey Approach." The Journal of Marketing, 21-35.

Palmatier, Robert W., Rajiv P. Dant, Dhruv Grewal, and Kenneth R. Evans (2006), "Factors Influencing the Effectiveness of Relationship Marketing: A Meta-Analysis," Journal of Marketing, 70 (4), 136-153.

-------, Cheryl Burke Jarvis, Jennifer R. Bechkoff, and Frank R. Kardes (2009), "The Role of Customer Gratitude in Relationship Marketing," Journal of Marketing, 73 (5), 1-18.

Pritchard, Robert D (1969), "Equity Theory: A Review and Critique," Organizational Behavior and Human Performance, 4 (2), 176-211. 
Qin, Yao, Na Wen and Wenyu Dou (2016), "Effects of Perceptual and Conceptual Similarities on Consumers' Evaluations of Copycat Brand Names," Journal of Consumer Behaviour, 15(2), 117-125.

Riedl, René, Marco Hubert, and Peter Kenning (2010), "Are there Neural Gender Differences in Online Trust? An fMRI Study on the Perceived Trustworthiness of eBay Offers." Mis Quarterly, 34(2), 397-428.

Roschk, Holger, and Susanne Kaiser (2013), "The Nature of an Apology: An Experimental Study on How to Apologize After a Service Failure," Marketing Letters, 24 (3), 293309.

Rousseau, Denise M., Sim B. Sitkin, Ronald S. Burt, and Colin Camerer (1998), "Not So Different After All: A Cross-Discipline View of Trust," Academy of Management Review, 23(3), 393-404.

Samaha (2015), "Transformational Relationship Events," American Marketing Association.

Schaubroeck, John, Douglas R. May, and F. William Brown (1994), "Procedural Justice Explanations and Employee Reactions to Economic Hardship: A field Experiment," Journal of Applied Psychology, 79 (3), 455.

Scheer, Lisa K (2012), "18 Trust, Distrust and Confidence in B2B Relationships," Handbook on Business to Business Marketing, 332.

Scheer, Lisa K., Nirmalya Kumar, and Jan-Benedict EM Steenkamp (2003), "Reactions to Perceived Inequity in US and Dutch Interorganizational Relationships," Academy of Management Journal, 46 (3), 303-316.

Schweitzer, Maurice E., John C. Hershey, and Eric T. Bradlow (2006), "Promises and Lies: Restoring Violated Trust," Organizational Behavior and Human Decision Processes, 101 (1), 1-19.

Scott, Marvin B. and Stanford M. Lyman (1968), "Accounts," American Sociological Review, 46-62.

Sheppard, Blair H., Roy J. Lewicki, and John W. Minton (1992), Organizational Justice: The Search for Fairness in the Workplace, New York: Lexington Books.

Simmons, Joseph P., Leif D. Nelson, and Uri Simonsohn (2011), "False-Positive Psychology: Undisclosed Flexibility in Data Collection and Analysis Allows Presenting Anything as Significant," Psychological Science, 22 (11), 1359-1366.

Sitkin, Sim B. and Robert J. Bies (1993), "Social Accounts in Conflict Situations: Using Explanations to Manage Conflict," Human Relations, 46 (3), 349-370. 
Smith, Amy K., Ruth N. Bolton, and Janet Wagner (1999), "A Model of Customer Satisfaction with Service Encounters Involving Failure and Recovery," Journal of Marketing Research, 356-372.

Stauss, Bernd and Bernhard Weinlich (1997), "Process-Oriented Measurement of Service Quality: Applying the Sequential Incident Technique," European Journal of Marketing, 31(1), 33-55.

Strout, Erin (2002), "To Tell the Truth," Sales and Marketing Management, 154 (7), 40-47.

Swan, John E., and Richard L. Oliver (1991), "An Applied Analysis of Buyer Equity Perceptions and Satisfaction with Automobile Salespeople, "Journal of Personal Selling \& Sales Management, 11 (2), 15-26.

Takaku, Seiji (2001), "The Effects of Apology and Perspective Taking on Interpersonal Forgiveness: A Dissonance-Attribution Model of Interpersonal Forgiveness," The Journal of Social Psychology, 141 (4), 494-508.

Tax, Stephen S., Stephen W. Brown, and Murali Chandrashekaran (1998), "Customer Evaluations of Service Complaint Experiences: Implications for Relationship Marketing," The Journal of Marketing, 60-76.

Tetlock, Philip E. and Antony S. Manstead (1985), "Impression Management Versus Intrapsychic Explanations in Social Psychology: A Useful Dichotomy?," Psychological Review, 92 (1), 59.

Tomlinson, Edward C (2011), "The Context of Trust Repair Efforts: Exploring the Role of Relationship Dependence and Outcome Severity," Journal of Trust Research, 1 (2), $139-157$.

and Roger C. Mryer (2009), "The Role of Causal Attribution Dimensions in Trust Repair," Academy of Management Review, 34 (1), 85-104.

-------, Brian R. Dineen, and Roy J. Lewicki (2004), "The Road to Reconciliation: Antecedents of Victim Willingness to Reconcile Following a Broken Promise," Journal of Management, 30 (2), 165-187.

-------, R. J. Lewicki and S. Wang (2012), "Trust Therapy: The Effects of Impact and Intent Strategies on Trust Repair," Research in Management: Perspectives on Trust and Justice in Organizations. Charlotte: Information Age Publishing.

Tucker, Danielle A., Jane Hendy, and James Barlow (2016), "The Dynamic Nature of Social Accounts: An Examination of How Interpretive Processes Impact on Account Effectiveness," Journal of Business Research, 69 (12), 6079-6087. 
Venkatraman, Vinod, Angelika Dimoka, Paul A. Pavlou, Khoi Vo, William Hampton, Bryan Bollinger, Hal E. Hershfield, Masakazu Ishihara, and Russell S. Winer (2015), "Predicting Advertising Success Beyond Traditional Measures: New Insights from Neurophysiological Methods and Market Response Modeling," Journal of Marketing Research, 52(4), 436-452.

Walster, Elaine, G. William Walster, and Ellen Berscheid (1978), "Equity: Theory and Research,".

Wat, Dennis and Margaret A. Shaffer (2005), "Equity and Relationship Quality Influences on Organizational Citizenship Behaviors: The Mediating Role of Trust in the Supervisor and Empowerment," Personnel Review, 34 (4), 406-422.

Yu, Ying, Yan Yang, and Fengjie Jing (2017), "The Role of the Third Party in Trust Repair Process," Journal of Business Research, 233-41. 


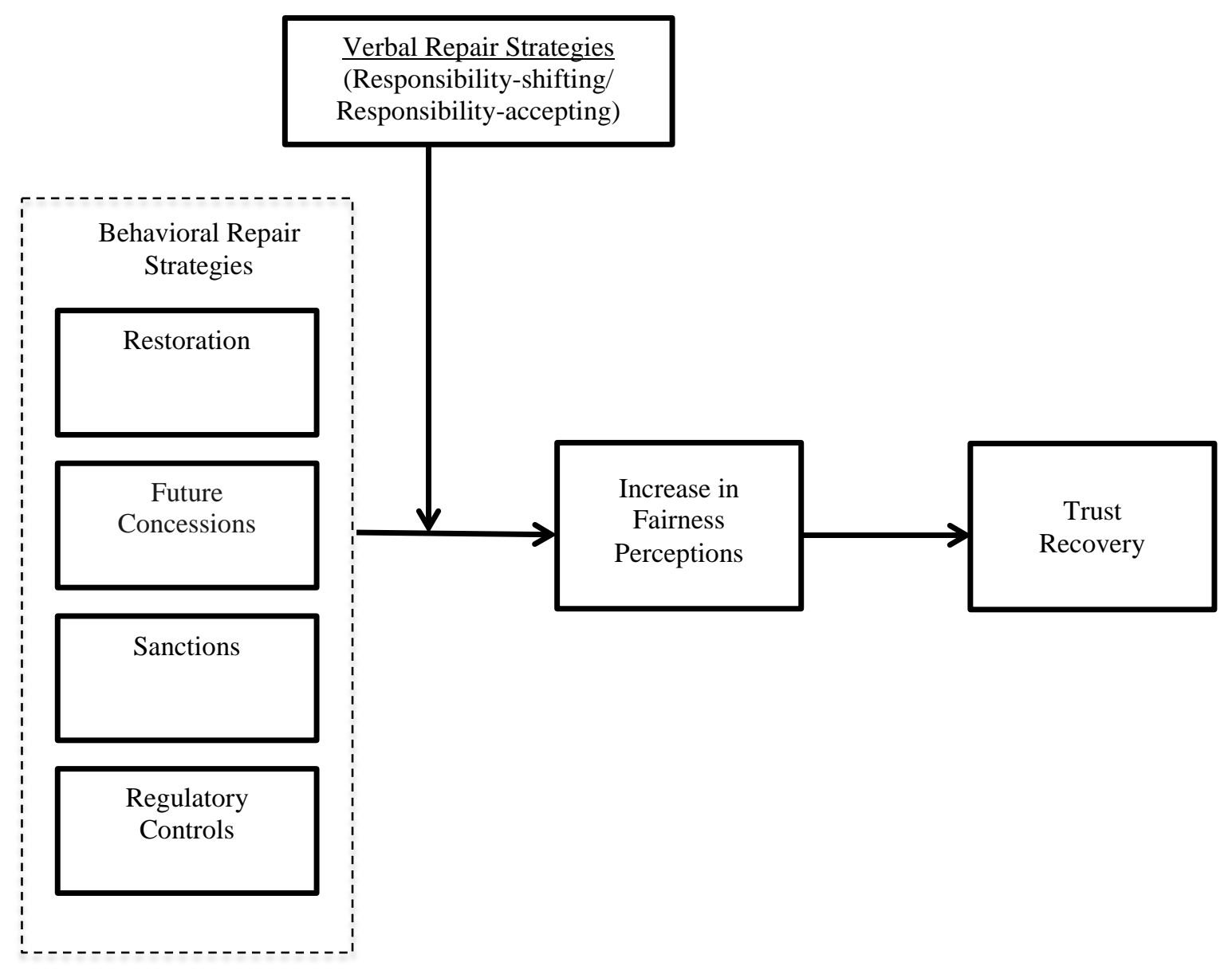


Figure 2: Experimental Procedures

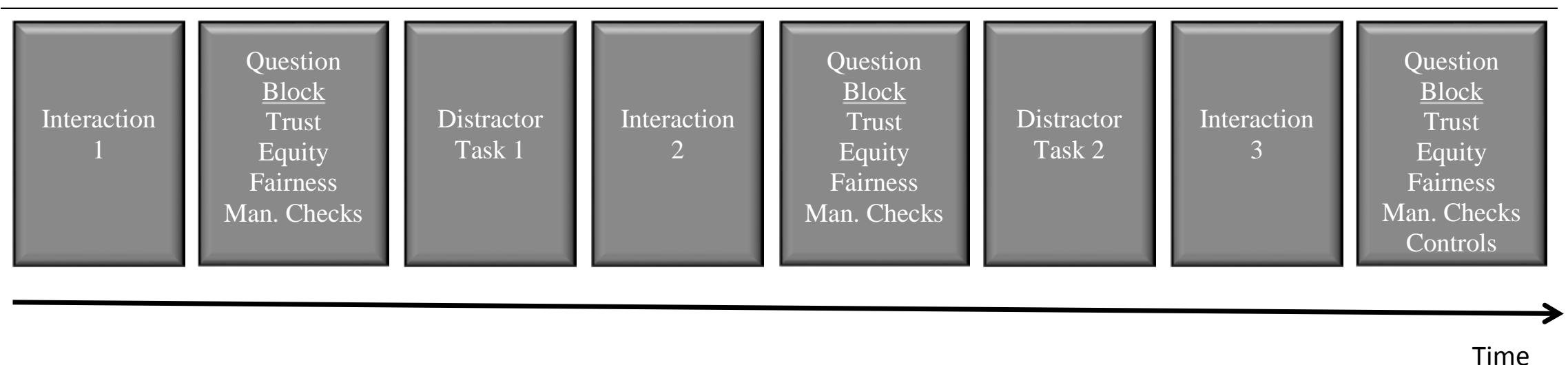


Figure 3: Mediation Results for Study 1 - PROCESS Model 4

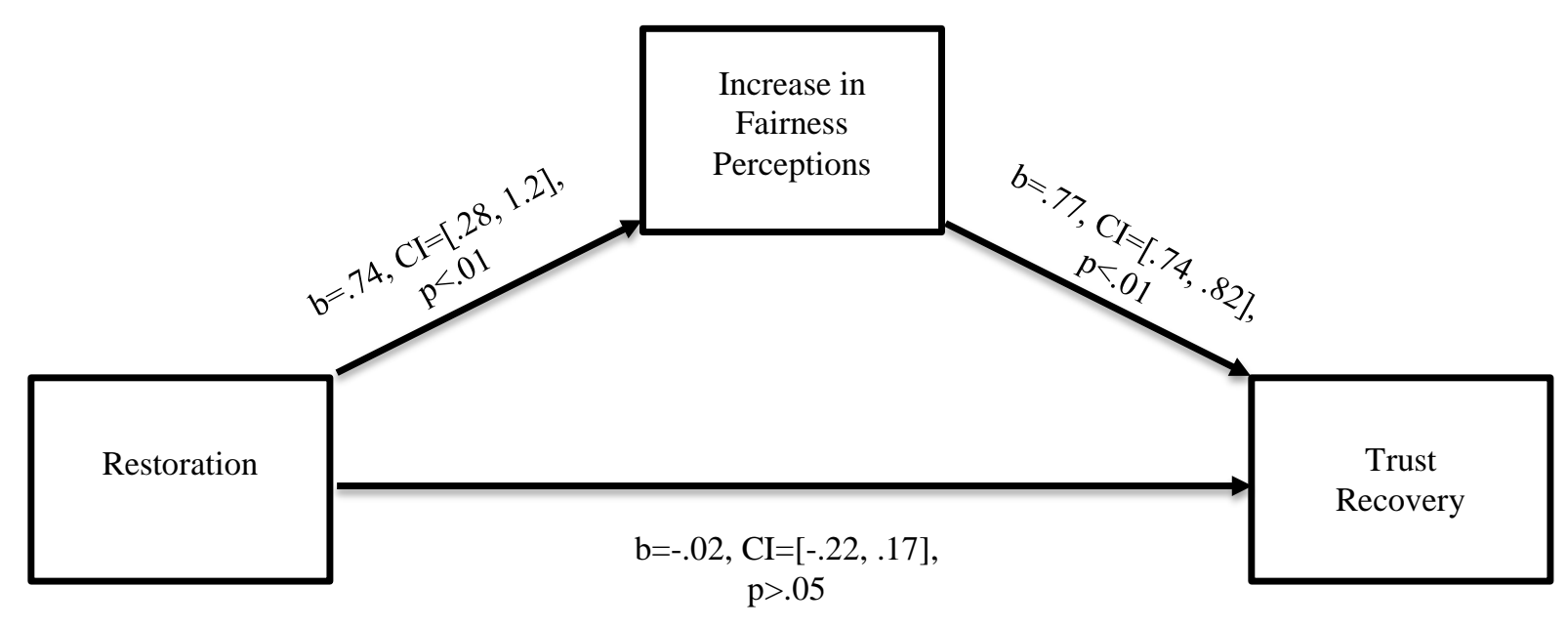


Figure 4: Scree Plot from the Exploratory Factor Analysis for Study 2

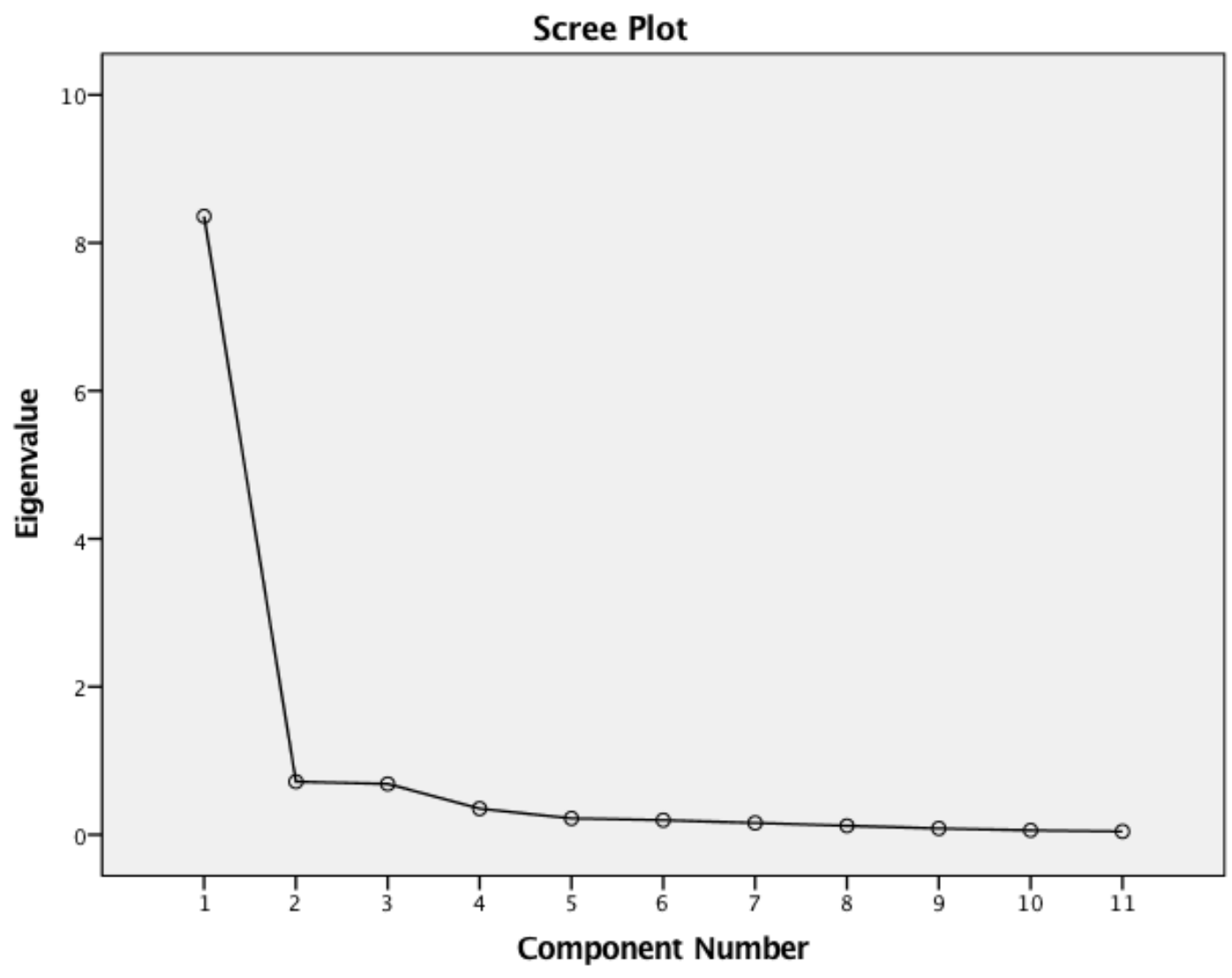



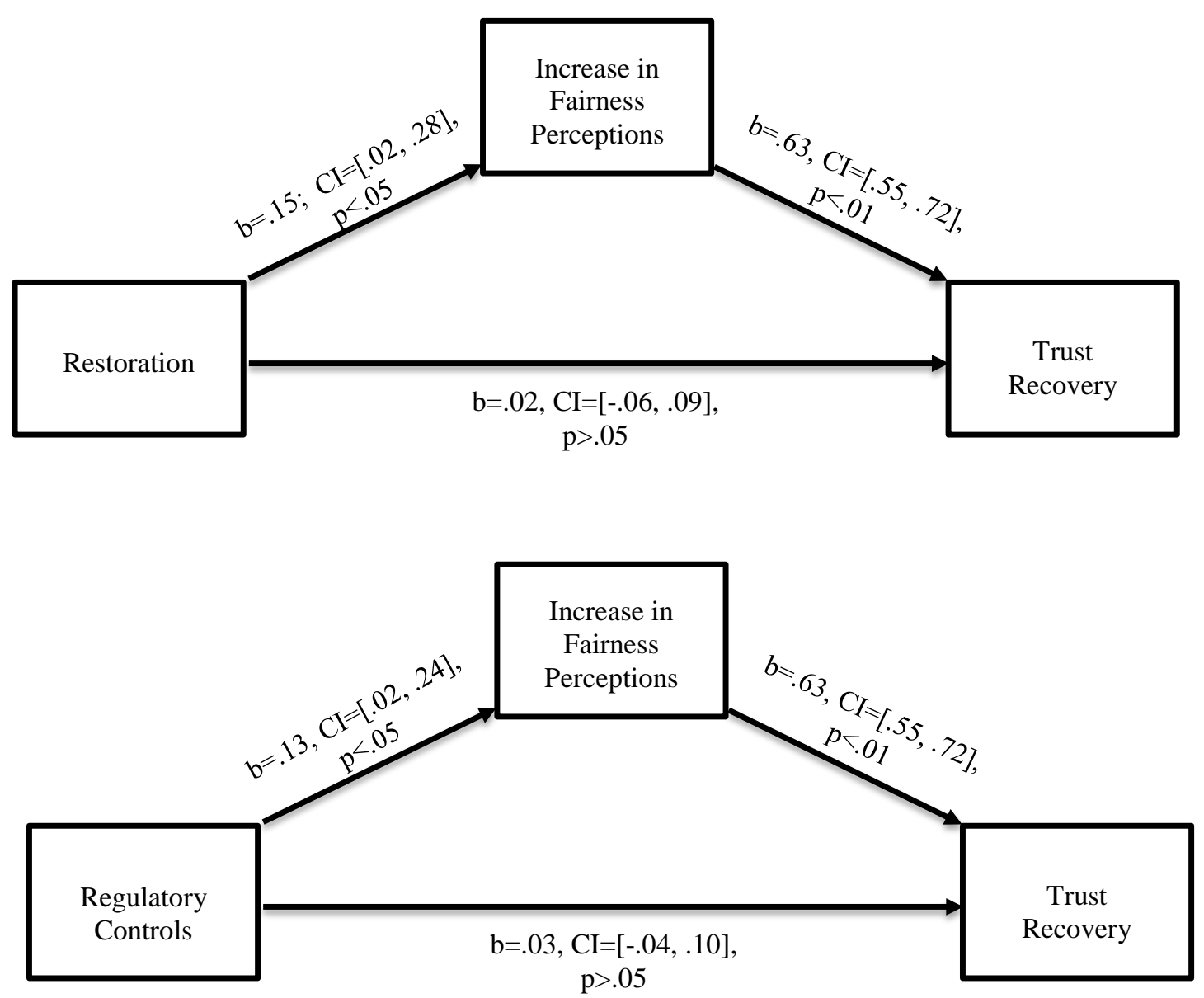
Table 1: Definitions of Social Accounts

\begin{tabular}{|c|c|c|c|}
\hline Social Account & Definition & $\begin{array}{l}\text { Nature of the } \\
\text { Repair Strategy }\end{array}$ & Core Message \\
\hline Denial & $\begin{array}{l}\text { "a statement whereby an allegation is explicitly } \\
\text { declared to be untrue (i.e., the statement } \\
\text { acknowledges no responsibility and hence no } \\
\text { regret" (Kim et al., 2004) }\end{array}$ & Verbal & Responsibility-shifting \\
\hline Excuse & $\begin{array}{l}\text { "Asks not to be held accountable claiming that } \\
\text { mitigating circumstances attenuate his or her } \\
\text { culpability... [excuses] communicate causes for the } \\
\text { negative outcome were uncontrollable" } \\
\text { (Tomlinson and Mayer 2009) }\end{array}$ & Verbal & Responsibility-shifting \\
\hline Justification & $\begin{array}{l}\text { "instead of lessening their responsibility, } \\
\text { individuals may accept responsibility while } \\
\text { attempting to reframe their behavior as in } \\
\text { accordance with some type of superordinate goal } \\
\text { or value, or by providing a more positive } \\
\text { interpretation of the negative outcome" } \\
\text { (Tomlinson and Mayer 2009). }\end{array}$ & Verbal & Responsibility-accepting \\
\hline Apology & $\begin{array}{l}\text { "conveys an admission of responsibility and regret } \\
\text { on the part of the offender for the violation and its } \\
\text { concomitant harm on the victim" (Tomlinson et al. } \\
\text { 2004). }\end{array}$ & Verbal & Responsibility-accepting \\
\hline
\end{tabular}


Table 2: Results of Structural Nested Model Comparisons

\begin{tabular}{lccccc}
\hline Model & Chi-square & df & p & CFI & RMSEA \\
Unidimensional Model & 314.79 & 35 & 0.00 & 0.95 & 0.13 \\
Two Factor Model & 169.70 & 34 & 0.00 & 0.98 & 0.09 \\
Chi-square value of the nested comparison & 145.09 & 1 & 0.00 & & \\
\hline
\end{tabular}

notes: Two Factor Model examines Trust Recovery and Increased Perceptions of Fairness as separate constructs. The unidimensional model loads all items on a single construct 
Table 3: Factor Loadings from the Confirmatory Factor Analysis for Study 1

\begin{tabular}{|c|c|c|c|c|}
\hline Indicator & & Latent Construct & Standardized Loadings & Standardized Error Terms \\
\hline TR1 & $\leftarrow$ & Trust Recovery & 0.84 & 0.29 \\
\hline TR2 & $\leftarrow$ & Trust Recovery & 0.82 & 0.32 \\
\hline TR3 & $\leftarrow$ & Trust Recovery & 0.87 & 0.24 \\
\hline TR5 & $\leftarrow$ & Trust Recovery & 0.83 & 0.31 \\
\hline TR6 & $\leftarrow$ & Trust Recovery & 0.88 & 0.23 \\
\hline TR7 & $\leftarrow$ & Trust Recovery & 0.92 & 0.16 \\
\hline IF1 & $\leftarrow$ & Increase Perceptions of Fairness & 0.93 & 0.13 \\
\hline IF2 & $\leftarrow$ & Increase Perceptions of Fairness & 0.95 & 0.10 \\
\hline IF3 & $\leftarrow$ & Increase Perceptions of Fairness & 0.92 & 0.15 \\
\hline IF4 & $\leftarrow$ & Increase Perceptions of Fairness & 0.90 & 0.19 \\
\hline
\end{tabular}


Table 4: Descriptive Statistics and Item Correlations for the Latent Variables in Study 1

\begin{tabular}{|c|c|c|c|c|c|c|c|c|c|c|c|c|}
\hline Variable & Mean & S.D. & 1 & 2 & 3 & 4 & 5 & 6 & 7 & 8 & 9 & 10 \\
\hline TR1 & 0.93 & 1.76 & - & & & & & & & & & \\
\hline TR2 & 0.59 & 1.75 & $0.74^{* *}$ & - & & & & & & & & \\
\hline TR3 & 0.90 & 1.84 & $0.79 * *$ & $0.74^{* *}$ & - & & & & & & & \\
\hline TR5 & 0.99 & 1.83 & $0.68 * *$ & $0.69 * *$ & $0.70 * *$ & - & & & & & & \\
\hline TR6 & 0.74 & 1.79 & $0.73^{* *}$ & $0.71 * *$ & $0.73^{* *}$ & $0.73^{* *}$ & - & & & & & \\
\hline TR7 & 0.84 & 1.80 & $0.74 * *$ & $0.76^{* *}$ & $0.78 * *$ & $0.76^{* *}$ & $0.85 * *$ & - & & & & \\
\hline IF1 & 0.91 & 1.80 & $0.74^{* *}$ & $0.71^{* *}$ & $0.78 * *$ & $0.74^{* *}$ & $0.77 * *$ & $0.82^{* *}$ & - & & & \\
\hline IF2 & 0.98 & 1.88 & $0.76^{* *}$ & $0.70 * *$ & $0.79 * *$ & $0.76^{* *}$ & $0.76 * *$ & $0.81 * *$ & $0.90 * *$ & - & & \\
\hline IF3 & 0.92 & 1.84 & $0.73^{* *}$ & $0.68 * *$ & $0.79 * *$ & $0.74^{* *}$ & $0.76 * *$ & $0.80 * *$ & $0.84 * *$ & $0.89 * *$ & - & \\
\hline IF4 & 0.89 & 1.89 & $0.73^{* *}$ & $0.71^{* *}$ & $0.78^{* *}$ & $0.74^{* *}$ & $0.76^{* *}$ & $0^{\prime} .80^{* * *}$ & $0.83^{* *}$ & $0.84^{* *}$ & $0.85^{* *}$ & - \\
\hline
\end{tabular}

$* * \mathrm{p}<.01$

Notes: Item TR4 was dropped from the analysis and is not shown in this table 
Table 5: Descriptive Statistics and Correlations for Study 1 Variables

\begin{tabular}{|c|c|c|c|c|c|c|c|c|c|c|}
\hline Variable & Mean & S.D. & 1 & 2 & 3 & 4 & 5 & 6 & 7 & 8 \\
\hline Trust Recovery & 0.84 & 1.59 & 0.74 & & & & & & & \\
\hline Increased Perceptions of Fairness & 0.93 & 1.75 & $0.90^{* *}$ & 0.86 & & & & & & \\
\hline Responsibility Accepting & $\mathrm{N} / \mathrm{A}$ & $\mathrm{N} / \mathrm{A}$ & 0.00 & -0.02 & $\mathrm{~N} / \mathrm{A}$ & & & & & \\
\hline Responsibility Shifting & $\mathrm{N} / \mathrm{A}$ & N/A & $0.24^{* *}$ & $0.27^{* *}$ & $-0.51^{* *}$ & $\mathrm{~N} / \mathrm{A}$ & & & & \\
\hline Restoration & $\mathrm{N} / \mathrm{A}$ & $\mathrm{N} / \mathrm{A}$ & 0.18 & $0.20^{* *}$ & 0.02 & 0.00 & $\mathrm{~N} / \mathrm{A}$ & & & \\
\hline Future Concessions & $\mathrm{N} / \mathrm{A}$ & N/A & $-0.11^{*}$ & -0.07 & -0.01 & 0.02 & $-0.33 * *$ & $\mathrm{~N} / \mathrm{A}$ & & \\
\hline Sanctions & $\mathrm{N} / \mathrm{A}$ & N/A & -0.07 & $-0.09^{*}$ & 0.00 & -0.01 & $-0.33 * *$ & $-0.33 * *$ & $\mathrm{~N} / \mathrm{A}$ & \\
\hline Regulatory Controls & $\mathrm{N} / \mathrm{A}$ & $\mathrm{N} / \mathrm{A}$ & 0.00 & -0.03 & -0.01 & -0.01 & $-0.33^{* *}$ & $-0.33^{* *}$ & $-0.33^{* *}$ & $\mathrm{~N} / \mathrm{A}$ \\
\hline
\end{tabular}

${ }^{\mathrm{s}} \mathrm{p}<05 ;{ }^{* \mathrm{~s}} \mathrm{p}<0$

notes: AVE is included on the diagonal for latent variables; the squared correlation between Trust Recovery and Increased Perceptions of Fairness $=.81$ 
Table 6: Regression Results

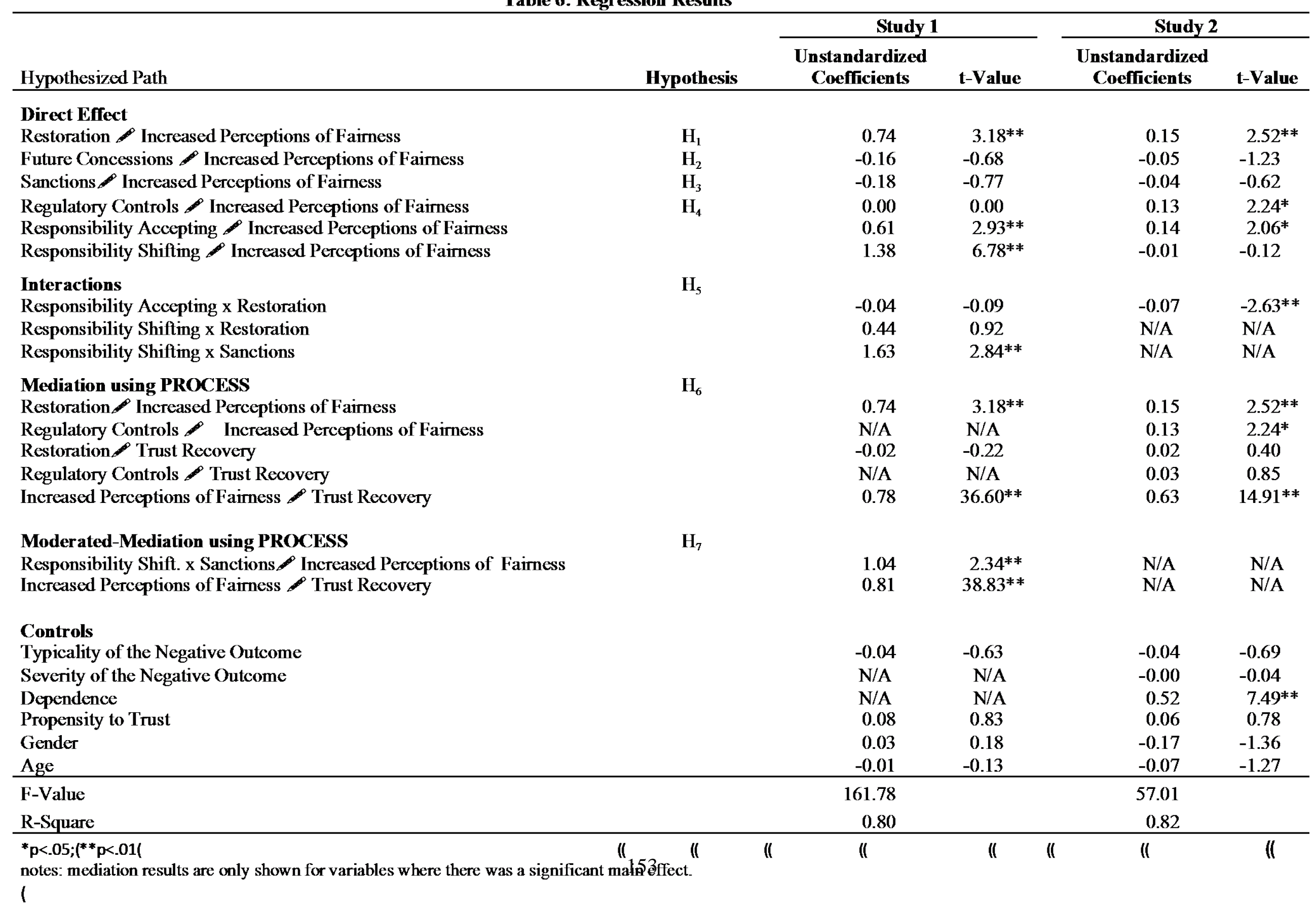


Table 7: Results of Structural Nested Model Comparisons

\begin{tabular}{lccccc}
\hline Model & Chi-square & df & $\mathbf{p}$ & CFI & RMSEA \\
Unidimensional Model & 341.67 & 44 & 0.00 & 0.90 & 0.18 \\
Two Factor Model & 120.15 & 43 & 0.00 & 0.98 & 0.09 \\
Chi-square value of the nested comparison & 221.52 & 1 & 0.00 & & \\
\hline
\end{tabular}

notes: Two Factor Model examines Trust Recovery and Increased Perceptions of Fairness as separate constructs. The unidimensional model loads all items on a single construct 
Table 8: Factor Loadings from the Confirmatory Factor Analysis for Study 2

\begin{tabular}{|c|c|c|c|c|}
\hline Indicator & & Latent Construct & Standardized Loadings & Standardized Error Terms \\
\hline TR1 & $\leftarrow$ & Trust Recovery & 0.54 & 0.71 \\
\hline TR2 & $\leftarrow$ & Trust Recovery & 0.89 & 0.21 \\
\hline TR3 & $\leftarrow$ & Trust Recovery & 0.92 & 0.15 \\
\hline TR4 & $\leftarrow$ & Trust Recovery & 0.62 & 0.62 \\
\hline TR5 & $\leftarrow$ & Trust Recovery & 0.91 & 0.18 \\
\hline TR6 & $\leftarrow$ & Trust Recovery & 0.91 & 0.18 \\
\hline TR7 & $\leftarrow$ & Trust Recovery & 0.96 & 0.08 \\
\hline IF1 & $\leftarrow$ & Increase Perceptions of Fairness & 0.93 & 0.13 \\
\hline IF2 & $\leftarrow$ & Increase Perceptions of Fairness & 0.97 & 0.06 \\
\hline IF3 & $\leftarrow$ & Increase Perceptions of Fairness & 0.97 & 0.05 \\
\hline IF4 & $\leftarrow$ & Increase Perceptions of Fairness & 0.95 & 0.10 \\
\hline
\end{tabular}


Table 9: Descriptive Statistics and Correlations for Study 2 Variables

\begin{tabular}{|c|c|c|c|c|c|c|c|c|c|c|c|c|c|}
\hline Variable & Mean & S.D. & 1 & 2 & 3 & 4 & 5 & 6 & 7 & 8 & 9 & 10 & 11 \\
\hline TR1 & 4.32 & 2.35 & - & & & & & & & & & & \\
\hline TR2 & 3.86 & 1.85 & $0.47 * *$ & - & & & & & & & & & \\
\hline TR3 & 3.85 & 1.96 & $0.55 * *$ & $0.82 * *$ & - & & & & & & & & \\
\hline TR4 & 4.16 & 1.79 & $0.32 * *$ & $0.56^{* *}$ & $0.56 * *$ & - & & & & & & & \\
\hline TR5 & 4.06 & 1.93 & $0.54 * *$ & $0.78 * *$ & $0.86^{* *}$ & $0.57 * *$ & - & & & & & & \\
\hline TR6 & 3.69 & 1.92 & $0.46 * *$ & $0.81 * *$ & $0.81 * *$ & $0.55^{* *}$ & $0.82 * *$ & - & & & & & \\
\hline TR7 & 3.68 & 1.94 & $0.49 * *$ & $0.85^{* *}$ & $0.89 * *$ & $0.61^{* *}$ & $0.86^{* *}$ & $0.88^{* *}$ & - & & & & \\
\hline IF1 & 4.06 & 1.86 & $0.49 * *$ & $0.78 * *$ & $0.76^{* *}$ & $0.45^{* *}$ & $0.77 * *$ & $0.78 * *$ & $0.80 * *$ & - & & & \\
\hline IF2 & 3.98 & 1.93 & $0.50 * *$ & $0.81 * *$ & $0.82 * *$ & $0.50 * *$ & $0.81^{* *}$ & $0.81^{* *}$ & $0.84 * *$ & $0.93 * *$ & - & & \\
\hline IF3 & 3.90 & 1.88 & $0.45 * *$ & $0.81 * *$ & $0.82 * *$ & $0.53^{* *}$ & $0.81^{* *}$ & $0.83 * *$ & $0.86^{* *}$ & $0.90 * *$ & $0.94 * *$ & - & \\
\hline IF4 & 3.85 & 1.93 & $0.47 * *$ & $0.80 * *$ & $0.82 * *$ & $0.53^{* *}$ & $0.79 * *$ & $0.84 * *$ & $0.84^{* *}$ & $0.86 * *$ & $0.91 * *$ & $0.94^{* *}$ & - \\
\hline
\end{tabular}


Table 10: Variance Explained from the Exploratory Factor Analysis for Study 2 Component Initial Eigenvalues Variance Explained Cumulative Variance Explained

$2 \quad 0.72$

$6.52 \%$

$82.51 \%$


Table 11: Descriptive Statistics and Correlations for Study 2 Variables

\begin{tabular}{|c|c|c|c|c|c|c|c|c|c|c|}
\hline Variable & Mean & S.D. & 1 & 2 & 3 & 4 & 5 & 6 & 7 & 8 \\
\hline Trust Recovery & 3.94 & 1.29 & 0.70 & & & & & & & \\
\hline Increased Perceptions of Fairness & 3.94 & 1.42 & $0.68^{* *}$ & 0.91 & & & & & & \\
\hline Responsibility Accepting & 4.31 & 3.01 & $0.63 * *$ & $0.54 * *$ & N/A & & & & & \\
\hline Responsibility Shifting & 4.35 & 1.96 & -0.08 & -0.02 & $-0.24^{* *}$ & N/A & & & & \\
\hline Restoration & 4.65 & 1.82 & $0.64 * *$ & $0.56^{* *}$ & $0.71 * *$ & -0.11 & N/A & & & \\
\hline Future Concessions & 4.14 & 2.18 & $0.46^{* *}$ & $0.34 * *$ & $0.38 * *$ & -0.03 & $0.47 * *$ & N/A & & \\
\hline Sanctions & 2.83 & 1.75 & $0.41 * *$ & $0.35^{* *}$ & $0.30 * *$ & $0.21 * *$ & $0.34 * *$ & $0.43 * *$ & N/A & \\
\hline Regulatory Controls & 3.08 & 1.87 & $0.51^{* *}$ & $0.47 * *$ & $0.41 * *$ & $0.18^{*}$ & $0.42^{* *}$ & $0.43^{* *}$ & $0.71^{* *}$ & N/A \\
\hline
\end{tabular}

notes: AVE is included on the diagonal for latent variables; the squared correlation between Trust Recovery and Increased Perceptions of Fairness $=.46$ 


\section{Appendix A: Distractor Tasks}

Distractor Task 1: Between Experimental Scenarios 1 and 2:

You will now be asked to participate in a learning activity. On the following 4 pages you will be presented with one word that is an anagram. An anagram is a word formed by rearranging the letters or another word. Please find 3 words that you can spell with the word presented to you in each question only using the letters from the presented word.

[The possible correct responses are listed below, but was not provided to respondents]

Page 1: Least

1. Slate

2. Stale

3. Steal

4. Tales

5. Teals

Page 2: Spread

1. Padres

2. Parsed

3. Rasped

4. Spared

5. Drapes

Page 3: Star

1. Rats

2. Arts

3. Tars 
Distractor Task 2: Between Experimental Scenarios 2 and 3:

You will now be asked to participate in a final learning activity. On the following two pages you will be presented with one word that is an anagram. An anagram is a word formed by rearranging the letters or another word. Please find 3 words that you can spell with the word presented to you in each question only using the letters from the presented word.

[The possible correct responses are listed below, but was not provided to respondents]

Page 1: Crates

1. Carets

2. Caters

3. Caster

4. Reacts

5. Recast

6. Traces

Page 2: Spear

1. Pares

2. Parse

3. Pears

4. Rapes

5. Reaps

6. Spare 


\section{Appendix B: Interaction Scenarios}

Scenario Interaction 1: In this scenario, you are interacting with your insurance agent, who will be referred to in this scenario as a salesperson. This is a salesperson that you trust. You can believe the information he provides to you, and feel confident that he is genuinely concerned with your welfare. He is always honest with you, cares about your long-term success, has been shown to be reliable, and genuinely likes you.

Scenario Interaction 2: Based on your own research, you question whether the product that the salesperson recommended was really in your best interest. You begin to wonder if the salesperson only recommended the product for the commission (i.e., extra money in his or her paycheck).

Scenario Interaction 3: You tell the salesperson about the research that you have done, and ask the salesperson why he or she made the recommendation. The salesperson tells you...

\section{Verbal Repair Strategies}

Responsibility-accepting Strategy: "I want to really apologize for the recommendation that I made. I understand that it does not provide you with the best option. I am so sorry, and completely understand why you are unhappy. If I was in your shoes I would fill the same way. I did not intend for this to happen and want to find a way to make this up to you and ensure that this will not happen again.”

Responsibility-shifting Strategy "The recommendation I made was not my fault because the information that I received from a third party vendor about this product was not accurate. I will not work with that vendor again. This issue was completely outside of my control. As a salesperson, I can only work with the information that is available.”

No Verbal Repair Strategy (Reticence): "I hope that you are doing well today. I do not want to spend too much time talking about the past. I want to find ways to help you in the future. That is what I am here to do. I want to act as a partner and find the best products for your company.”

\section{Behavioral Repair Strategies}

Future Concession Strategy: The salesperson gives you a 20\% discount on your next order, which more than makes up for the costs associated with the sub-optimal recommendation.

Regulatory Controls Strategy: The salesperson signs a contract that states that going forward he/she will consult with at least two subject matter experts before making any product recommendations to your firm. The advice of the subject matter experts will be documented and provided to you. If this does not occur, your entire order will be refunded and you will still be able to keep the product.

Restoration Strategy: The salesperson does some in depth research and finds the optimal product for your needs. This product is even better than the product that you found. The salesperson then switches you to the superior product at no cost to you. 
Sanctions Strategy: The salesperson forfeits his or her commission for the sale. This is verified by the sales manager providing the buyer with a letter documenting the reprimand of the salesperson, which includes a statement declaring that the salesperson did not receive a commission for the sale. 


\section{Appendix C: Measurement Scales}

\begin{tabular}{l}
\hline Scale \\
$\begin{array}{l}\text { Scale Reliability } \\
\text { Study } 1\end{array}$ \\
\hline Fairness Scale [Study $\mathbf{1}$ - Question Blocks 1, 2, and 3] \\
Oliver and Swann $\mathbf{1 9 8 9}$ (7 pt. agreement scale) \\
I am treated fairly by the salesperson. \\
I am treated right by the salesperson. \\
My relationship with the salesperson is fair. \\
Overall, what I get compared to what I put into the relationship \\
is fair. \\
\hline Notes: adapted so there were no reverse coded items and slightly modified to relational \\
wording. \\
\hline Trust Scale [Study 1 - Question Blocks 1, 2, and 3] \\
Doney and Cannon $\mathbf{1 9 9 7}$ (7 pt. agreement scale) \\
This salesperson has been frank in dealing with us. \\
This salesperson does not make false claims. \\
We think this salesperson is completely open in dealing with \\
us. \\
This salesperson is not only concerned about himself/herself. \\
This salesperson seems to be concerned with our needs. \\
The people at my firm would trust this salesperson. \\
This salesperson is trustworthy. \\
\hline Notes: adapted so there were no reverse coded items \\
\hline Increased Perceptions of Fairness Scale [Study 1 - Question \\
Blocks 1, 2, and 3] \\
Oliver and Swann 1989 (7 pt. agreement scale) \\
I am treated fairly by the salesperson. \\
I am treated right by the salesperson. \\
My relationship with the salesperson is fair. \\
Overall, what I get compared to what I put into the relationship \\
is fair. \\
\hline Notes: scale anchors adapted - Please rate the following statements based upon how your \\
perceptions of salesperson fairness changed after the repair attempt: (-3=greatly decreased, - \\
2=decreased, -1= somewhat decreased, 0=about the same, 1=somewhat increased, \\
2=increased, 3=greatly increased) \\
\hline
\end{tabular}




\section{Scale}

Scale Reliability

Study 1

Trust Recovery Scale [Study 2]

N/A

Study 2

Doney and Cannon 1997 (7 pt. agreement scale)

0.93

This salesperson has been frank in dealing with us.

This salesperson does not make false claims.

We think this salesperson is completely open in dealing with

us.

This salesperson is not only concerned about himself/herself.

This salesperson seems to be concerned with our needs.

The people at my firm would trust this salesperson.

This salesperson is trustworthy.

Notes: scale anchors adapted - Please rate the following statements based upon how your perceptions of salesperson trust changed after the attempt to repair your trust: (-3=greatly decreased, $-2=$ decreased, $-1=$ somewhat decreased, $0=$ about the same, $1=$ somewhat increased, 2=increased, $3=$ greatly increased)

\section{Control Variables}

\section{Relationship Age [Study 2]}

N/A N/A

Harmeling et al., 2015

How many years have you been a customer of the salesperson?

\section{Dependence Scale [Study 2]}

$\mathrm{N} / \mathrm{A}$

0.94

Scheer, Miao, and Garrett 2010 (7 pt. agreement scale)

Our firm receives benefits from doing business with this

salesperson that could not be fully duplicated with the next best

alternative.

If we stopped working with this salesperson, our firm's

products would be less attractive to our customers.

If our firm had to replace this salesperson, the alternative would not be as affective.

If our firm ended its business relationship with this salesperson, it would be costly to locate and implement a replacement.

If our firm replaced this salesperson, we would incur significant replacement costs.

It would be costly to our firm to end its business relationship

with this salesperson. 
Propensity to Trust Scale [Study 1 - Question Block 3;

Study 2]

1.00

0.82

Mayer and Davis, 1999 (7 pt. agreement scale)

Most experts tell the truth about the limits of their knowledge.

Most people can be counted on to do what they say they will

do.

Most adults are competent at their jobs.

Most salespeople are honest in describing their products.

Most people answer public opinion polls honestly.

Typicality of the Event [Study 1 - Question Block 3; Study

2]

Harmeling et al., 2015 (7 pt. agreement scale)

0.91

0.88

Characteristic of my experiences

Is extremely typical

Occurs frequently

Severity of the Failure [Study 2]

N/A

0.93

Hess et al., 2003

Based on your experience working with salespeople, how

would you describe the negative outcome

Mild problem—Severe problem

Minor problem-Major problem

Insignificant problem-Significant problem

Notes: adapted from services to sales

Gender [Study 1 - Question Block 3; Study 2]

N/A

N/A

What is your gender? (male, female, prefer not to answer)

Age [Study 1 - Question Block 3; Study 2]
What best represents your age range?
$18-29$
$30-39$
$40-49$
$50-59$
$60+$
Prefer not to answer




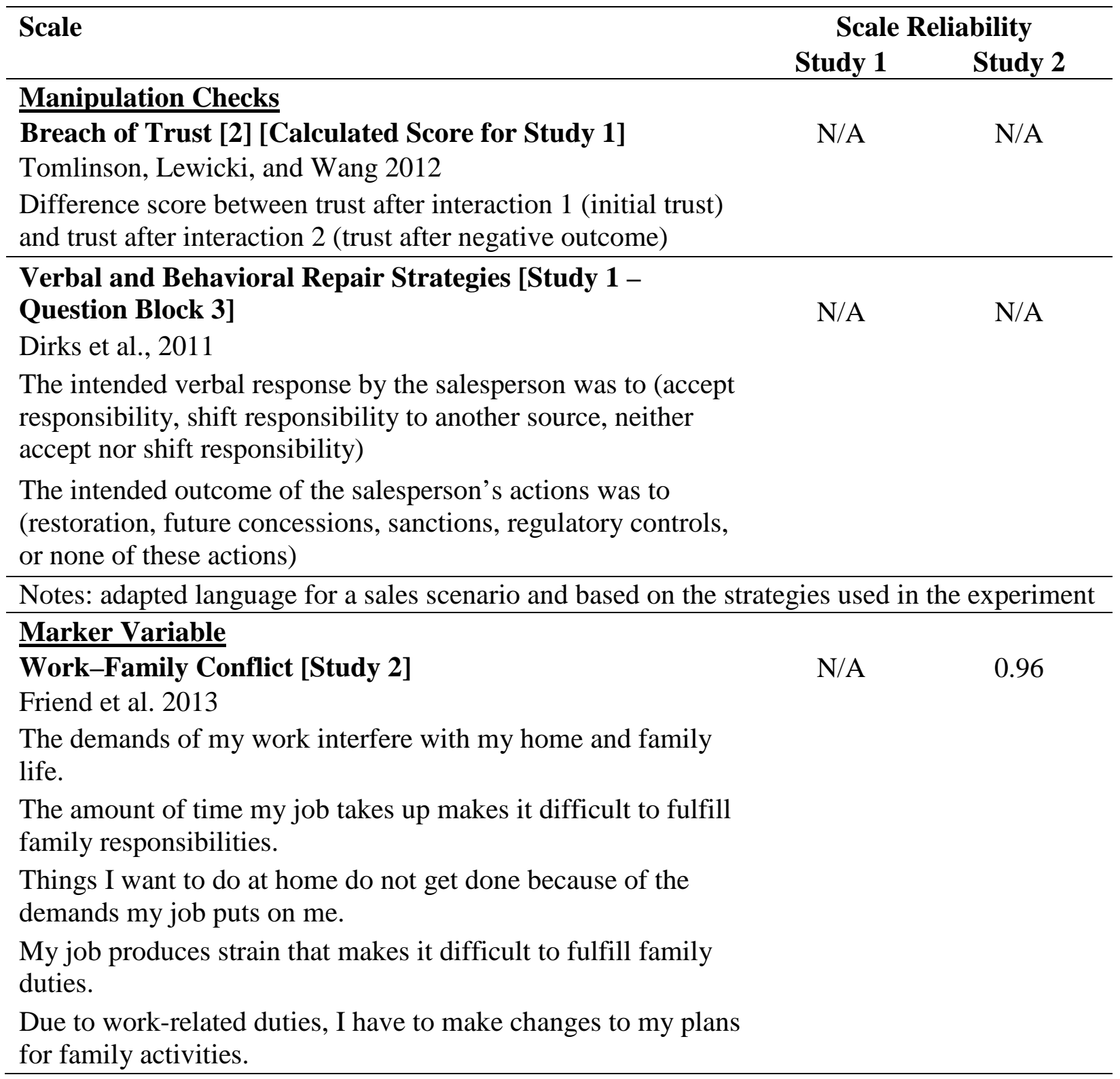




\section{Appendix D: Recruitment Info}

\section{[Date]}

I am writing to ask your help in a research study involving buyer-seller relationships. This study is part of an effort to learn more about the salesperson's role in reestablishing trust after it has been damaged.

It is my understanding that you [currently purchase insurance - Study 1 participants] or [are a professional purchasing agent - Study 2 participants]. We are contacting you [to ask questions about a hypothetical scenario that could occur when purchasing from an insurance salesperson Study 1 participants] or [to ask questions about a time that a salesperson has damaged your trust - Study 2 participants]. We need people with experiences and expertize like yours to complete this study.

Results of the survey will be used to help salespeople better manage the trust of buyers like you, so that they can do a better job maintaining buyer-seller relationships in the future.

Your answers are completely confidential. All data will be reported in the aggregate and no individual answers will be identified. I will not ask any information that should lead back to your identity as a participant. Your participation is completely voluntary. There are no right or wrong answers, I am only interested in your thoughts and opinions. This project is on file with the Institutional Review Board at Duquesne University.

As a token of our appreciation for your time and effort, [we are providing \$1.75 inducement Study 1] or [Research Now will be providing a small inducement on our behalf] for completing this survey.

Should you have any questions about this research project, please feel free to contact me by email at nelsonc2@duq.edu.

Thank you for your time and help with this project.

Sincerely,

Christopher A. Nelson

Assistant Professor of Marketing

Palumbo-Donahue School of Business Administration

Duquesne University 


\section{Appendix E: Implied Consent}

Description: The purpose of this research is to investigate buyer perceptions of salesperson trust after a negative outcome occurs. We will assess your general feelings and consumer beliefs. We appreciate your time and ask that you please answer each question thoroughly so that we may better understand your perceptions and beliefs. This questionnaire should take [Study 1: less than 15 minutes to complete] or [Study 2: about 20 minutes to complete].

Risks \& Benefits: There are no anticipated risks to participating in the study. The benefits include contributing to the knowledge base regarding trust in the buyer-seller relationship and receiving monetary compensation.

Voluntary Participation: Your participation in the research is completely voluntary.

Confidentiality: Your responses will be recorded anonymously. All information will be kept confidential to the extent allowed by law and University policy. Results for the research will be reported as aggregate data.

Right to Withdraw: You are free to refuse to participate in the research and stop the survey at any time by closing your browser.

Completing the Survey Implies your Consent.

Select the "Continue" Option and Click the $>>$ Button to Continue the Survey. Select the "Exit" Option and Click the $>>$ Button if you Wish to Exit the Survey. 


\section{Appendix F: Critical Incident Technique Questions}

[Panel company is screening to ensure that participants are over 18 years of age and work as a business to business buyer (i.e., purchasing agent).]

In business-to-business relationships, salespeople may damage the trust of the buyers that they are working with. Common examples of this include, but are not limited to: lying to the buyer; pushing products that are not in the buyer's best interest; overpromising either on a product or on a unrealistic delivery date; sharing a buyer's confidential information; missing an important deadline; failing to accurately understand a buyer's needs; or sending an incorrect or late shipment. This damage to trust may be caused by a single incident or the accumulation of multiple incidents.

What you are attempting to recall is the moment in time that you realized that your trust in the salesperson had been damaged. This can sometimes occur when dealing with a new salesperson where trust has not been established. This is not what we are examining in this study. We are interested in examining a time that a salesperson that you had a relationship with damaged your trust. This would be a salesperson that you believed that you could rely on. This would be an extended relationship, in which you and the salesperson came to know each other sufficiently well so that the other's behavior was predictable.

S1. Do you recall a time when a salesperson you had a relationship with damaged your trust? 01 Yes 02 No [Terminate]

Thinking about the salesperson that damaged your trust, please answer the following questions based on how you currently feel.

Q1. When you think about your entire relationship with the salesperson, how satisfied are you where $1=$ Not at all satisfied and 7 = Completely satisfied?

Q2. If a business associate asked you to recommend a salesperson how likely would you be to recommend the salesperson where 1 = Definitely not recommend and 7 = Definitely recommend?

Q3. What is the likelihood that you will purchase something from the salesperson in the next 12 months where 1 = Very unlikely and 7 = Very likely.

Instructions: Now take a minute and really think about that memorable event when you realized that your trust in the salesperson had been damaged. Think deeply about that incident. Go back to what you were thinking and feeling on that day. Focus on exactly what the salesperson did to damage your trust.

Q4. In a few sentences, please describe how the salesperson damaged your trust? [Open ended] 
Now, I would like for you to describe in your own words what the salesperson said and did when attempting to repair your trust. Please focus on taking the time to really provide a detailed account of what happened. These details are the key to this research. This is the last time that you will be asked to type out a detailed account in the survey.

Q5. What did the salesperson say to attempt to repair your trust? [Open ended]

Q6. What did the salesperson do to attempt to repair your trust? In other words, what actions did the salesperson take to try to prove that he/she could be trust again? [Open ended]

\section{Aided Recall of Repair Strategies}

Please indicate whether the salesperson used the following strategies in an attempt to regain your trust using a scale from 1 to 7 where $1=$ Strongly disagree and $7=$ Strongly agree.

Accepted responsibility for the negative outcome that damaged your trust Expressed contrition (i.e., regret) for the negative outcome that damaged your trust Explained that he or she has positive intentions towards you (i.e., wants to do what is best for you)

Shifted responsibility for the negative outcome to an outside source.

Attempted to restore the relationship through taking action to find a solution to your problem. Provided a future tangible compensation (e.g., discount on a future order, complementary service)

Accepted a sanction designed punished the salesperson Implemented regulatory controls (i.e. create rules or procedures to fix the flawed behavior moving forward/designed to prevent flawed behavior from reoccurring) 


\section{Chapter 5: Conclusion}

Trust is the cornerstone of marketing exchange relationships. It can lead to increased commitment, loyalty, and financial performance (Morgan and Hunt 1994; Palmatier et al., 2006). While trust can develop quickly, it tends to grow over time as reliability is demonstrated. There are key events in a relationship that can substantively change the rate and direction of that relationship (Palmatier et al., 2013). One such event is the initial meeting between exchange partners, such as when a salesperson meets with a buyer for the first time. There is very little known about how trust is developed during that initial encounter in the buyer-seller relationship (Evans et al., 2012). Another such event that impacts the rate and direction of the relationship occurs when an exchange partner attempts to recover trust after it has been damaged. Currently, there is no research that examines trust recovery in actual marketing exchange relationships. The research that is available on trust recovery focuses primarily on the words used to recover trust and neglects or undervalues substantive actions. Over the course of three essays, this dissertation research has attempted to better understand how these pivotal events affect exchange relationships, specifically focusing on buyer-seller interactions

In Essay 1, a fMRI meta-analysis was conducted to examine the role of initial facial trustworthiness perceptions on the trust development process. I theorized that in exchange relationships, buyers make a subconscious approach-avoidance decision based on a brief exposure to a salesperson's face. This is predicated on the idea that humans can instinctively determine whether another individual looks trustworthy or not. This leads to trustworthy faces being considered as positive and untrustworthy faces being perceived as negative. These valence determinations influence subsequent more intentional trust determinations (e.g., Doalla et al., 2012; Kim et al., 2012). The results of the meta-analysis supported my theory that initial 
trustworthiness evaluations are largely subconscious valence decisions and identified the network of brain regions that are paramount to facial trustworthiness evaluations.

I employed a grounded theory approach (essay 2) driven by interviews with salespeople, professional buyers, and sales executives to better understand trust recovery in the buyer-seller relationship. Those interviews were triangulated with a discourse analysis of the popular business press and the academic literature. This was used to identify a three step process designed to increase trust recovery. In conflict with the current literature, the interviews provided evidence that trust recovery is achieved through "rebalancing the scales" to "make things right" with the buyer. This indicated that increasing fairness through reducing inequity could be of fundamental importance to trust recovery.

This led to Essay 3, which used equity theory to develop a framework for how both verbal and behavioral repair strategies can be used in trust recovery. I used a longitudinal experiment and a business-to-business panel study to test the proposed conceptual framework and hypotheses empirically. The results of the study provided evidence that fairness is a key mediating variable between verbal and behavioral repair strategies and trust recovery.

These three dissertation essays advance theory about initial trust development and trust recovery, which are of fundamental importance to positively affecting the rate and direction of buyer-seller relationships. They also provide key strategic guidance regarding how salespeople can develop initial trust and recover trust that has been damaged. This work advances the perspective that trust is the foundation of business relationships, and that trust should be developed and maintained through an ethical, integrity-based approach designed to produce mutually beneficial outcomes for both the buyer and the salesperson. 


\section{REFERENCES}

Doallo, Sonia, Jane E. Raymond, Kimron L. Shapiro, Monika Kiss, Martin Eimer, and Anna C. Nobre (2012), "Response Inhibition Results in the Emotional Devaluation of Faces: Neural Correlates as Revealed by fMRI," Social Cognitive and Affective Neuroscience, 7 (6), 649-659.

Evans, Kenneth R., Richard G. McFarland, Bart Dietz, and Fernando Jaramillo (2012), "Advancing Sales Performance Research: A Focus on Five Underresearched Topic Areas," Journal of Personal Selling \& Sales Management, 32 (1), 89-105.

Kim, Hackjin, Min-Jo Choi, and In-Ji Jang (2012), "Lateral OFC Activity Predicts Decision Bias Due to First Impressions During Ultimatum Games," Journal of Cognitive Neuroscience, 24 (2), 428-439.

Morgan, Robert M., and Shelby D. Hunt (1994), "The Commitment-Trust Theory of Relationship Marketing," The Journal of Marketing, 58(3), 20-38.

Palmatier, Robert W., Rajiv P. Dant, Dhruv Grewal, and Kenneth R. Evans (2006), "Factors Influencing the Effectiveness of Relationship Marketing: A Meta-Analysis," Journal of Marketing, 70 (4), 136-153.

-------, Mark B. Houston, Rajiv P. Dant, and Dhruv Grewal (2013), "Relationship Velocity: Toward a Theory of Relationship Dynamics," Journal of Marketing 77 (1), 13-30. 